RESEARCH

SERIES

NUMBER 122

March 2021

\title{
DEMAND FOR THE STATUTORY HOME SUPPORT SCHEME
}

\section{BRENDAN WALSH AND SEÁN LYONS}

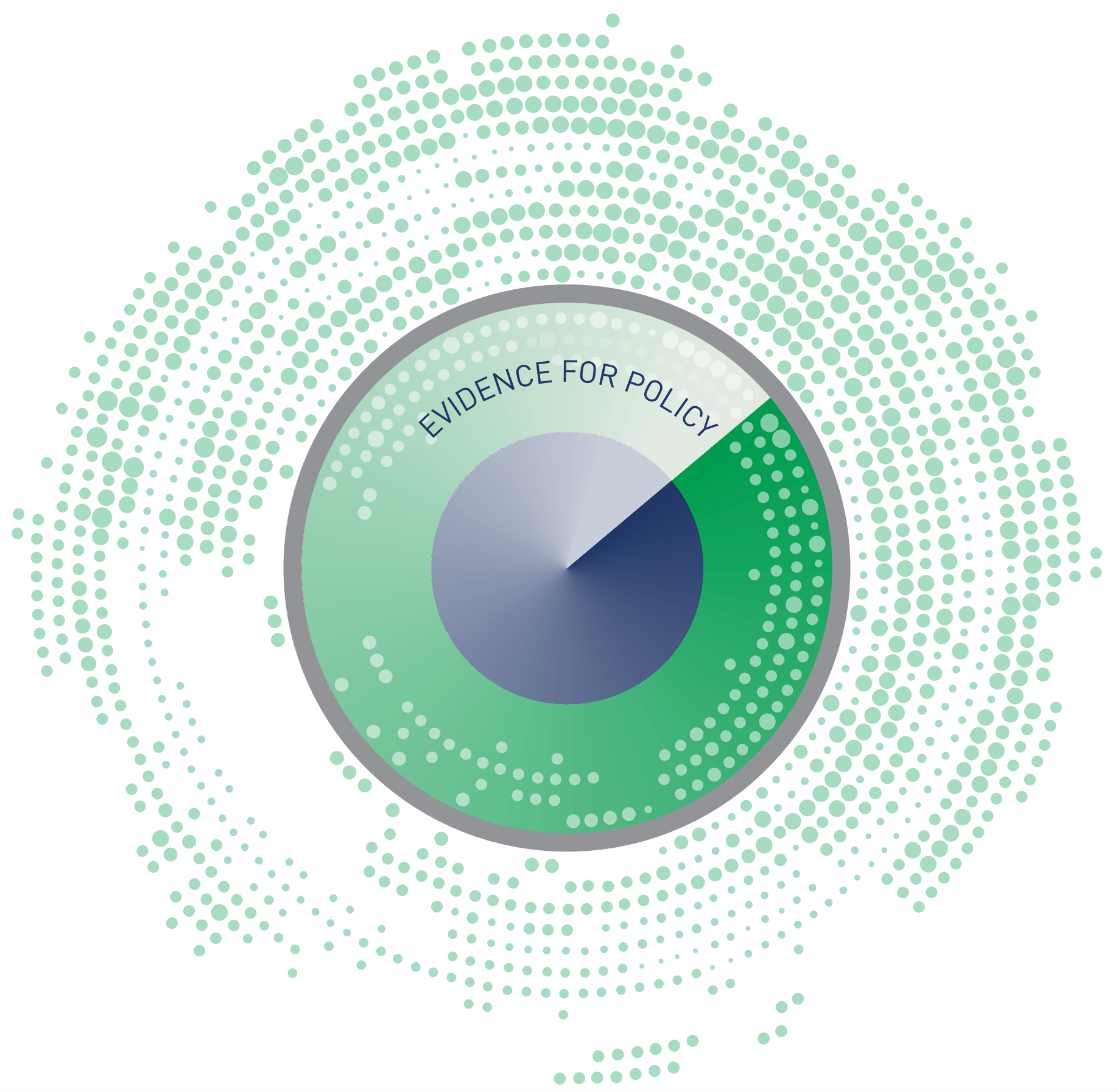




\section{DEMAND FOR THE STATUTORY HOME SUPPORT SCHEME}

Brendan Walsh

Seán Lyons

March 2021

\section{RESEARCH SERIES}

NUMBER 122

Available to download from www.esri.ie

(C) The Economic and Social Research Institute

Whitaker Square, Sir John Rogerson's Quay, Dublin 2

https://doi.org/10.26504/rs122

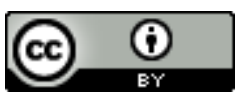

This Open Access work is licensed under a Creative Commons Attribution 4.0 International License (https://creativecommons.org/licenses/by/4.0/), which permits unrestricted use, distribution, and reproduction in any medium, provided the original work is properly credited. 


\section{ABOUT THE ESRI}

The mission of the Economic and Social Research Institute is to advance evidencebased policymaking that supports economic sustainability and social progress in Ireland. ESRI researchers apply the highest standards of academic excellence to challenges facing policymakers, focusing on 12 areas of critical importance to 21st Century Ireland.

The Institute was founded in 1960 by a group of senior civil servants led by Dr T. K. Whitaker, who identified the need for independent and in-depth research analysis to provide a robust evidence base for policymaking in Ireland.

Since then, the Institute has remained committed to independent research and its work is free of any expressed ideology or political position. The Institute publishes all research reaching the appropriate academic standard, irrespective of its findings or who funds the research.

The quality of its research output is guaranteed by a rigorous peer review process. ESRI researchers are experts in their fields and are committed to producing work that meets the highest academic standards and practices.

The work of the Institute is disseminated widely in books, journal articles and reports. ESRI publications are available to download, free of charge, from its website. Additionally, ESRI staff communicate research findings at regular conferences and seminars.

The ESRI is a company limited by guarantee, answerable to its members and governed by a Council, comprising 14 members who represent a cross-section of ESRI members from academia, civil services, state agencies, businesses and civil society. The Institute receives an annual grant-in-aid from the Department of Public Expenditure and Reform to support the scientific and public interest elements of the Institute's activities; the grant accounted for an average of 30 per cent of the Institute's income over the lifetime of the last Research Strategy. The remaining funding comes from research programmes supported by government departments and agencies, public bodies and competitive research programmes.

Further information is available at www.esri.ie 


\section{THE AUTHORS}

Brendan Walsh is a Research Officer at the ESRI and an Adjunct Assistant Professor at Trinity College Dublin. Seán Lyons is an Associate Research Professor at the ESRI and an Adjunct Professor at Trinity College Dublin.

\section{ACKNOWLEDGEMENTS}

Financial support for this research was provided by the Department of Health. The authors thank the members of the Steering Group of the ESRI Research Programme in Healthcare Reform for their input. The authors would like to thank Kathleen Mac Lellan, Sarah Cooney, Abigail Chantler, Maeve O'Brien, Gerard Noonan, Eimear Allen, and Eithne Fitzgerald in the Department of Health for their assistance with the project. The authors are grateful to those in TILDA, Kathleen Jordan in the HSE, and others in the HSE Social Care Division for providing data for this project and feedback on an earlier draft. We would also like to thank Anne Nolan, Maev-Ann Wren, Sheelah Connolly, two internal ESRI reviewers, and an external reviewer for their insightful comments. We thank all those who provided contributions while acknowledging that the authors bear sole responsibility for the analyses and interpretations presented.

This report has been accepted for publication by the Institute, which does not itself take institutional policy positions. All ESRI Research Series reports are peer reviewed prior to publication. The authors are solely responsible for the content and the views expressed. 



\section{TABLE OF CONTENTS}

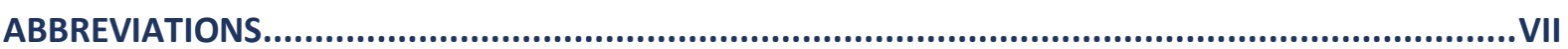

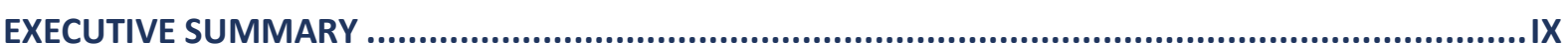

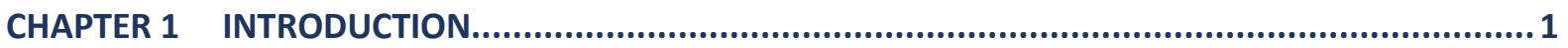

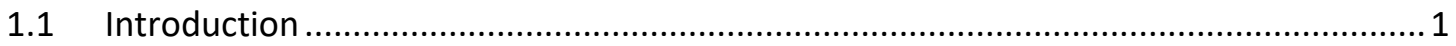

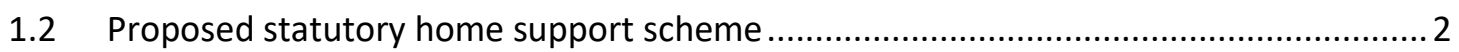

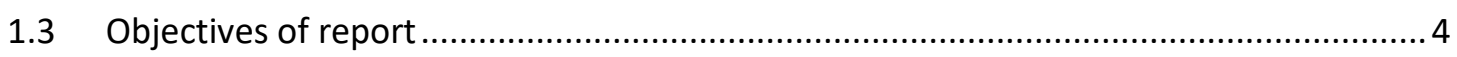

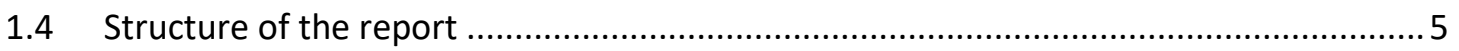

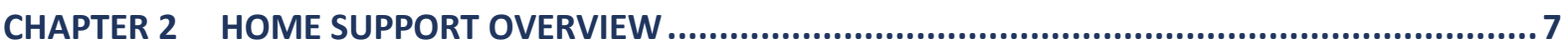

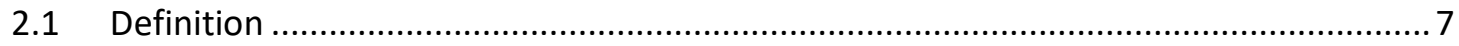

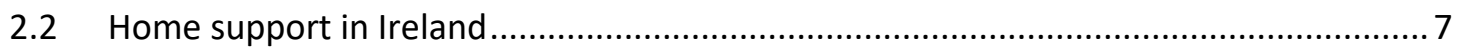

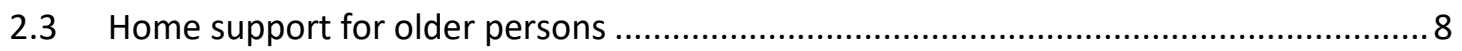

2.4 Home support for those living with a disability ........................................................ 12

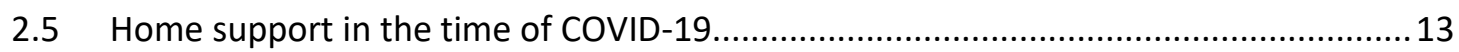

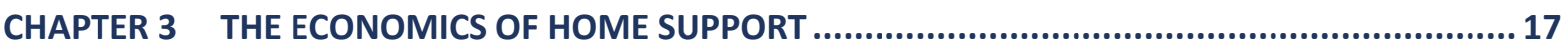

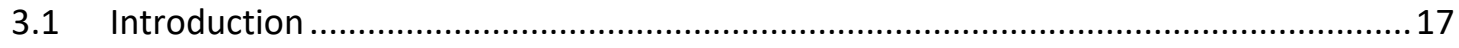

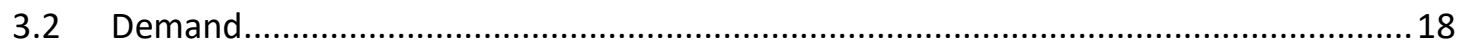

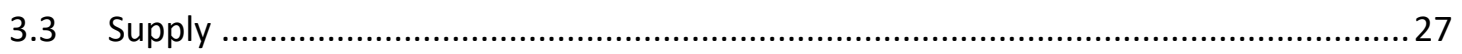

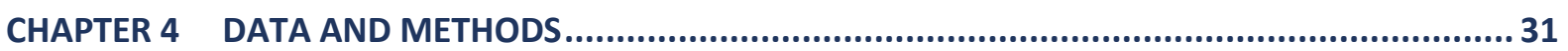

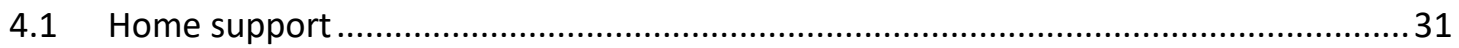

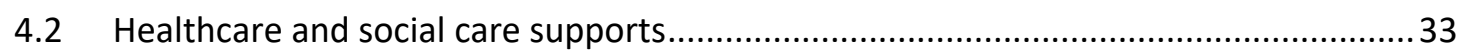

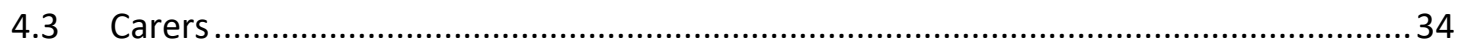

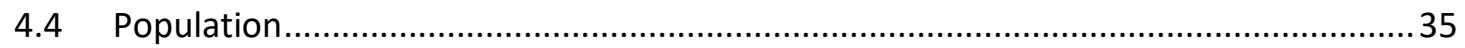

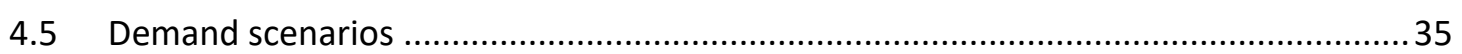

CHAPTER 5 HOME SUPPORT DEMAND PROJECTIONS UNDER STATUTORY SCHEME .................. 45

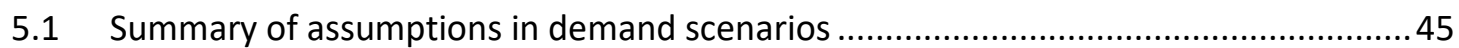

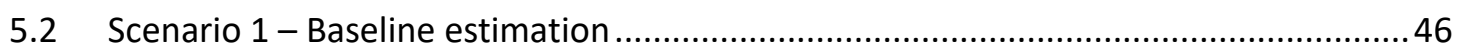

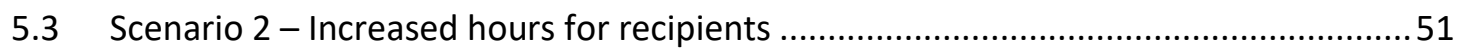

5.4 Scenario 3 - Substitution for long-term residential care............................................ 52

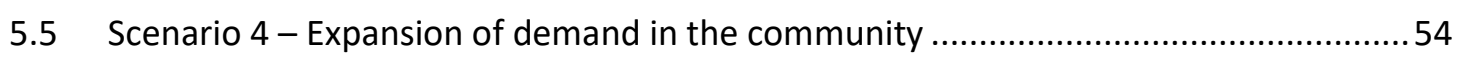

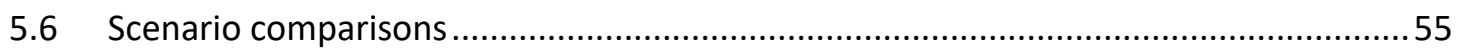

CHAPTER 6 HOME SUPPORT RECIPIENTS' USE OF HEALTHCARE AND SOCIAL CARE SERVICES .... 57

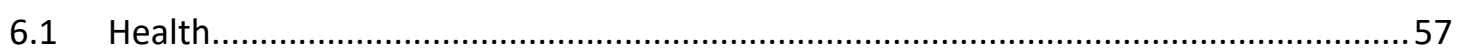

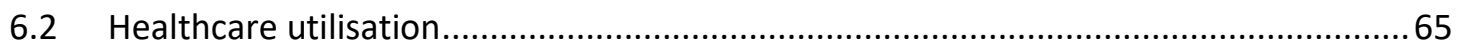

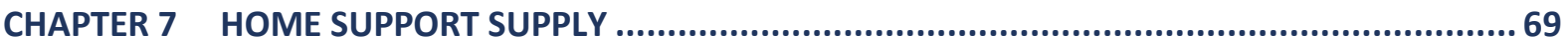

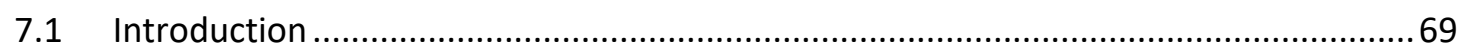

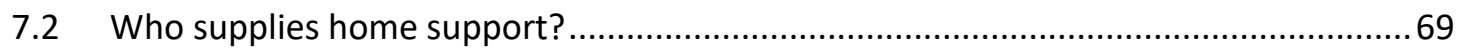

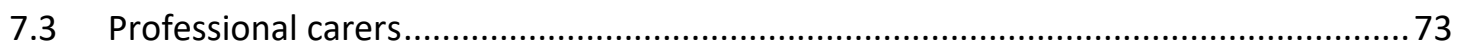




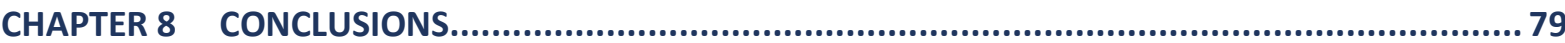

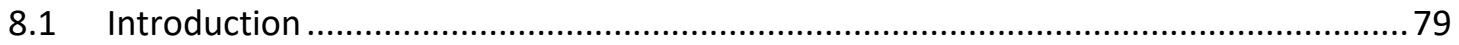

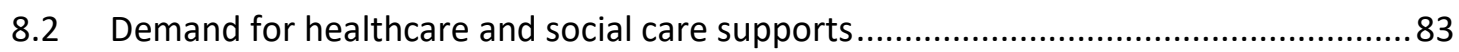

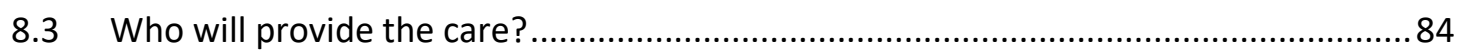

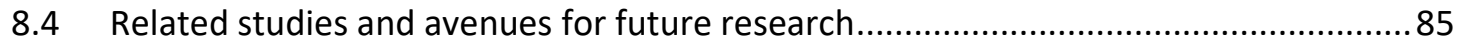

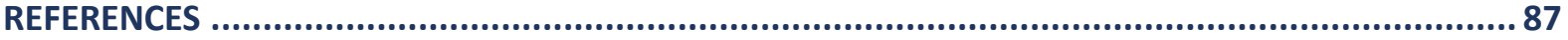

APPENDIX

\section{LIST OF BOXES}

Box $1.1 \quad$ Features of proposed statutory home support scheme …......................................... 3

Box 2.1 Expert panel on nursing homes views on care for older people.................................. 15

Box $3.1 \quad$ Features of InterRAI Single Assessment Tool ............................................................. 29 


\section{LIST OF TABLES}

Table E1 Estimated and simulated demand for home support across scenarios - recipients:

Ages $65+$

Table E2 Estimated and simulated demand for home support across scenarios - hours:

Ages 65+

Table 2.1 Local health offices ( $\mathrm{LHO})$ in each community health organisation ( $\mathrm{CHO}$ )

Table 3.1 Resource utilisation and costs of care among people with dementia (Carter et al., 2019)

Table 4.1 Baseline estimation (Scenario 1): Data and methods 36

Table 4.2 Scenario 2 (Increased hours for recipients): Data and methods. 39

Table 4.3 Scenario 3 (Substitution for long-term residential care): Data and methods. 41

Table 4.4 Scenario 4 (Expansion of demand in community): Data and methods.

Table 5.1 Baseline estimation (Scenario 1): Recipients and home support hours: Ages $65+\ldots \ldots . .47$

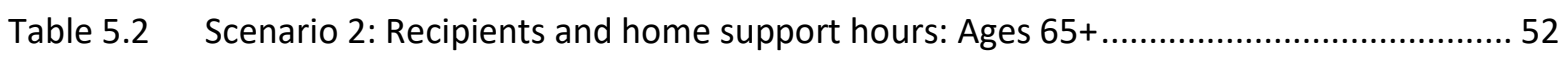

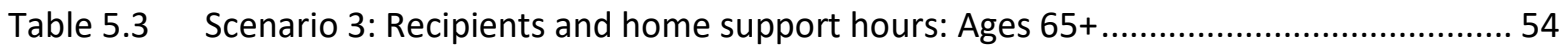

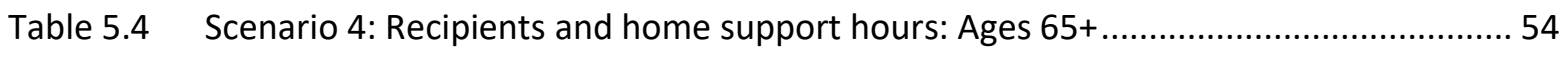

Table 5.5 Estimated and simulated demand for home support across scenarios - recipients:

Ages $65+$ 55

Table 5.6 Estimated and simulated demand for home support across scenarios - hours:

Ages $65+$

Table 7.1 Profile of HSE social care division older peoples care (community) employed carers, December 2019

Table 7.2 Socio-demographic characteristics of carers, nurses and other healthcare workers in Ireland.

Table 8.1 Baseline estimation (Scenario 1): Recipients and home support hours: Ages $65+\ldots \ldots . .80$

Table 8.2 Estimated and simulated demand for home support across scenarios - recipients:

Ages 65+

Table 8.3 Estimated and simulated demand for home support across scenarios - hours:

Ages 65+

Table 8.4 Healthcare and social care service utilisation in the previous 12 months: Ages $65+\ldots 84$

Table 8.5 Estimated home support hours (millions) for older persons provision by HSE, voluntary, and for-profit staff in $2019 .$.

Table A.1 Prioritisation criteria for home support services: January 2021 .................................. 95

Table A.2 Home support for older people (ages 65+) demand projections, 2015-2030 ............... 96

Table A.3 Estimation of home support hours required by delayed transfers of care.................... 96

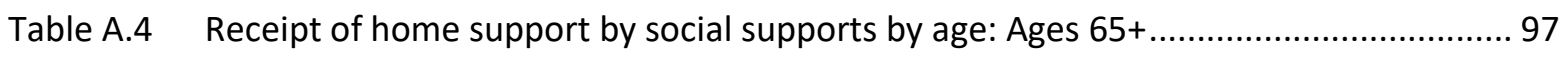

Table A.5 Receipt of home support by socioeconomic status (education and equivalised household income) by age: Ages $65+$. 


\section{LIST OF FIGURES}

Figure 2.1 Home help recipients and Home Care Package recipients by CHO December 2016.... 10

Figure 3.1 Framework for healthcare activity (The Health Foundation) ........................................ 18

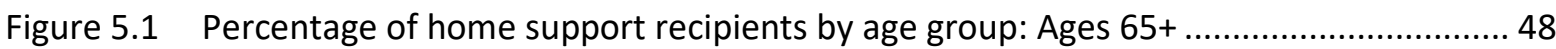

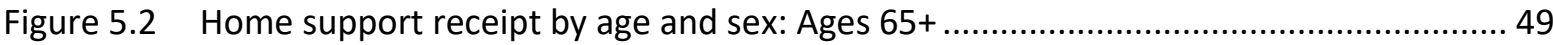

Figure 5.3 Public and private home support receipt rates by age and sex: Ages $65+\ldots \ldots \ldots \ldots \ldots \ldots . .50$

Figure 5.4 Public and private home support recipient numbers by age and sex: Ages $65+\ldots \ldots \ldots . . .51$

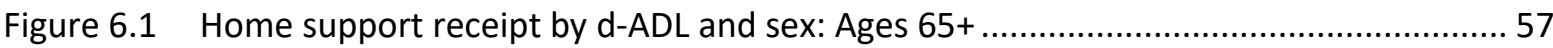

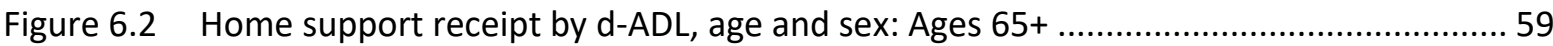

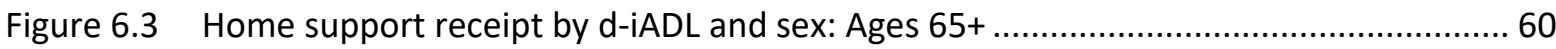

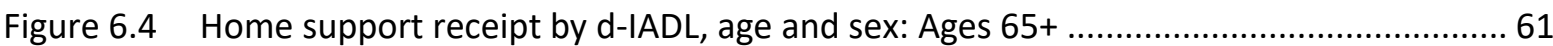

Figure 6.5 Percentage with falls in previous 12 months by home support receipt status:

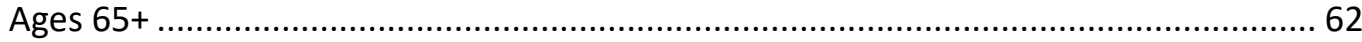

Figure 6.6 Home support receipt by falls status in previous 12 months, age and sex: Ages $65+\ldots 63$

Figure 6.7 Percentage with moderate/severe cognitive impairment by home support receipt status: Ages $65+$.

Figure 6.8 Home support receipt by moderate/severe cognitive impairment status, age and sex: Ages $65+$

Figure 6.9 GP visits and inpatient stays by home support receipt status: Ages 65+ 66

Figure 6.10 Public health nurse, occupational therapy, physiotherapy visits by home support receipt status: Ages $65+$

Figure 6.11 Day centre, respite care, and convalescent care by home support receipt status: Ages 65+ 68

Figure 7.1 Home support for older persons: Provision by HSE and non-HSE staff in 2019 70

Figure 7.2 Public home support for older persons by LHO: Provision by HSE and non-HSE staff in 2019

Figure 8.1 Home support receipt by age and sex: Ages 65+

Figure A.1 Delayed transfers of care by reason in public hospitals, July 2016 - June 2018

Figure A.2 Delayed transfers of care by length of delay and reason in public hospitals, July 2016 - June 2018. 98

Figure A.3 Receipt of home support by educational attainment and sex: Ages 65+.... 99

Figure A.4 Receipt of public and private home support by equivalised household income quantile and sex: Ages $65+$

Figure A.5 Receipt of public and private home support by d-ADL and sex: Ages 65+ 100

Figure A.6 Receipt of public and private home support by d-iADL and sex: Ages 65+... 101 


\section{ABBREVIATIONS}

\begin{tabular}{|c|c|}
\hline $\mathrm{CDHS}$ & Consumer Directed Home Support \\
\hline $\mathrm{CHO}$ & Community Health Organisation \\
\hline CSAR & Common Summary Assessment Report \\
\hline$d-A D L$ & Difficulties with Activities of Daily Living \\
\hline FEMPI & Financial Emergency Measures in the Public Interest \\
\hline $\mathrm{HCA}$ & Healthcare Assistants \\
\hline $\mathrm{HCCl}$ & Home and Community Care Ireland \\
\hline HCSA & Health Care Support Assistants \\
\hline HIS & Healthy Ireland Survey \\
\hline iADL & Instrumental Activities of Daily Living \\
\hline $\mathrm{iHCP}$ & intensive Home Care Package \\
\hline LHO & Local Health Offices \\
\hline LTRC & Long Term Residential Care \\
\hline MAPLe & Method of Assigning Priority Levels \\
\hline $\mathrm{NCCN}$ & National Community Care Network \\
\hline NHSS & Nursing Homes Support Scheme \\
\hline OT & Occupational Therapists \\
\hline PHN & Public Health Nurses \\
\hline SAT & Single Assessment Tool \\
\hline WTE & Whole Time Equivalent \\
\hline
\end{tabular}





\section{EXECUTIVE SUMMARY}

A new statutory home support scheme was proposed in the 2017 Sláintecare report (Houses of the Oireachtas Committee on the Future of Healthcare, 2017), and was included in the 2020 'Programme for Government' (Department of the Taoiseach, 2020). The detailed design of the scheme has not yet been published. To help inform policymakers on the level and pattern of demand that could arise when a scheme is in place, this report estimates service demand for home support services for the population aged $65+$ in Ireland under various policy scenarios. We understand that the new scheme may extend to adults of all ages including those living with a disability, but data limitations prevented us from extending the analysis to younger groups.

The analyses are set in 2019, starting with a baseline estimate of actual activity and examining three further scenarios that successively extend the possible sources of additional demand for public home support.

\section{- Scenario 1 -Baseline Estimation}

This represents an estimate of the actual levels of home support utilisation and unmet demand in 2019 under the current system.

- Scenario 2 - Increased Hours for Recipients

Building on Scenario 1, this scenario assumes that all private recipients of home support move into the public scheme. Informed by the HSE's Winter Plan 2020/21, this scenario also increases home support hours for baseline recipients by between 10 per cent and 20 per cent, depending upon a recipient's difficulties with activities of daily living ( $d-A D L)$.

- Scenario 3 -Substitution for Long-Term Residential Care

Adding to Scenario 2, this scenario assumes a 50 per cent reduction in the number of people normally exiting public home support and entering longterm residential care (LTRC) (from 8 per cent to 4 per cent). Those substituting home support for LTRC receive an intensive Home Care Package (iHCP), providing the equivalent of 52 home support hours per week.

\section{- Scenario 4 - Expansion of Demand in Community}

Extending Scenario 3, we further assume that demand for home support amongst those with a $d$-ADL increases by 50 per cent following the introduction of a new statutory scheme.

\section{SCENARIO 1 BASELINE ESTIMATES}

There were an estimated 65,246 people aged 65+ in receipt of home support in 2019. Home support was received by 53,417 people through the public home 
support scheme, and 235 people received an iHCP. Of these, an estimated 14,200 public home support recipients also purchased private home support. We estimate that 11,600 people purchased private home support only. An estimated 24.7 million home support hours were received across public and private home support in 2019. Of these, the majority were provided through the public home support (18.2 million hours) or iHCP ( 0.36 million hours) schemes. An estimated 6.1 million hours, or 25 per cent of all home support received, were privately purchased.

There were 5,436 people on the waiting list for any public home support in December 2019. ${ }^{1}$ We estimate a 'demand' from this source for an additional 1.3 million hours in 2019. Taking delayed transfers of care from public hospitals into account, the overall baseline estimate of home support demanded in 2019 was just over 26.2 million hours.

\section{SIMULATIONS OF SCENARIOS 2 TO 4}

Table E1 illustrates the actual and simulated levels of demand across the four scenarios discussed above. When we include increases in support to recipients, substitution of LTRC for home support and expansion of demand, simulated demand for home support increases by over 13,000 people, or by over 30,000 people being supported by public home support. Were this to occur, we project that this would result in $\mathbf{1 2 . 5}$ per cent of all over-65s living at home in Ireland receiving home support through a new statutory scheme.

TABLE E1 ESTIMATED AND SIMULATED DEMAND FOR HOME SUPPORT ACROSS SCENARIOS RECIPIENTS: AGES 65+

\begin{tabular}{|c|c|c|c|c|c|}
\hline & $\begin{array}{c}\text { Baseline Estimation } \\
\text { (Scenario 1) }\end{array}$ & Scenario 2 & Scenario 3 & Scenario 4 \\
\hline \multicolumn{2}{|c|}{ Public home support scheme } & 53,417 & 53,417 & 53,417 & 53,417 \\
\hline \multicolumn{2}{|c|}{ Public Intensive Home Care Packages } & 235 & 235 & 235 & 235 \\
\hline \multicolumn{2}{|c|}{ Reductions in Admissions to LTRC } & & & $\underline{2,137}$ & 2,566 \\
\hline \multicolumn{2}{|c|}{$\begin{array}{l}50 \% \text { increase in Pop with d-ADLs } \\
\text { demanding care }\end{array}$} & & & & $\underline{10,700}$ \\
\hline \multicolumn{2}{|c|}{ Total public home support delivered } & 53,652 & & & \\
\hline \multicolumn{2}{|c|}{ Private Home Support ${ }^{\mathrm{a}}$} & 11,594 & & & \\
\hline \multicolumn{2}{|c|}{ Home support moved from private to public ${ }^{b}$} & & $\underline{11,594}$ & 11,594 & 11,594 \\
\hline \multicolumn{2}{|c|}{ Total home support delivered } & 65,246 & & & \\
\hline \multicolumn{2}{|c|}{ Public Home Support Waiting List } & 5,436 & 5,436 & 5,436 & 5,436 \\
\hline \multicolumn{2}{|c|}{ Scenario Total Demand ${ }^{c}$} & $\underline{70,700}$ & $\underline{70,700}$ & $\underline{72,800}$ & $\underline{84,000}$ \\
\hline \multicolumn{6}{|c|}{$\begin{array}{ll}\text { Source: } & \text { Authors' analysis of HSE Social Care Division da } \\
\text { Notes: } & \text { a Recipients includes 'private-only'. Hours inclu } \\
& \text { b All private home support is assumed to be co } \\
& \text { c The number of recipients affected by delayed } \\
& \text { support scheme. } \\
& \text { d-ADL = difficulties with activities of daily living }\end{array}$} \\
\hline
\end{tabular}

1 An additional 2,473 public home support recipients were awaiting additional supports in December 2019. 
However, the largest increases in demand are mainly seen in hours (see Table E2). Across the four scenarios, the simulated number of hours provided through public home support schemes increases from 18.56 million hours to almost 42 million hours. This represents a 70 per cent increase in home support provided in 2019, and a 126 per cent increase on what the HSE provided through the public home support and iHCP schemes in 2019.

TABLE E2 ESTIMATED AND SIMULATED DEMAND FOR HOME SUPPORT ACROSS SCENARIOS HOURS: AGES 65+

\begin{tabular}{|c|c|c|c|c|}
\hline & $\begin{array}{c}\text { Baseline } \\
\text { Estimation } \\
\text { (Scenario 1) }\end{array}$ & Scenario 2 & Scenario 3 & Scenario 4 \\
\hline Public Home Support Scheme & $18,200,000$ & $20,895,600$ & $20,895,600$ & $20,895,600$ \\
\hline Public Intensive Home Care Packages & 360,000 & 360,000 & 360,000 & 360,000 \\
\hline Reductions in Admissions to LTRC & & & $\underline{4,222,700}$ & $5,070,400$ \\
\hline $\begin{array}{l}50 \% \text { increase in Pop with d-ADLs } \\
\text { demanding care }\end{array}$ & & & & $\underline{5,259,400}$ \\
\hline Total public home support delivered & $18,560,000$ & & & \\
\hline Private Home Support ${ }^{\mathrm{a}}$ & $6,147,400$ & & & \\
\hline \multicolumn{2}{|l|}{$\begin{array}{l}\text { Home care moved from private to } \\
\text { public }^{b}\end{array}$} & $\underline{6,762,100}$ & $6,762,100$ & $8,630,200$ \\
\hline Total home support delivered & $24,707,400$ & & & \\
\hline Public Home Support Waiting List & $1,512,900$ & $1,664,100$ & $1,664,100$ & $1,664,100$ \\
\hline $\begin{array}{l}\text { Delayed Transfers of Care (public } \\
\text { hospitals) }\end{array}$ & 39,300 & 39,300 & 39,300 & 39,300 \\
\hline Scenario Total Demand & $\underline{26,259,500}$ & $\underline{29,721,100}$ & $\underline{33,943,800}$ & $\underline{41,918,900}$ \\
\hline $\begin{array}{l}\text { Authors' analysis of HSE Social Care } \\
\text { a Recipients includes 'private-only'. } \\
\text { b All private home support now ass }\end{array}$ & cludes pr & 2-4 Researc & $\begin{array}{l}\text { ata File. } \\
\text {-only and pu }\end{array}$ & te recip \\
\hline
\end{tabular}

To support the analyses and provide background information relevant to the design of the statutory scheme, the report includes a discussion of relevant aspects of the economics of home support services, and there is a detailed section on data and methods.

The report also profiles home support recipients' use of broader healthcare and social care services. The expansion of service provision associated with the introduction of a statutory scheme is likely to increase demand for such related services. For example, home support recipients have much higher use of public health nurses, occupational therapists and day centre care than the general population of older people. 


\section{HOME SUPPORT SUPPLY}

We provide a brief discussion on the supply of home support services in Ireland. The success of a new statutory scheme will be determined by the ability of the scheme to meet the demands of the home support recipients in an efficient and equitable manner. Demand is likely to grow considerably due to the introduction of the statutory scheme and the effects of demographic change. If supply of services does not keep pace, there are likely to be further extensions in waiting lists for care, diversion of demand to private provision and substitution by alternatives such as LTRC and acute hospital care. The ability to meet demand in a timely way could be the greatest challenge to implementation.

Home support services in Ireland are provided by a mixture of the HSE, voluntary organisations and for-profit organisations. The majority of home support is provided by for-profit organisations in Ireland. Approximately 33 per cent of total home support in 2019 was provided by HSE staff ( 8.2 million hours), 9 per cent was provided by the voluntary sector ( 2.1 million hours), and 58 per cent provided by for-profit organisations (14.4 million hours).

The report provides a short overview of what is known about professional home carers in Ireland. The majority of HSE employed home carers are Healthcare Support Assistants (previously Home Helps) and 96 per cent of HSE home carers are female. There is relatively little information on how many carers are employed in voluntary organisations and for-profit organisations, the skills of these carers, and the scope to increase carer numbers. Information on carers employed in voluntary organisations is even more limited. Collection of comprehensive and upto-date data on carers in Ireland, for example through a carer register or regular large-scale surveys, would be of assistance to policymakers, employers, carers, and home support recipients.

\section{RELATED STUDIES AND AVENUES FOR FUTURE RESEARCH}

We refer to ongoing research (planned for 2021 and 2022) that may also help inform the design of the statutory scheme:

- Further research is planned at the ESRI on the implications of potential funding mechanisms (e.g. Exchequer funding, co-payments, asset-testing) for the allocation of costs, distributional effects and demand for services.

- A second report will project the costs of home support in Ireland in the longer term, as part of a wider analysis of primary, community, and longterm care in Ireland using the ESRI's Hippocrates model.

- Recently the ESRI, HSE and Department of Health began work to prepare national and regional projections of healthcare workforce requirements. This research should help provide a forward-looking perspective on the 
analysis of workforce requirements, allow regional differences to be examined and facilitate analysis of how workforce needs will change as the reform agenda progresses.

Useful areas for future research include:

- How home support acts as a substitute or complement for other healthcare and social care services.

- Examination of the demand associated with the population under 65 years old and in receipt of disability services, as soon as data limitations have been addressed. 



\section{Introduction}

\section{$1.1 \quad$ INTRODUCTION}

This report develops scenarios on the potential service demand that could arise if a statutory home support scheme is introduced in Ireland. This type of scheme was proposed in the Sláintecare report (Houses of the Oireachtas Committee on the Future of Healthcare, 2017) and reiterated in the most recent 'Programme for Government' document (Department of the Taoiseach, 2020). At the time of writing, the parameters of the proposed statutory home support scheme have not been finalised and are currently being developed by the government. Home support, or home care, in this report refers to personal and domestic care provided to people in their own home; and in modelling the demand associated with such a scheme we focus on 'formal' or professional care provided by paid professional carers. In this report we construct scenarios to explore the demand implications of introducing a statutory scheme of care. However, the detailed arrangements of the finalised scheme may be different from what is described here.

The findings from this report are intended to provide information to inform the design of the scheme and on key scheme parameters. We understand that the new scheme may extend to adults of all ages (see Box 1.1) but, owing to the limited data available on home support for younger adults, this report focuses on home support amongst the older population: those aged 65 years and older. The older population are the main users of home support in Ireland, but future work examining the younger population - so key parameters can be tailored to this population - would be valuable.

Within the analytical chapters of this report that examine the potential demand for a statutory home support scheme, we first provide baseline estimates of public and private home support utilisation for those aged 65 years and older in 2019. Building upon this baseline estimate, we set out a range of scenarios for ways in which a statutory scheme might extend services and we simulate the increased demand for home support associated with these scenarios. In addition to estimating the potential demand for professional home support under a new statutory scheme, this report discusses a range of factors that will impact demand and supply of home support. To inform this discussion, the report profiles home support recipients and their healthcare and social care utilisation and provides an overview of home support supply and home carers in Ireland. 
This report builds upon several recent research studies published by the ESRI on home support, care for older people, and care for people living with a disability (Brick et al., 2020; Mac Domhnaill et al., 2020; Privalko et al., 2019; Smith et al., 2019; Walsh et al., 2019; Wren et al., 2017). Many of these studies have been published as part of the ESRI/Department of Health Healthcare Reform Programme. This report also draws on other pertinent research from Ireland and internationally that has examined various aspects of home support services, including the central role of unpaid or family carers in Ireland. While this report does not focus on unpaid care, we draw on recent work by McGarrigle and Kenny (2020), who examine the relationship between unpaid care and professional home support provided through state funded programmes.

This report will be the first of three planned outputs from the ESRI on home support in 2021/2022 that will be funded by the Department of Health. The second output is being prepared by the Tax, Welfare and Pensions research team at the ESRI. This will involve a micro-simulation analysis using the ESRI SWITCH model ${ }^{2}$ and data from the Central Statistics Office's (CSO) Survey of Incomes and Living Conditions (SILC). This study will examine the implications of potential funding mechanisms (e.g. Exchequer funding, means-tested co-payments, asset-testing) for the allocation of costs, distributional effects and take-up of a statutory scheme. The third output will project future costs of home support in Ireland to 2035 as part of a wider analysis of primary, community, and long-term care in Ireland. These projections will be provided by the ESRI's Hippocrates model, which has been developed under a programme of research funded by the Department of Health. Findings from the present report will be integral in informing the subsequent research outputs.

\subsection{PROPOSED STATUTORY HOME SUPPORT SCHEME}

The Department of Health is currently in the process of developing a statutory scheme for the financing and regulation of home support services. Box 1.1 outlines some of the features of the planned statutory home support scheme that are assumed to apply for the purposes of this report. The approach is being developed within the broader context of the ongoing reform of Ireland's healthcare and social care system, as envisaged in the Sláintecare Report (2017). The design will be informed by international policy and practice as well as by lessons learnt in the Irish context in respect of the delivery of home support and, more broadly, of the Nursing Homes Support Scheme (NHSS). 
In this report we assume that the home support services provided through the new home support scheme will be accessible to all adults (aged 18 and over) on the basis of their assessed care needs using InterRAl as a single assessment tool. Further detail is provided on this tool in Box 3.1 Chapter 3. The assessments made using the tool can be used to place each individual in a care band commensurate with their assessed need, once an appropriate system of care bands has been developed. We understand that the new home support scheme will include care previously provided through the HSE's current home support scheme and intensive Home Care Package (iHCP) scheme. We understand that the new home support scheme will be integrated with other healthcare and social care services (including the NHSS) to provide person-centred care. It is important that the planned statutory scheme be complementary to, and supportive of, the provision of care by families and other unpaid carers. A service user may move through the continuum of care, and eventually need long-term residential care. In accordance with the vision set out in the Sláintecare Report for everyone to have 'access to an affordable, universal, single-tier healthcare system', we understand that the design of the new home support scheme will aim to ensure that cost is not a barrier to accessing services. Planned work by the Tax, Welfare and Pensions team at the ESRI will examine the financing model for the scheme, affordability, and how factors such as user contributions will impact demand and costs.

\section{BOX 1.1 FEATURES OF PROPOSED STATUTORY HOME SUPPORT SCHEME}

- The Department of Health is currently in the process of developing a statutory scheme for the financing and regulation of home support services.

- This scheme will succeed the current provision of Home Support Services by the HSE.

- The optimal approach to the new home support scheme is being developed within the broader context of the ongoing reform of Ireland's healthcare and social care system, as envisaged in the Sláintecare Report (Houses of the Oireachtas Committee on the Future of Healthcare, 2017).

- It is envisaged that the home support services that will be provided through the new home support scheme will be accessible to all adults (aged 18+).

- Provision will be on the basis of individuals' assessed care needs using InterRAl as a Single Assessment Tool (SAT). It is intended to develop a system of care bands which will be used to place an individual in a care band commensurate with their assessed need.

- A service user may move through the continuum of care, and eventually need long-term residential care. Therefore, it is intended that the new home support scheme will be integrated with other healthcare and social care services (including the NHSS) to provide person-centred care. 
- In accordance with the principle, central to Sláintecare, that everybody should have 'access to an affordable, universal, single-tier healthcare system', the new home support scheme will aim to ensure that cost is not a barrier to accessing services.

- The financing model for the new scheme has not yet been determined, but a range of options for this is being considered. Further work is being undertaken by the Department of Health with the ESRI's Tax, Welfare and Pensions team which will inform decision making in this regard.

- While the Department of Health's Sláintecare Implementation Strategy (Government of Ireland, 2018) commits to the establishment of the scheme by the end of 2021, progress on the development of the scheme has been impacted by the diversion of resources in response to COVID-19. Nevertheless, the Department remains committed to advancing this work as a priority, taking on board the learning from the response to COVID-19.

Source: Department of Health correspondence.

In this report we examine three additional scenarios to explore how demand may change when a statutory home support scheme is introduced. The scenarios focus on three channels through which demand is likely to change: i) increased supply to current recipients; ii) changes in the model of care that provides increased support to individuals at home instead of within residential care facilities; iii) increased demand from those living in the community who are not yet in receipt of home support. The scenarios are assembled in an additive manner.

\subsection{OBJECTIVES OF REPORT}

The main aim of this report is to assist policymakers involved in the planning and design of the proposed statutory home support scheme. The research in the report concentrates on the potential demand for home support amongst the population aged 65 years and older within the public healthcare and social care system if a statutory scheme were to be introduced.

To undertake this research, the report estimates the realised demand for publicly financed and privately purchased home support, in addition to accounting for unmet need (numbers waiting for publicly financed home support, delayed transfers of care in public hospitals) in 2019. This provides us with a baseline demand for home support in the existing home support environment.

The report also profiles the sociodemographic characteristics of home support recipients and their use of other healthcare and social care services. This information is important when designing a statutory home support scheme that 
sits within a wider care continuum. Additionally, the report provides background information on the supply of home support in Ireland. The report highlights the mixed nature of existing home support provision and emphasises the importance of ensuring an adequate supply of skilled carers to meet the demands for recipients under a statutory home support scheme.

\subsection{STRUCTURE OF THE REPORT}

The report is structured as follows. Chapter 2 defines home support, provides an overview of home support in Ireland and describes how the current model of care has evolved over time. There is also a brief discussion of how the COVID-19 pandemic has affected home support. Chapter 3 outlines the economics of home support. It identifies some of the factors likely to affect demand and supply of home support and how these factors might be addressed estimating the potential level of demand for home support when introducing a statutory scheme. Chapter 4 discusses the data and methods we use in the analytical chapters of the report and sets out the scenarios we consider in the report when projecting demand for a new statutory home support scheme. Chapter 5 provides projections of demand for home support across each of the scenarios. Chapter 6 profiles home support recipients and their patterns of healthcare utilisation. Chapter 7 provides an overview of home support supply in Ireland and discusses providers of care and home carers. Chapter 8 concludes. 



\section{CHAPTER 2}

\section{Home support overview}

\subsection{DEFINITION}

In this report, home support, or home care, refers to health and domestic care provided to people in their own homes (Murphy et al., 2015). In general, home support is provided to older people with personal and care needs and to people living with an illness or disability. While forms of home support are also provided to children and younger people (Privalko et al., 2019), due to data limitations this report focuses on services provided to older people. It is this group who will be most affected by the proposed statutory home support scheme.

This report focuses on 'formal' or professional home support for those aged 65+, which we define as home support packages provided by paid professional carers such as healthcare assistants or home helps (healthcare support assistants), and, where applicable, community nurses and allied health professionals. Other research, to which we refer in in this report, has examined demand for and supply of 'informal' or unpaid care, i.e. provided by individuals' families or communities on a non-contractual basis, often without payment (McGarrigle and Kenny, 2020). ${ }^{3}$ Throughout this report we will use the terms 'home care' and 'home support' to mean professional care or support.

\subsection{HOME SUPPORT IN IRELAND}

Formal home support has been an integral part of healthcare and social care in Ireland since the 1970 Health Act. Yet, there has never been a statutory scheme for home support. This is in contrast to LTRC, where the NHSS provides a statutory basis for the financing of LTRC for people in need of long-term nursing home care (and has done so since 2009). Home support, and care provided through the NHSS, are generally, but not exclusively, provided to those aged 65 years and older (Wren et al., 2017).

Wider home support arrangements in Ireland follow a family-based structure similar to countries in southern European such as Italy, Spain, and Greece (Hanly and Sheerin, 2017; Ilinca et al., 2015). The approach in Ireland differs from the typical systems in other northern European countries where the use of professional carers plays a much larger role in meeting domestic and personal care needs of the older population, as well as those of adults living with a disability 
(Kiersey and Coleman, 2017). The 2016 Census found that 4.1 per cent of the population provided unpaid care to others (of all ages) (CSO, 2018). Recent research from The Irish Longitudinal Study on Ageing (TILDA) highlights that unpaid home support remains the bedrock on which professional care and support is delivered (McGarrigle and Kenny, 2020).

Within the current home support structure, individuals can apply for care from the HSE home support scheme for older people or apply for personal care or home support from the HSE's disability services. These home support services are currently free at the point of use. However, access to State-financed home support also depends upon the supply available to individuals in their local area. Provision of public home support differs widely across regions (Smith et al., 2019). As with healthcare more generally in Ireland, the private sector (for-profit organisations) both provides a large component of publicly funded professional home support and provides services directly to many individuals who purchase home support privately.

Within the Sláintecare report (Houses of the Oireachtas Committee on the Future of Healthcare, 2017), emphasis was placed on providing more care in primary and community settings. Sláintecare emphasised that people should be supported to live at home and to receive the required care and support in their home or as close to home as possible. In particular, for vulnerable groups such as older persons and individuals living with a disability, reducing the use of residential care in favour of a 'home first' approach was highlighted. In light of these recommendations, an early step in the Sláintecare implementation strategy was to establish a home support scheme on a statutory basis. The decision to establish a statutory scheme for home support was reiterated in the most recent 'Programme for Government' document (Department of the Taoiseach, 2020). The document stated the intention to 'introduce a statutory scheme to support people to live in their own homes which will provide equitable access to high quality, regulated home care.' With the onset of the COVID-19 pandemic, and the substantial impact this is having on older people and people within residential care facilities, increased home support has been provided by the State, specifically through the Winter Plan 2020/21 (HSE, 2020).

\subsection{HOME SUPPORT FOR OLDER PERSONS}

Formal home support provision in Ireland was first included in legislation as part of the 1970 Health Act which established the home help scheme (Murphy et al., 2015). ${ }^{4}$ The act set an important precedent for home support by giving each

This seminal act also established the General Medical Services (GMS) scheme ('A health board shall make available without charge a general practitioner medical and surgical service for persons with full eligibility') and what would become the regional health board structure. 
regional health board discretion on how to supply home support to individuals in each health board region (Timonen and Doyle, 2008). This feature of the act meant that from the outset of the first publicly financed home support scheme in Ireland, a decentralised approach with power provided to more local decision-makers was adopted. However this act, and subsequent scheme changes, did not put home support on a statutory footing.

Between 1970 and 2006, the home help scheme was the only scheme used to provide professional home support in Ireland. The home help scheme was designed to provide a range of domestic supports including assistance with basic household tasks such as cooking and cleaning, as well as some minor health-related tasks. Until recently, care provided through the home help scheme was provided mainly by State-employed home helps or personal care attendants or through a large number of voluntary agencies. However, in more recent years, the for-profit sector has become a bigger component of both public home support as well as providing privately purchased home support (Mercille and O’Neill, 2020).

In 2006, another home support scheme was established: the Home Care Package (HCP) scheme. Initially, the home help scheme and the HCP scheme differed in terms of services provided. The home help scheme, as was initially intended, provided mainly domestic support, while the HCP scheme provided more intensive care to older people and was targeted at those discharged from a hospital or a rehabilitation facility. A HCP often included a mix of home support, nursing services, and therapy services that better targeted the specific needs of the HCP recipients. A third scheme, the intensive Home Care Package (iHCP) scheme was also established. iHCPs are even more targeted than a HCP, and these more intensive care packages have been provided to a relatively small number of people who have very high care needs such as severe dementia. Coordination and funding of iHCPs was provided in conjunction with Genio, a philanthropic organisation that helps to support social care services (Keogh et al., 2018a).

In addition to having three different public home support schemes in recent years, the decentralised organisation of the schemes meant that the public home support system in Ireland was somewhat fragmented. Large differences developed in how Local Health Offices (LHOs, see Table 2.1) provided home support and which scheme they emphasised when providing it. Similarly, access to various home support schemes differed across LHOs. For example, in some LHOs people were in receipt of hours from both schemes, while in others this did not occur. Furthermore, as home help and HCPs began to converge in terms of type of care being provided, in some LHOs a HCP was essentially used to provide additional hours to support an older person already receiving home help. 
TABLE 2.1 LOCAL HEALTH OFFICES (LHO) IN EACH COMMUNITY HEALTH ORGANISATION (CHO)

\begin{tabular}{|l|l|}
\hline & Local Health Offices \\
\hline CHO 1 & Donegal, Sligo/Leitrim/West Cavan, Cavan/Monaghan \\
\hline CHO 2 & Galway, Roscommon, Mayo \\
\hline CHO 3 & Clare, Limerick, North Tipperary/East Limerick \\
\hline CHO 4 & Kerry, North Cork, North Lee, South Lee, West Cork \\
\hline CHO 5 & South Tipperary, Carlow/Kilkenny, Waterford, Wexford \\
\hline CHO 6 & Wicklow, Dun Laoghaire, Dublin South East \\
\hline CHO 7 & Kildare/West Wicklow, Dublin West, Dublin South City, Dublin South West \\
\hline CHO 8 & Laois/Offaly, Longford/Westmeath, Louth/Meath \\
\hline CHO 9 & Dublin North, Dublin North Central, Dublin North West \\
\hline
\end{tabular}

Figure 2.1 points to some of the variation in how home support was provided across LHOs. This figure shows the number of recipients of home support from the home help scheme and the HCP scheme in December 2016 across regions. Results are presented across Community Health Organisations (CHOs) instead of LHOs for the sake of brevity. However, clear differences are still evident across CHOs. In CHO 4 (Kerry, North Cork, North Lee, South Lee, West Cork) for example, home help was by far the most dominant scheme while in $\mathrm{CHO} 9$ (Dublin North, Dublin North Central, Dublin North West), the HCP scheme was more prevalent.

FIGURE 2.1 HOME HELP RECIPIENTS AND HOME CARE PACKAGE RECIPIENTS BY CHO DECEMBER 2016

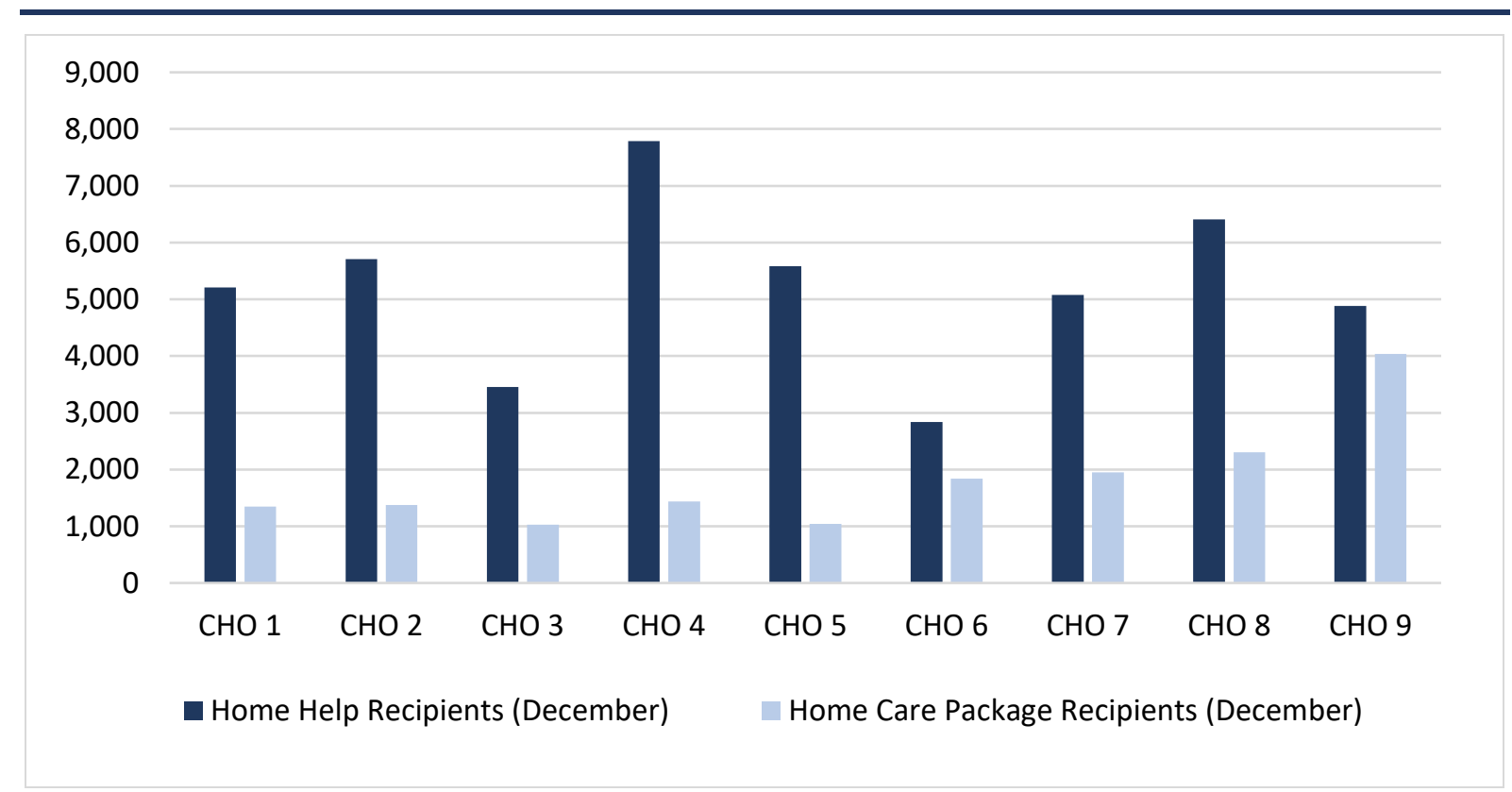

Figure 2.1 points to the fragmented way public home support has developed in Ireland. While devolution of responsibility to local regions may help local health service managers to distribute care in a manner that matches the needs of the local 
population, it is not clear whether the devolved public home support structure better accommodated local circumstances. The fragmented organisation of home support may, at least in part, explain some of the large differences in supply of home support per capita across regions in Ireland (Smith et al., 2019) and local variations in the ability to meet demand for home support.

Over time, the home help and HCP schemes came to deliver similar types of care (Care Alliance Ireland, 2018). This culminated with the merging of these schemes into the current home support scheme in 2018. However, iHCPs are still provided in a separate scheme, although numbers receiving iHCPs are low. Much of the analysis in this study is based on the current home support scheme. The scheme provided care to over 53,000 individuals in 2019 , at a cost of over $€ 440$ million. While there is no definitive breakdown of care to these individuals by age, it is estimated that at least 90 per cent of the home support recipients in this scheme were aged 65 years and older. ${ }^{5}$ Care provided as part of the public home support scheme is provided free of charge to recipients. However, many people do pay out of pocket for privately purchased home support. In this context, payment for home support is a feature of the broader home support environment in Ireland.

Other countries, such as England, have social care systems incorporating co-payments for home support provided through local public home support schemes, alongside significant numbers of recipients paying the market price for privately purchased home support (Kiersey and Coleman, 2017). In England, 19 per cent of home support recipients pay privately for care, and 21 per cent pay co-payments to 'top-up' support provided through local authorities (Glendinning, 2012). However, the use of co-payments can affect the take-up of services by some people. In Ireland, many people without a Medical Card (or GP visit card) pay for healthcare and social care services such as GP visits or physiotherapy visits. The individuals must pay the market price of the healthcare service, and there is extensive literature showing that the requirement to pay for healthcare reduces its use (Ma and Nolan, 2016; Nolan, 2007; 2008; 2011). Similar results on the effect of co-payments on healthcare have been seen in other healthcare systems (Baicker et al., 2012; 2013; Landsem and Magnussen, 2018).

Traditionally, care provided through the home help scheme was provided mainly by State-employed home helps or personal care attendants or through a large number of voluntary agencies. In more recent years, the for-profit sector has been a larger supplier of both public and privately purchased home care (Mercille and O'Neill, 2020). There is evidence of the system incrementally shifting toward 
greater marketisation since the introduction of the HCP in 2006, with the role of for-profit organisations becoming more pronounced (Mulkeen, 2016).

\subsection{HOME SUPPORT FOR THOSE LIVING WITH A DISABILITY}

Both home support and personal assistance for people with a disability are provided through the HSE Social Care Division's Disabilities programme. This programme focuses on supporting people with lifelong disability where onset of a complex disability occurred before age 65 . Individuals supported through this programme include people living with physical or sensory disabilities or intellectual disabilities. We understand that the new statutory home support scheme will provide support to this population.

The demand for and use of home support amongst the population living with a disability is much more difficult to estimate than demand for home support provided to the older population, due to poor data infrastructure in this sector (Brick et al., 2020). Therefore, it was not possible to examine home support for the population with disabilities in this report. The data do not currently allow for a comprehensive baseline to be constructed or coherent projection scenarios to be examined and modelled. Furthermore, the definition of home support, and the services provided, may vary more than in older persons' care. This means it will not be feasible to apply the same demand scenarios used for the older population to the population living with a disability. To project demand for home support under a new statutory home support scheme among those living with a disability, additional analysis, interrogation of data sources, and discussions with people involved in the care of people with disabilities are required.

There is evidence of considerable variation across countries in how community living for the population with a disability is supported in practice (Mac Domhnaill et al., 2020). Provision of care services at home differs by the types of disabilities people are living with. Individuals with an intellectual disability receive care through home help or home support services schemes. Individuals with a physical and/or sensory disability receive care through personal assistance and assisted living services or home support services.

Historically, a high proportion of services for people with disabilities was delivered through residential services, typically in residential institutions. Policy has changed over time, and there is now a much greater emphasis on supporting people with disabilities in the community. The development of day services, respite services, and social welfare supports like Domiciliary Care Allowance and Carer's Allowance support people with disabilities living with their families. The Independent Living Movement, the establishment of Centres for Independent Living, and the introduction of Personal Assistance has supported a certain number of people with 
physical or sensory disabilities to live independently in their own homes rather than in residential care. In line with the recommendations of the report Time to Move On from Congregated Settings (HSE, 2011), official policy is to support people with disabilities to live in mainstream housing in the communities, and the process of deinstitutionalisation is being steadily progressed under its implementation programme. A significant change occurred in the 1990s when a nationwide network of Centres for Independent Living was established (Department of Health, 2012; Review Group on Health and Personal Social Services for People with Physical and Sensory Disabilities, 1996; The Commission on the Status of People with Disabilities, 1996). The Value for Money and Policy Review of Disability Services report put much greater emphasis on supporting the individual with a disability as far as possible to participate in education, employment and society, and to maximise his or her potential' (Department of Health, 2012). The subsequent Transforming Lives programme (HSE, 2016) has the aim of supporting people with disabilities to 'live ordinary lives in ordinary places'.

In a detailed analysis of HSE and Health Research Board (HRB) databases that collect information on services provided to those living with an intellectual disability or physical and/or sensory disability, Brick et al. (2020) examined the utilisation of public care services by people living with a disability in Ireland in 2017. They found that a large proportion of care for those living with disabilities is still provided through residential care, often in community group homes, as well as in the remaining congregated care settings. In 2017, 26.9 per cent $(7,627)$ of people on the National Intellectual Disability Database received full-time (at least five days per week) residential care services (Brick et al., 2020). In addition, 889 individuals on the National Physical and Sensory Disability Database were in receipt of fulltime residential care services (Brick et al., 2020). Similar to the Older Peoples' home support scheme, there are no co-payments of public home support for those living with a disability. However, there are large numbers waiting for care and evidence of large differences in supply across regions (Mac Domhnaill et al., 2020).

\subsection{HOME SUPPORT IN THE TIME OF COVID-19}

The COVID-19 pandemic has dramatically affected the economy, society and healthcare and social care system in Ireland. Much of the analysis included in this report uses information and data collected before the pandemic. It is difficult to discuss and plan for the new proposed statutory home support scheme without taking some account of the changes during the pandemic. National and international experiences of COVID-19 may inform many policies around caring for older and more vulnerable population groups, putting a greater emphasis on keeping people at home for longer (Ní Shé et al., 2020; Pierce et al., 2020). Therefore, the demand for home support by 2022 and beyond may differ significantly from the position before COVID-19. 
The home support system in Ireland was greatly affected by the COVID-19 pandemic. A Department of Health and HSE joint paper ${ }^{6}$ indicates that on 31 March 2020, home support was temporarily suspended to some recipients who were categorised as lower priority (priority levels 3 and 4, see Table A.1 for a breakdown of the four priority levels used). Alternative community or voluntary supports were offered to this group. Furthermore, the joint paper says that many home support recipients suspended their service voluntarily for a period of time. It is difficult to fully ascertain COVID-19 infection and mortality amongst home support recipients in Ireland and whether home support recipients have COVID-19 infection rates and mortality higher (lower) than similar individuals not in receipt of home support. The joint paper highlights COVID-19 outbreaks ${ }^{7}$ linked to home support services. There were 80 cases associated with outbreaks in home support services, far fewer than the number linked with outbreaks in LTRC. However, evidence from England and Wales shows that in Wave 1 of the pandemic, older people in receipt of home support (domiciliary care) had high rates of COVID-19 mortality (Glynn et al., 2020).

The LTRC sector has experienced substantial negative impacts from the illness. LTRC was at the epicentre of COVID-19 deaths in the early phase of the pandemic in Europe. The LTC COVID Network at the London School of Economics estimates that during the initial phase of the pandemic, Ireland had one of the highest proportions of COVID-19 deaths that occurred in LTRC homes in comparison to 15 other countries (Comas-Herrera et al., 2020b; 2021). Recent research by the LTC COVID Network estimates that over 4 per cent of care home (nursing home/LTRC) residents in Ireland in 2020 died due to COVID-19 (Comas-Herrera et al., 2020a). The elevated risk to older people from the pandemic and the difficulties in preventing the spread of disease in congregated settings has added urgency to efforts to reduce the nation's reliance on residential care and the enhanced roles for home care and primary and community healthcare supports in Ireland.

There is increased recognition from politicians, policymakers, advocates, and the general public on the need to move away, where possible, from the traditional practice of maintaining large numbers of people living within congregated and residential settings. This recognition is summed up by the Expert Panel on Nursing Homes report (Frazer et al., 2020) in Box 2.1.

Department of Health and HSE Joint Paper (January 2021). Home Support Services: Preparedness and impact of COVID-19 on services. https://www.gov.ie/pdf/?file=https://assets.gov.ie/124134/96d68eaf-cd8d-4232-9676414468f46c27.pdf\#page=1.

7 A COVID-19 outbreak is identified by the Health Protection Surveillance Centre as 1) a cluster/outbreak, with two or more cases of laboratory confirmed COVID-19 infection regardless of symptom status. This includes cases with symptoms and cases who are asymptomatic, or 2) a cluster/outbreak, with one laboratory confirmed case of COVID-19, and at least one additional case of illness with symptoms consistent with COVID-19 infection (as per the COVID-19 case definition). URL: https://www.hpsc.ie/a-z/respiratory/coronavirus/novelcoronavirus/casedefinitions/covid19outbreakcasedefinitionforireland/. 
'Home support and personal assistance services were also emphasised as playing an important role in enabling older persons and persons with a disability to live independent lives in the community for as long as possible. Such services are important, not just in empowering people to pursue their life choices, but also to remain connected with their community, neighbours and friends, as well as the natural supports in their lives. It was noted that personal assistance services are not available to those over the age of 65 and that the COVID-19 pandemic has further highlighted the need for work on a national personal assistance policy and home care standards to be expedited.'

Source: $\quad$ Frazer et al., 2020.

In the short- to medium term there may be an increase in the demand for home support and community care from those who previously may have used residential care settings, due to diversion from hospital care for some patients and quicker discharge from hospital for others. There is increasing pressure to align policies more closely towards caring for people at home. A much broader scoping and detailed analysis can be found in the Expert Panel on Nursing Homes report, which also discusses some of the specific issues of COVID-19 with LTRC homes (Frazer et al., 2020).

While LTRC homes across many countries were gravely impacted by COVID-19, issues around regulation, oversight, and the large role played by the for-profit sector in LTRC may have impeded the swiftness of policy responses (Frazer et al., 2020). Some of these institutional challenges may also be relevant when considering the design for the proposed statutory home support scheme.

COVID-19 has also had important impacts on unpaid care and on the ways that vulnerable individuals interact and communicate with their families and communities. The pandemic and consequent restrictions have led to spells of unemployment or underemployment for many workers, changed work practices across the economy, and spurred a vast increase in home working among those able to work in this way. The unemployment rate was 14.7 per cent in September 2020, up from 4.9 per cent in February 2020 (McQuinn et al., 2020). In addition to those listed as unemployed, many others are not working, or are furloughed, and are receiving benefits through the Pandemic Unemployment Payment scheme, and the Employment Wage Subsidy Scheme (McQuinn et al., 2020).

One might expect the sharp rise in unemployment to be associated with an increased supply of unpaid home care. No doubt some households have experienced withdrawal of support services when professional carers were asked to isolate or when the person receiving the care was asked to do so, with unpaid carers replacing some of this professional care. To the extent that family members have had time freed up from formal employment, some might offer additional 
hours of home care and thereby reduce the demand for professional home support. Previous evidence has shown that in times of high unemployment in European countries such as during the Great Recession, the supply of unpaid care increased (Costa-Font et al., 2016). A similar link between employment status and unpaid care hours has also been found for Ireland (Walsh and Murphy, 2018). However, this crisis may be different. While a rise in unemployment may generally tend to increase unpaid care supply, the scale of this effect likely depends upon the demography of unemployment (i.e. there will be a weaker effect if unemployment falls disproportionately upon younger people with a lower likelihood of having a relative who needs care). In addition, fears of passing on COVID-19 to a vulnerable family member (especially as PPE is unlikely to be a feature of unpaid care giving) or other aspects of COVID-related restrictions such as movement limits may temper some of the potential increases in unpaid care provision from being realised. This is especially the case for working age relatives who live outside the home of the person requiring care or for migrants who cannot easily travel to provide assistance.

Effects of the pandemic on provision of unpaid care seem to have varied considerably depending upon individual circumstances. Evidence from England showed that between March and May 2020 there were an additional four million unpaid carers (an increase of 50 per cent, albeit using a broad definition of unpaid care) as a result of COVID-19 and the ensuing employment reductions/changes and restrictions (Carers Week, 2020). ${ }^{8}$ However, other evidence from England found that in the early months of COVID-19, amongst individuals aged 70 years and older, two-thirds reported receiving unpaid care, although 17 per cent of older people living alone with two or more difficulties with personal care received no unpaid care (Evandrou et al., 2020).

We are not aware of any information yet being available for Ireland on the changes in unpaid and family care provision during the pandemic. However, we may expect that while unpaid care did increase in some cases, for those living alone or with low social connectedness, this may not be the case. While it is difficult to predict employment numbers or the scale of working from home arrangements over the medium to longer term, economic analyses do assume that COVID-19 will have sizeable effects on the economy in 2021 and 2022 at least (McQuinn et al., 2020). Policymakers should be cognisant that demand for home support at the introduction of a new scheme may differ from the following years due to differences in the supply of unpaid care. While higher levels of unpaid care may be available in 2021/2022, these may dissipate over time as the economy and society moves back towards a more normal operating environment after the COVID-19 pandemic has subsided. 


\section{CHAPTER 3}

\section{The economics of home support}

\subsection{INTRODUCTION}

This chapter discusses what factors impact demand and supply for home support. The factors identified and discussed are used to inform the demand projection scenarios modelled later in the report.

Healthcare and social care systems often limit demand to match the available supply of care through mechanisms such as rationing, or deter some demand by requiring co-payments for care (Cullis et al., 2000). In Ireland, demand for home support is greater than supply at current prices (i.e. no cost for public home support service) (Smith et al., 2019). These mismatches between demand and supply are managed by queuing (in the form of waiting lists). Persistently supplying lower levels of support than the underlying level of demand can also reduce future demand. This can happen where some potential recipients are discouraged from seeking home support as they believe it will not be offered in a timely way. In addition, constraints on supply can divert some demand to alternative channels of support such as private provision (effectively indirectly imposing charges for home support on many people). Poor access to home support may also increase use of residential care, and this has been shown in other countries (de Meijer et al., 2015; Guo et al., 2015). There is evidence in Ireland that lower supply of home support within a region increases length of stay for hospital inpatients, especially those with longer length of stays who are likely to be clinically ready for discharge (Walsh et al., 2020a).

Many of the factors that impact demand will be outside the control of policymakers. But policymakers should be cognisant of how factors such as population health, local supply of carers, ability to meet recipients' complex care needs, and the supply of unpaid care will impact demand for home support. Where possible, we draw on national and international evidence. However, compared to many other healthcare and social care services, home support has received relatively little attention in Ireland and internationally from economists and health service researchers. Often it is only possible to identify the direction of the relationship between home support demand and a factor of interest, as opposed to estimating the magnitude of the relationship. Section 3.3 also discusses the economics of home care supply and asks how factors such as waiting lists and rationing of services, and financing of home support, may impact demand under a new statutory scheme. 


\subsection{DEMAND}

In order to understand how certain factors impact demand for healthcare and social care, it can be helpful to start with a simple economic model. Within health economics and the health service research literature, models such as the Grossman model (Grossman, 1972) and the Andersen healthcare utilisation model provide frameworks to understand peoples' health-seeking behaviour. These models, and the literature based on them, indicate that factors such as co-payments, local supply, knowledge of services, matching care needs with correct skill-mix etc., are all extremely important in determining healthcare and social care demand and are important aspects to be considered when designing the proposed statutory home support scheme.

Another more recent conceptual framework, not dissimilar to Grossman, that may be useful to policymakers in social care has been proposed by The Health Foundation. In a recent examination of NHS activity in England, Tallock et al. (2020), descriptively, and illustratively, examined the interactions between policy decisions, funding, supply, demand, and utilisation (activity). These are shown in Figure 3.1.

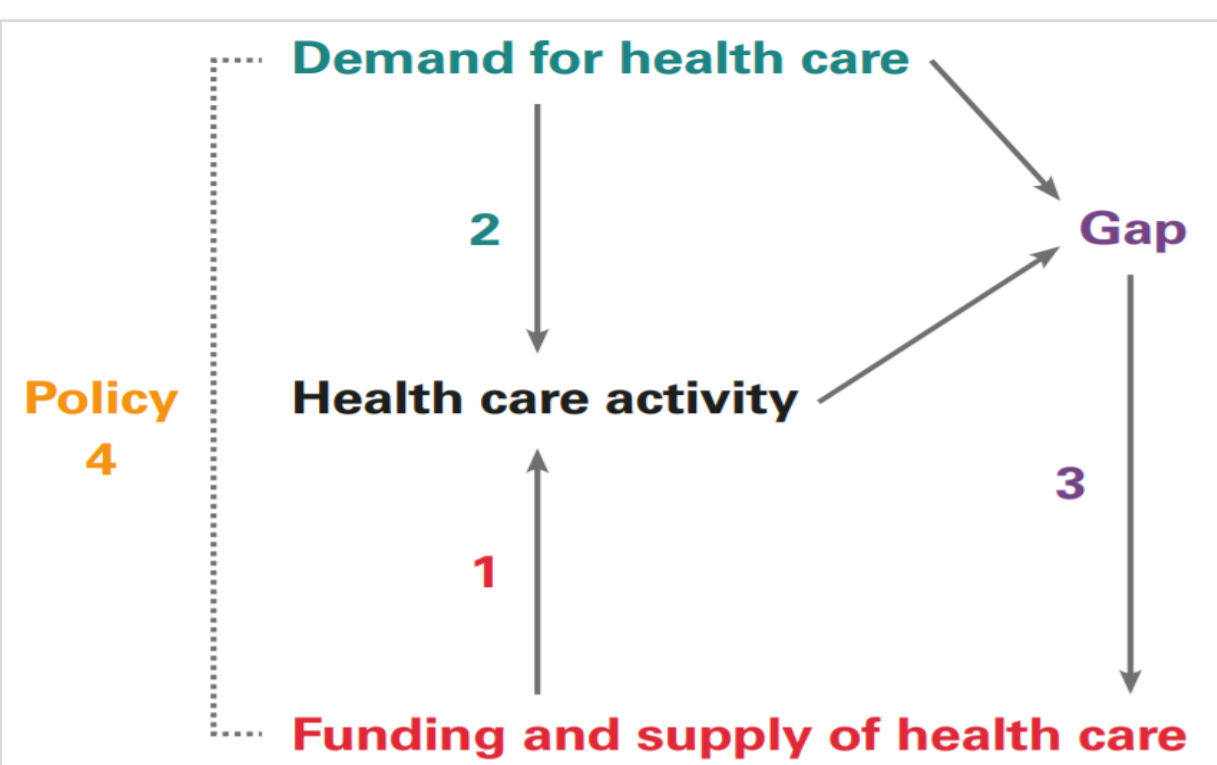

The authors highlight four key features within their framework that are useful when examining specific parameters of a proposed statutory home support scheme and anticipating how these factors will impact demand for home support.

1) Funding determines how much supply (e.g. staff) can be afforded;

2) The demand for healthcare is driven by a complex combination of factors; 
3) When demand grows faster than supply, unmet needs for care will increase; and

4) Governments can try to influence the size of the gap (i.e. unmet demand) through their policy choices.

The Health Foundation model emphasises that demographic factors such as the size, age and sex profile of the population will affect demand, especially age because of its association with increased morbidity and proximity to death.

There are other factors where policymakers in health and social care may have less control in the short-run such as medical advances, technological capabilities and wider determinants of health (Tallock et al., 2020). Finally, the authors acknowledge the tension between the provision of care that meets the current needs of an individual and the provision of other care (or actions) that may reduce future need for which there is not yet visible demand. For example, there might be cases where a small number of hours provided to someone who is not currently frail could postpone the development of frailty in the future, or where support for an unpaid carer could reduce the carer's future need for home support or other healthcare and social care services. The realised demand for home support is also dependent upon the extent of public knowledge about the support available, the quality and/or type of support available, and the ability to manoeuvre through administrative barriers that may exist to access necessary support (Ensor and Cooper, 2004).

In the following sub-sections, we list some of the key factors that impact demand for home support and draw on evidence from the literature as to how important each factor is likely to be.

\subsubsection{Demographics}

As highlighted above, age is a key determinant of healthcare and social care demand, including home support demand. Some of this is due to increases in morbidity at older ages, and there is a related association between age and proximity to death (care demand increases significantly in final years of life) (Weaver et al., 2009). Previous ESRI research estimates that the population aged 65 years and older is projected to increase by 78 per cent between 2016 and 2030 (Keegan et al., 2020). Between 2015 and 2030, the demand for home support was projected to increase by between 38 per cent and 66 per cent (Wren et al., 2017) as shown in Appendix Table A.2. This projection was made assuming no change in the model of care, and it did not anticipate the introduction of a statutory scheme. Changing demographics are also impacting the availability of family carers and are likely to reduce the overall supply of unpaid care. A recent report from the Houses 
of the Oireachtas claims that the supply of family carers is unlikely to rise at the same rate as demand for home support (O'Sullivan, 2019).

\subsubsection{Activities of daily living and instrumental activities of daily living}

Home support aims to allow people with health and/or domestic care needs to remain and be supported in their own home. Support arrangements target not just the healthcare needs of the individual but other aspects of their circumstances that allow them to continue to live their everyday lives such as dressing, shopping, cooking and cleaning. The latter supports are often characterised as social care. While the levels of social care needs differ across individuals, data on these requirements are often captured by researchers using two standardised metrics: activities of daily living (ADL) and instrumental activities of daily living (iADL).

Demand for home support broadly depends upon the need of people to be supported in their everyday tasks. ADLs are tasks relating to personal care (e.g. eating, dressing, toilet use), while iADLs are those tasks that allow people to live more independent lives such as housekeeping, grocery shopping and taking their medications. The InterRAI SAT algorithm used to measure the needs of people for home support looks closely at difficulties with ADL ( $d-A D L)$ or iADL (d-iADL). ${ }^{9}$ This tool will systematically assess individuals' care needs, including based upon d-ADLs, and apportion care packages accordingly. Having any d-ADL or d-iADL, and the number of them reported by an individual, are positively correlated with receipt of home support in the current system (Kamiya et al., 2012; Murphy et al., 2015).

\subsubsection{Social and community supports}

\section{Unpaid and family care}

While d-ADL and d-iADL are key indicators of potential need for professional home support, the vast majority of care to the Irish population is provided by unpaid carers (Hanly and Sheerin, 2017; Ilinca et al., 2015). In practice, therefore, demand for public or private professional home support will often be affected by the availability to an individual of unpaid care and social supports. Evidence from Ireland and many jurisdictions internationally shows that having access to a family member or neighbour to assist with meeting personal and care needs can dramatically reduce demand for professional home support (McGarrigle and Kenny, 2020).

A report from The Irish Longitudinal Study on Ageing (TILDA) examined the receipt of professional and unpaid care in Ireland using TILDA Waves 2-5 (McGarrigle and 
Kenny, 2020). A key aspect of the report's findings were that for older people living at home with some functional limitations (i.e. a d-ADL or d-iADL), family members, particularly spouses, were the main caregivers (McGarrigle and Kenny, 2020). Both children and non-relatives provide a small, but non-insignificant proportion of informal care. Previous research from TILDA has highlighted that being married greatly reduces use of home support (Murphy et al., 2015). For people with an intellectual disability, parents are the main informal carers, but among those aged over 60, siblings are more likely to be the primary unpaid carer (Doyle and Carew, 2018). While unpaid care may act as a substitute for professional home support for many people, more recent evidence has highlighted a more nuanced relationship between unpaid and professional care. Recent evidence from Scotland (where public home support is free) found that having an unpaid carer was actually related with an increase in professional home support provided, by 1 hour and 14 minutes weekly (Lemmon, 2020). The authors argue that the findings may be a result of a number of factors, including the possibility that home support recipients without an unpaid carer to advocate for them may have insufficient home support to meet their needs.

There is evidence that demand for support also differs between men and women. Previous research from Ireland shows for home support, especially at older ages, demand is higher amongst women (McGarrigle and Kenny, 2020; Murphy et al., 2015; O'Halloran et al., 2020). This may be due to females living longer than men, implying a reduction in the likelihood of having a living spouse to provide care at older ages. The authors also show that non-married individuals, especially those who live alone, tend to have greater demand for home support. In general, this is thought to be due to non-married individuals having lower access to unpaid care on average, so that formal home support is more often required (McGarrigle and Kenny, 2020).

Previous research has shown that many unpaid carers themselves have high rates of need for healthcare and social care services (Coe and Van Houtven, 2009; Kamiya et al., 2012; Van Houtven et al., 2020). This in turn may lead to an increase in demand for home support (and other healthcare and social care services) for unpaid carers at some point in the future. In addition, the broader policy goal of providing care closer to home implies that additional care demands will be placed on unpaid carers, even in cases where professional home support is being provided. For example, having some support needs covered by an unpaid carer might fill in gaps in the available professional care, enabling the individual to remain at home. Therefore, ensuring that support is also provided to unpaid carers should be considered a complementary policy to moving provision of more types of care into a community or home setting. 
COVID-19 has likely increased unpaid care provision due to unemployment, furloughed workers, and more flexible working arrangements (e.g. working from home). However, some groups such as older people who live alone may see no increase in unpaid care from these changes. Changes in the age at which people normally retire or policies affecting the age at which pensions are received may also affect the supply of unpaid care. Previous research shows a positive association between retirement and provision of unpaid care (Fischer and Müller, 2020).

\section{Community care services}

In general, people in receipt of home support also have high need for, and use of, other healthcare and social care services, compared to those not in receipt of home support. If, for instance, there is insufficient access to respite care or occupational therapy, demand for home support may be reduced and individuals may be forced to access care in hospital or in residential care facilities. Constraints on access to other healthcare and social care services may also reduce the ability of unpaid carers to care for those with more complex needs, and thereby increase demand for professional home support.

Previous work by the ESRI has shown considerable geographical variation in the distribution of primary and community care services in Ireland (Smith et al., 2019). Other evidence has indicated that home support recipients and their carers can find it very difficult to find specialist services in their local areas (McDonald et al., 2019). In localities where demand for primary and community care is high but provision is not sufficient, home support use may be deterred in favour of residential care.

\subsubsection{Methods of financing}

The methods of providing and financing a home support scheme will also impact demand for the scheme. For example, whether or not co-payments will be part of the scheme, whether individuals will be facilitated to choose the service and provider, and the ease of accessing the scheme will all impact demand for home support. This will be explored in greater detail in subsequent research by the ESRI, but below we briefly discuss the two important areas that will also potentially impact demand for home support.

\section{Consumer directed home support}

Within the current public home support scheme in Ireland, decisions about who will provide home support are usually made by the body funding the provision of care. In contrast, in many countries, individuals have greater autonomy to choose the carers and services that best meet their needs. Recipients are assigned funding 
and permitted to direct the purchase of services themselves. Expansion of decision-making to a care recipient and their family may provide more independence and improve the match between services and needs. It might also encourage greater use of home support by some individuals. Recent research using discrete choice experiments finds that flexible service provision is highly valued by home support recipients in Ireland (Walsh et al., 2020c).

However, user-directed models can also involve increased administrative burdens for users (and their family or advocates) and providers of care, and these models may make accountability for outcomes more challenging to monitor and manage. For these reasons, jurisdictions that adopt user-directed models tend to incorporate assessments of suitability for users and often allow for the possibility that intermediaries could be engaged to help users manage their services (Mac Domhnaill et al., 2020).

Recently, Ireland's home support scheme introduced the option of consumer directed home support (CDHS) (Phelan et al., 2017; 2019)..$^{10}$ CDHS allows for home support recipients, or their carers or advocates, to request to deal directly with an approved provider. A pilot of the CDHS within the public home support scheme was undertaken to determine its effectiveness. The CDHS was found to be cost neutral. However, overall, the authors suggested that the CDHS was not a suitable model for the universal delivery of a statutory scheme (Phelan et al., 2019), although it was suggested that it may be an option for some people, especially those with lower dependency levels, and with greater capacity to make complex decisions. The authors pointed to challenges posed by the lack of choice available to recipients, especially in areas with a shortage of carers or scarcity of those with specific care training.

In the wider context of disability policy, a Task Force on Personalised Budgets considered possible models for personalised budgets to be used for personal social services (Department of Health, 2018b). The proposed model would offer those assessed as having appropriate care needs a choice between traditional managed services or use of a personalised budget. The budget could be managed by the user, co-managed with a service provider or managed by a broker. A demonstration project is currently underway within the HSE to refine and evaluate this approach. ${ }^{11}$ Analysis of this pilot of personalised budgets for people with disabilities may also provide useful lessons on how to incorporate CDHS into a statutory scheme. 


\section{Out of pocket payments}

Care provided as part of the current public home support scheme is provided free of charge to recipients. No out of pocket contribution is required. We understand that co-payments are being considered for possible use with the planned statutory home support scheme, as they are within the LTRC Fair Deal scheme. In the current model, limited provision of public home support indirectly results in some households making out of pocket payments for privately purchased care as they seek to supplement or substitute for public care. In this sense, the current model of service provision indirectly induces out of pocket payments for home support by some individuals.

Within the health economics and health service research literature, many studies have demonstrated that co-payments can deter take-up of health and social care. A series of papers by Nolan et al. in Ireland has found that gaining (losing) a Medical Card increases (decreases) GP visits (Ma and Nolan, 2016; Nolan, 2008; 2011; Nolan and Layte, 2017). Evidence from other countries has found corresponding relationships between co-payments and health care use (Nilsson and Paul, 2018; Olsen and Melberg, 2018). As far as we know, there has not been any study that explicitly examines home support co-payments and demand for home support.

It seems likely that introducing charges on recipients for part or all of the cost of support may reduce demand. While imposing co-payments, especially on those above a certain income level, may help meet the overall cost of the proposed statutory home support scheme, the potential effects on take-up of services should be taken into account. A follow up analysis by the Tax, Welfare and Pensions team at the ESRI will examine the implications of introducing co-payments and model scheme parameters such as the use of income thresholds.

\subsubsection{Changes to the model of care}

Changing the model of care to reduce the use of residential care facilities for older people and the population living with a disability will increase demand for home support. Clinical observers, gerontology communities and care advocates have emphasised the benefits of developing a model of care for older people that focuses on keeping people at home rather than in residential care. Keeping people in their homes should have benefits for patient health and wellbeing, and it may also serve to reduce the demand on LTRC and acute hospital facilities. Analysis from the ESRI shows that hospital inpatients from areas with higher relative home support supply per capita had a shorter length of stay in hospital (Walsh et al., 2020a). The shorter length of stay was most apparent for inpatients likely to be delayed transfers of care. However, the strength of substitution between LTRC and home support may not be as strong as some have hoped. A recent study in the Netherlands showed that substitution of LTRC by home support helped to reduce 
LTRC use (Bakx et al., 2020). However the authors found that this substitution did not reduce costs to the healthcare system. Nevertheless, there are still likely to be considerable welfare gains from this model of care change, as many people have a preference for being supported in their own homes (Costa-Font et al., 2009).

A study in Ireland of the HSE-Genio Dementia Intensive Home Care Programme concluded that some cost savings may be made from providing care through an iHCP as compared to LTRC (Carter et al., 2019). The authors estimated that the average weekly cost of an $\mathrm{iHCP}$ in addition to community care provision, medications and housing was $€ 1,127$, which was lower than the authors' estimate of an average weekly stay in public long-stay care facilities at $€ 1,526$ (Carter et al., 2019). This study also emphasised that extensive support was required to allow people with a high level of support needs to stay in their own home. The average number of public home support hours provided was 33-38 hours per week (dependent upon the sample included). The considerable range of services used by people with iHCPs in Ireland is illustrated in Table 3.1. Across the services examined, 61 per cent used a public health nurse, 21 per cent used an occupational therapist, (other therapy was also common), while 35 per cent reported supplementing public home support with private home care. Thus, even for some people receiving an $\mathrm{iHCP}$, the relatively high level of support provided was not sufficient to meet demand. 
TABLE 3.1 RESOURCE UTILISATION AND COSTS OF CARE AMONG PEOPLE WITH DEMENTIA (CARTER ET AL., 2019)

\begin{tabular}{|c|c|c|}
\hline Activity & $\begin{array}{l}\text { Resource utilization, } \\
\mathrm{n}(\%)\end{array}$ & $\begin{array}{l}\text { Average cost } \\
\text { per week }\end{array}$ \\
\hline Intensive home care package & $42(100)$ & $€ 774.18$ \\
\hline \multicolumn{3}{|l|}{ Primary and community care } \\
\hline GP & $20(5 \mathrm{I})$ & $€ 7.11$ \\
\hline \multicolumn{3}{|l|}{ Nursing } \\
\hline Public health nurse & $23(6 \mathrm{I})$ & $€ 7.66$ \\
\hline Community mental health nurse & $3(8)$ & $€ 0.63$ \\
\hline \multicolumn{3}{|l|}{ Allied health therapies } \\
\hline Physiotherapist & $4(10)$ & $€ 0.88$ \\
\hline Occupational therapy & $8(21)$ & $€ 1.26$ \\
\hline Speech and language therapy visit & $5(13)$ & $€ 0.63$ \\
\hline Chiropodist & $6(15)$ & $€ 0.75$ \\
\hline Social worker & $2(5)$ & $€ 0.38$ \\
\hline Other health professional & $8(21)$ & $€ 1.13$ \\
\hline \multicolumn{3}{|l|}{ Services } \\
\hline Day care & II (28) & $€ 75.05$ \\
\hline Meals on wheels & $2(5)$ & $€ 2.33$ \\
\hline \multicolumn{3}{|l|}{ Out-patient visits } \\
\hline $\begin{array}{l}\text { Geriatrician } \\
\text { Psychiatrist }\end{array}$ & $\begin{array}{l}4(10) \\
5(13)\end{array}$ & $\begin{array}{l}€ 3.54 \\
€ 4.43\end{array}$ \\
\hline Neurologist & $0(0)$ & $€ 0.00$ \\
\hline Psychologist & I (3) & $€ 0.37$ \\
\hline A\&E attendance & $2(5)$ & $€ 3.24$ \\
\hline \multicolumn{3}{|l|}{ In-patient visits } \\
\hline Acute hospital admission & $2(5)$ & $€ 220.63$ \\
\hline Emergency admission to acute hospital & I (3) & $€ 5.25$ \\
\hline Psychiatric hospital & $0(0)$ & $€ 0.00$ \\
\hline Day hospital & $2(5)$ & $€ \mathrm{€I.79}$ \\
\hline \multicolumn{3}{|l|}{ Prescribed medication } \\
\hline Anti-dementia medication & $22(56)$ & $€ 7.90$ \\
\hline Anti-psychotic medication & $10(27)$ & $€ 7.57$ \\
\hline Anti-depressant medication & $13(33)$ & $€ 2.33$ \\
\hline Private care & $14(35)$ & $€ 390.63$ \\
\hline Informal care & $38(100)$ & $€ 593.34$ \\
\hline
\end{tabular}

Note: Not everyone who received an intensive home care package responded to each subsequent resource use question. The percentage value reflects actual respondents for each item of resource use.

Carter, L., S. O'Neill, F. Keogh, M. Pierce and E. O'Shea (2019). 'Intensive home care supports, informal care and private provision for people with dementia in Ireland', Dementia (London): 1471301219863580.

Notes: $\quad$ IHCP support hours per week: median (interquartile range) - 33 (30-42) (in-depth sample) and 38 (29-48) (broad sample). Informal care costs were valued using an opportunity cost methodology.

Importantly, all iHCP recipients in the Carter et al. (2019) sample received unpaid care. Therefore, even with the extensive amount of healthcare and social care services provided, availability of unpaid care is a key factor to allow people with extensive care needs to be treated at home. This analysis highlighted that substituting home support for LTRC will not be straightforward and will require a 
substantial investment in home support and wider healthcare and social care supports in the community, as well as complementary support by unpaid carers.

\subsection{SUPPLY}

Up to this point we have focused on the factors affecting demand for care to provide context for the key objectives of this report, i.e. to examine the potential implications on demand for a statutory home support scheme. But variations in supply also have a significant effect on how much demand is met. Publicly funded systems of healthcare and social care often give rise to some level of rationing as supply is funded at levels that do not fully meet demand. This tends to result in waiting lists for care, with some individuals leaving or supplementing the public system and sourcing care directly from the private sector. This is epitomised by the long waiting times for outpatient and inpatient public hospital care in Ireland (Brick and Keegan, 2020). While the level of resources is the primary determinant of public home support services delivered in Ireland, two other specific characteristics of Ireland's approach to home support supply are also important to acknowledge: the method of resource allocation and the role of private provision of care.

\subsubsection{Resource allocation}

Even in the presence of constraints on funding, an effective resource allocation model can be used to efficiently and equitably allocate healthcare and social care services. However, Ireland does not have a resource allocation mechanism currently in place. This fact has been highlighted on numerous points previously (Brick et al., 2010; Smith et al., 2019). This makes it difficult to efficiently match supply and demand and to target those populations with the greatest need for care. In Ireland wide variations in home support supply have been identified across regions (Smith et al., 2019). More recently concerns around supply have been raised by a patient advocacy group (Care Alliance Ireland, 2018), employer organisations ( $\mathrm{HCCl}, 2019 \mathrm{a})$, and researchers in this area (Phelan et al., 2019). These concerns with supply could be better alleviated in the presence of a resource allocation model.

A key element of Sláintecare is the establishment of Regional Health Areas (RHAs). The Sláintecare report stated that these new RHAs were to be 'designed on the basis of optimum organisation and regional health resource allocation' (Houses of the Oireachtas Committee on the Future of Healthcare, 2017). However, the new structures may take a number of years to implement. In order to match local needs to care supply the following are required:

- improved data collection;

- an evidence-based approach to potential substitution between services and integration across services (e.g. hospital to community); 
- planning for the development and expansion of the healthcare workforce;

- regular updating of resource allocation in line with regional population projections.

To what extent the planned statutory home support scheme will be organised across RHAs is as yet unknown. Within the economics literature, many benefits of more devolved decision-making have been found (Saltman et al., 2007). Across the UK, the NHS already devolves coordination of care to constituent countries. In England, social care has been devolved to local authorities. Contrastingly, healthcare is organised nationally through NHS England, though recently some have argued that greater devolution of healthcare to the local level should occur (Walshe et al., 2018). There are suggestions that this dichotomy has impeded integration of care through the Better Care Fund. ${ }^{12}$ Evidence has found difficulties around agreeing and aligning spending programmes and resource allocation, as well as around managing shared budgets. This may have hindered efforts to integrate healthcare and social care in England (Harlock et al., 2020).

There are potential negative aspects of devolution of decision-making to regional authorities. Many of these negative aspects have been identified within the previous home support schemes. From the outset of the home help scheme, home support has been historically coordinated at the local level, with methods differing across localities. Across Ireland, the per capita supply of home support between the (relatively) best supplied and worst supplied LHOs differs by a factor of 2 (Walsh et al., 2019; 2020a). Similarly, as discussed in Chapter 3, there were large differences across LHOs in terms of how they coordinated the home help and the HCP schemes. Inequities in home support supply and other primary and community care supply across regions make the efficient allocation of home support supply difficult. Without appropriate measures, such inequities could be replicated in a new statutory scheme and continue the current 'postcode lottery'. The use of the InterRAI SAT will be an important tool to help understand how demand and care needs differ, not just across individuals but regions, and to distribute supply in an efficient manner.

\subsubsection{Single assessment tool}

The InterRAI Single Assessment Tool (SAT) has recently been introduced in Ireland to support allocation and planning of services, and we understand that this will be used to support care allocation under the planned statutory scheme. The SAT is a standardised tool designed to comprehensively assess individuals requiring home support or residential care in Ireland. It takes into account a broad range of health, 
wellbeing, and social support information on the person being assessed. Based upon this information, it provides an assessment of the types and levels of care and support required. The assessment can therefore not only help tailor services to the specific care needs of the individual but can also indicate the level of care that is required. More information is provided in Box 3.1. We understand that a system of care bands will be developed relating to SAT results and each individual will be placed in a care band that indicates a level and type of support commensurate with their assessed need.

\section{BOX 3.1 FEATURES OF INTERRAI SINGLE ASSESSMENT TOOL}

- $\quad$ The Single Assessment Tool (SAT) is an IT-enabled healthcare and social care needs assessment (InterRAl System (C) used to assess the healthcare and social care needs of people who may be looking for support through the current public home support scheme, the future statutory scheme and the Nursing Homes Support Scheme (NHSS).

- $\quad$ The InterRAI SAT replaces the previously used paper-based Common Summary Assessment Report (CSAR). The InterRAI SAT Assessment System has been designed to be a user-friendly, reliable, person-centred assessment system that informs and guides comprehensive care and service planning.

- We understand that it is intended a method of assigning priority levels (MAPLe) will be used to develop a system of care bands, informed by the SAT, and this system will help place an individual in a care band commensurate with their assessed need.

- $\quad$ The SAT provides a comprehensive assessment of needs across a number of domains that assess functional performance, cognition/mental health, social life, and clinical needs.

Sources: $\quad$ https://www.hse.ie/eng/services/list/4/olderpeople/sat/;

https://www.ehealthireland.ie/Stakeholder-Engagement/eHealth\%2Olreland\%20EcoSystem/eHealth-Innovations-for-Homeand-Community-Care/Dr-Natalie-Verker.pdf.

The benefit of this tool to the efficient allocation of home support resources within a statutory scheme should be significant. The SAT can help to harmonise the allocation of services provided across ages and regions and to tailor services to individuals' particular needs. Furthermore, the SAT may also contribute to greater integration between the home support scheme and the NHSS and allow for better coordination across services with a view to providing person-centred care.

The SAT is currently being rolled out on a phased basis. Data from early pilot studies using the InterRAI SAT have been collected. These data will be invaluable to understand some of the limitations of the present system that can then be used to inform the design of the planned statutory scheme. 


\subsubsection{Private provision}

Public home support in Ireland relies significantly on private providers (Mercille and O'Neill, 2020; Mulkeen, 2016). This is not solely an Irish phenomenon (Kiersey and Coleman, 2017), and not unique to the home support sector (for example a majority of NHSS residents live in private nursing homes (Collins, 2019)). Private provision of home support or social care is common in Scandinavia (Szebehely and Meagher, 2017), the UK (Watt et al., 2018), and other European countries (Kiersey and Coleman, 2017). While in these countries the state remains the chief funder of home support, public health authorities fund voluntary or for-profit organisations to deliver care.

There are a number of potential reasons for this approach, but one factor that might encourage outsourcing home support to voluntary or for-profit organisations is to lower costs. The cost of providing a home support hour through HSE staff is not simply the cost of the carer's pay for that hour. Other, not insignificant, costs including costs related to recruitment, travel, sick leave, superannuation and other overhead costs are also borne by the HSE. The HSE also bears the cost of managing external provision including operating tender processes in the public home support scheme. However, outsourcing care places the onus upon voluntary or for-profit organisations to manage these costs. Private organisations may also have more flexibility in terms of recruiting and removing staff to meet changes in demand. 


\section{CHAPTER 4}

\section{Data and methods}

The following Chapter outlines the data sources and methods used to generate demand projections within the report. The first step is to estimate the realised demand for home support in a base year, 2019. We then simulate service demand arising under three scenarios chosen to illustrate possible sources of variation in demand. Each scenario builds upon the preceding scenarios in an additive manner. The four scenarios examined in this report are:

1. Scenario 1 - Baseline

2. Scenario 2 - Increased Hours for Recipients

3. Scenario 3 - Substitution for Long-Term Residential Care

4. Scenario 4 - Expansion of Demand in Community.

In estimating increased demand in Scenarios 2-4, we take into account a range of factors that might affect the numbers of persons requiring care and the number of hours they might be allocated. We do not make any adjustment for possible constraints associated with funding the activity or on the availability of care staff to supply it. As noted earlier, planned future research by colleagues at the ESRI will address possible funding models for the statutory scheme. Chapter 5 makes some observations on home support supply in Ireland.

The report uses both administrative and survey-based data. In some cases, multiple data sources are used. When assembling the baseline, 2019 data are used where available, and otherwise the most up-to-date available data are employed.

\subsection{HOME SUPPORT}

\subsubsection{Recipients}

Both administrative HSE data and survey data from The Irish Longitudinal Study on Ageing (TILDA) dataset are used to estimate the shares of recipients of home support in Ireland with different groupings of characteristics relevant to our analysis.

HSE administrative data provide the number of home support recipients and home support hours provided in 2019. These data are grouped by $\mathrm{LHO}$ and $\mathrm{CHO}$, and by whether the home support hours were provided by HSE staff or voluntary/ 
for-profit organisations. However, no age or sex breakdown is available from these data.

TILDA data from Waves 2-4 (collected in 2012-2016) are used to examine publicly funded ('public home support') and privately purchased home support ('private home support'). TILDA was designed to be nationally representative, but we apply survey weights across all of the analyses in an effort to reflect the national population as accurately as possible. To align this analysis with the HSE data, we restrict the sample to study participants aged 65 years and older at the time of the survey. To provide a better picture of overall home support use, within the analyses, we combine both public and private home support use when examining the characteristics of home support users. Where applicable, we compare public and private home support rates of use and characteristics of recipients.

Within TILDA, the following questions are used to create an indicator variable denoting receipt of home support. For public home support, respondents were asked:

'In the last 12 months, did [you/Rname] receive any of the following State services?'

- Home help (a person employed by State to help [you/Rname] with household chores such as cleaning and cooking)

- Personal care attendant (a person employed by the State to assist [you/him/her] with bathing, showering, bodily care etc.)

- Home Care Package.

As the current home support scheme originated in 2018 after the TILDA surveys were undertaken, we combined responses to these three questions to estimate whether or not the person was a recipient of some form of public home support.

For private home support, respondents were asked:

'In the last 12 months, did [you/Rname] pay any individual or private company to provide home help or personal care?'

A positive response to this question was used as an indicator of use of private home support. As many in receipt of private home support were also in receipt of public home support, and as we wish to simulate potential demand for a statutory scheme, we created an indicator variable for receipt of home support that combined public and private services. This is in line with previous work (Wren et al., 2017). 


\subsubsection{Waiting lists}

Data on total numbers awaiting public home support were provided by the Department of Health. These data equate to those collected by the Social Care Division of the HSE. Within the analysis, we include the total numbers awaiting home support in December 2019. No age or sex breakdown of these data is available.

\subsubsection{Public hospital delayed transfers of care}

Information on delayed transfers of care awaiting home support was taken from an independent review commissioned by the Department of Health on delayed transfers of care (delayed discharges) (Department of Health, 2018a). The report collected information on delayed transfers of care across public hospitals in Ireland between 2016 and 2018. Information collected included numbers waiting for discharge, the reasons they were waiting (service required), and length of time waiting. Figure A.1 and Figure A.2 in the Appendix illustrate this information. We estimated the overall mean number of bed days used by delayed transfers of care awaiting home support using this information.

Second, in order to apportion home support hours to delayed transfers of care days, we use information provided by the HSE on the 2019 'egress' scheme. This scheme was designed to allow people to leave hospital at an earlier stage and return home. The HSE provided information on the average daily hours of home support provided to delayed transfers of care within this scheme. We assigned the average hours provided as part of this scheme to all delayed transfers of care.

Table A. 3 in the Appendix provides more information on delayed transfers of care, mean length of delayed stays, and assignment of egress home support hours.

\subsection{HEALTHCARE AND SOCIAL CARE SUPPORTS}

Because implementing home support on a statutory basis will have implications for wider elements of the health and social support system, we sought data on a range of primary and community care services that also help to support care for older people at home. In this analysis, we use information from TILDA Waves 2-4.

Within TILDA, the following questions are used to create a home support recipient variable. For public home support, respondents were asked:

'In the last 12 months, did [you/Rname] receive any of the following State services?'

- $\quad$ Public Health or Community Nurse

- Occupational therapy 
- Physiotherapy services

- $\quad$ Respite services

- $\quad$ Day centre services.

A binary variable was created to indicate receipt of each service.

We also examine the relationship between home support demand and GP use. Within TILDA, the following question is used to create a GP use variable:

'In the last 12 months, about how often did [you/he/she] visit [your/his/her] GP?'

From this response, we created a binary variable to indicate 0-4 visits (low usage), and $5+$ visits (high usage). Using a binary variable to reflect broad levels of usage, as opposed to employing the precise number of visits reported by each subject, may be more appropriate given that some subjects could have had difficulty remembering the exact number of visits over a 12-month period.

Finally, we estimated use of acute inpatient hospital care services. TILDA respondents were asked:

'In total, about how many nights did [you/he/she] spend in hospital in the last 12 months?'

From this we created a variable to capture how many nights, if any, were spent in hospital. Similar to the construction of the variable for GP visits, we coded the variable to distinguish between no usage ( 0 nights) and any usage.

\subsection{CARERS}

There is no centralised source of data on home support professionals in Ireland. We use information from the Health Service Personnel Census (HSPC) on home carers (or personal care assistants) who work for the HSE, and the Healthy Ireland Survey (HIS) to examine the profile of carers in Ireland more generally. The HSPC captures the number and average whole time equivalent (WTE) carers across HSE divisions, LHOs and over time. No information is available on the demographics of HSE-employed home carers, such as age or gender. The Personnel Census also does not capture information about carers for voluntary or for-profit companies in Ireland.

We use information from the HIS to examine the socio-demographic characteristics of carers. The HIS is a cross-sectional survey collected by the Department of Health and IPSOS MBRI annually since 2015. The survey is 
administered to respondents on a face-to-face basis and collects information on a representative sample of individuals aged 15 years and older. The HIS includes information on a range of health-related and demographic information, including the employment status and the occupation of workers using the Standard Occupational Classification (SOC) 2010. This is a standardised measure of occupation and it allows us to identify respondents aged 15-70 who worked as carers in Ireland. Pooling HIS Waves 1-4, we captured information on 513 carers (SOC10 4-digit: 6145). ${ }^{13}$ Unfortunately, the HIS does not capture the specific sector that carers work in. Therefore, the source includes both LTRC workers and home care workers.

Using HIS we examine the demographic characteristics of carers including age, sex, underlying health conditions, and nationality (Irish-born or not). To our knowledge, this is the first time the characteristics of care staff in Ireland have been examined and the results may provide useful information for care workforce planning as a new statutory scheme is developed. We use survey sampling weights to help ensure the results are nationally representative.

\subsection{POPULATION}

Population estimates at the national and regional level used in preparing this report were provided by Adele Bergin at the ESRI. These estimates have been used previously in the second Hippocrates report on the demand and projected demand for healthcare and social care (Keegan et al., 2020).

\subsection{DEMAND SCENARIOS}

In this section we provide details of the four scenarios examined in the report.

\subsubsection{Scenario 1 - Baseline estimation}

In order to simulate the likely impact of expanding home support in Ireland, it is first important to characterise the current level of home support use. To this end, we estimate baseline levels of home support receipt and unmet demand in 2019. This baseline scenario does not encompass all home support need, in terms of numbers in receipt or hours demanded. But this scenario does reflect those who were in receipt of public home support, purchased private home support, or whose demand for support resulted in them being added to a waiting list. This is a key scenario as the three subsequent demand scenarios are variations of it. Results

13 SOC2010 methodology state that code 6145 relates to: 'Care workers and home carers attend to the personal needs and comforts of the elderly and the infirm with care and support needs (service users) within residential care establishments, day care establishments or in their own homes.' https://onsdigital.github.io/dp-classificationtools/standard-occupational-classification/data/SingleClass.html?soc=6145. 
from Scenario 1 are also used to provide a profile of professional home support in Ireland in 2019.

A baseline demand/receipt scenario is also important as it reflects the funding environment for home support before a statutory scheme has been introduced and the supply of home support across public, voluntary, and for-profit carers. It is therefore useful as a baseline for comparison with scenarios involving future changes to policy.

The year 2019 was chosen for the demand scenarios for a number of reasons. First, HSE data - a key data resource - and population data were available for the year 2019. Second, 2019 reflects home support arrangements before the widespread disruption brought about by the COVID-19 pandemic.

The assumptions underpinning Scenario 1 are summarised in Table 4.1. To build up a picture of baseline demand, we estimate actual receipt of home support in 2019 by combining data on receipt of public home support in 2019, private home support from TILDA Waves 2-4 (receipt rates are applied to 2019 population), and intensive Home Care Packages. In addition, we incorporate waiting numbers for public home support in December 2019 and delayed transfers of care from public hospital awaiting home support. In December 2019, there were 5,436 people waiting for any public home support service. A further 2,473 current recipients were waiting for additional support. In Scenario 1, we only include those awaiting any home support (Scenario 2 discusses increases in support to current recipients).

\section{TABLE 4.1 BASELINE ESTIMATION (SCENARIO 1): DATA AND METHODS}

\begin{tabular}{|c|c|}
\hline Name & Data \\
\hline $\begin{array}{l}\text { HSE Social Care } \\
\text { Division } \\
\text { Administrative Data }\end{array}$ & $\begin{array}{l}\text { - Total number of public home support recipients in } 2019 . \\
\text { No disaggregation by age or gender. } \\
\text { - Total number waiting for any public home support end- } \\
\text { December 2019. No disaggregation by age or gender. } \\
\text { Total number of intensive Home Care Packages in } 2019 . \\
\text { No disaggregation by age or gender. }\end{array}$ \\
\hline $\begin{array}{l}\text { TILDA Waves } 2-4 \\
\text { Research Microdata } \\
\text { File Data }\end{array}$ & $\begin{array}{l}\text { - Recipient rate of public home support and private home } \\
\text { support. Disaggregation by Single Year of Age (SYOA) and } \\
\text { gender. }\end{array}$ \\
\hline $\begin{array}{l}\text { Independent Review } \\
\text { on Delayed Transfers } \\
\text { of Care }\end{array}$ & $\begin{array}{l}\text { - Number of delayed transfers of care awaiting home support by } \\
\text { length of stay. No disaggregation by age or gender. }\end{array}$ \\
\hline
\end{tabular}


Recipients

- To estimate the recipient rates across age groups for public home support, the distribution of recipient rates from TILDA Waves 2-4 data is apportioned to the HSE administrative data using the following steps. First, rates of public home support receipt across age and gender are estimated using TILDA data. Second, these rates are multiplied by the number of people at each age, and by gender, using 2019 population estimates. Third, the numbers of recipients in each age and sex cell are grossed-up to the overall number of public home support recipients recorded by the HSE administrative data.

- Due to the small numbers with intensive Home Care Packages, no age or gender breakdown is estimated.

- Public Home Support Waiting List: To estimate the rate of waiting for home support across age groups for public home support, we apply the age-gender distributions of public home support recipients as described above to the HSE administrative data.

- The rates of private home support receipt by age and gender are estimated using TILDA Wave 2-4 data.

- Rates of 'private-only' and 'public and private' receipt by age and gender are estimated using TILDA Wave 2-4 data. 'Public and private' recipient rates are grossed up in line with the steps used to estimate the age and gender distribution for public home support as described above.

- Delayed transfers of care are assumed to already be captured within the set of home support recipients discussed above.

Hours

- To estimate the rates of public home support hours across age and gender, the distribution of rates from TILDA Waves 2-4 Research Microdata File data is apportioned to the HSE administrative data using the following steps. First, public home support hours across age and gender are estimated using TILDA data by multiplying the average number of days respondents received home support (home help or Home Care Packages) in the previous month by 12 , and multiplying this by the average number of hours they received on a given day. Second, we need to adjust for the fact that not all individuals in receipt of home support will be in receipt for a 12-month period. Some may take up home support in later months, while a recent study found approximately 19 per cent of recipients had their home support discontinued with admission to LTRC (8 per cent) and death (9 per cent), the most common reasons (Aspell et al., 2019). To account for this, we scale down the average hours estimated in TILDA to the average hours provided through the home support scheme in 2019. Third, these rates are multiplied by the number of people at each age, and gender, using 2019 population estimates. Finally, the numbers of recipients in each age and sex cell are grossed-up so the totals match the overall number of public home support hours recorded by the HSE administrative data in 2019.

- Due to the small numbers with intensive Home Care Packages, no age or gender breakdown is estimated. 
- To estimate the hours likely to be provided to those on the waiting lists, we assume they receive the same number of hours as those in receipt of home support based on their age and gender.

- No data were available for private home support hours in TILDA. However, the $\mathrm{HCCl}$ estimates that the agencies it represents provide 2.3 million home support hours to their 8,000 private home support clients in 2018 . This equates to 287.5 hours per annum to each client. We assume all private home support recipients receive this average number of hours annually.

- The total number of days that delayed transfers of care are waiting for home support are estimated from a Department of Health commissioned 'Delayed Discharges' report (Department of Health, 2018b). This report estimates the number of delayed transfers of care awaiting home support, and the number of days they are waiting. Using data from the most recent egress scheme, we assign the average hours provided as part of this scheme to all delayed transfers of care. Information of how the delayed transfers of care hours were estimated are provided in the Appendix - See Figure A.1, Table A.3 and Table A.4.

\subsubsection{Scenario 2 - Increased hours for recipients}

Demand Scenario 2 is based upon the assumption that additional hours might be provided to those who are currently in receipt of home support. This scenario builds upon the Winter Plan 2020/21 which sets out to increase hours to current recipients. ${ }^{14}$ In addition, in December 2019, there were 2,473 public home support recipients awaiting additional support. While previous analysis of home support recipients found an average of a 15 per cent gap between assessed home support need and actual home support provision (Care Alliance Ireland, 2018), it is difficult to assess how many additional hours are required by those who already use the scheme. Therefore, we make stylised assumptions within this scenario, loosely based upon the Winter Plan 2020/21 (HSE, 2020) and estimates of home support gaps identified by Care Alliance Ireland. We assume a 10 per cent increase in hours for those without a d-ADL and a 20 per cent increase for those with any d-ADL. ${ }^{15}$ Details of the assumptions are given in Table 4.2.

Within this scenario we assume that those purchasing home support privately will now receive their home support through the proposed statutory home support scheme. This assumption is in part based around LTRC, where vast majority of residents are funded through the NHSS (Wren et al., 2017). However the authors of this report do note that 9 per cent of LTRC residents in 2015 privately purchased

14 The 2021 HSE National Service Plan expects 24 million home support hours to be provided in 2021 to 55,910 recipients aged 65 years and older. https://www.hse.ie/eng/services/publications/serviceplans/national-service-plan-2021.pdf.

15 The 2021 HSE National Service Plan expects a 21 per cent increase in home support hours provided to recipients https://www.hse.ie/eng/services/publications/serviceplans/national-service-plan-2021.pdf. 
their care (Wren et al., 2017). A similar small minority of home support recipients may purchase care privately, even after the introduction of a statutory home support scheme.

\section{TABLE 4.2 SCENARIO 2 (INCREASED HOURS FOR RECIPIENTS): DATA AND METHODS}

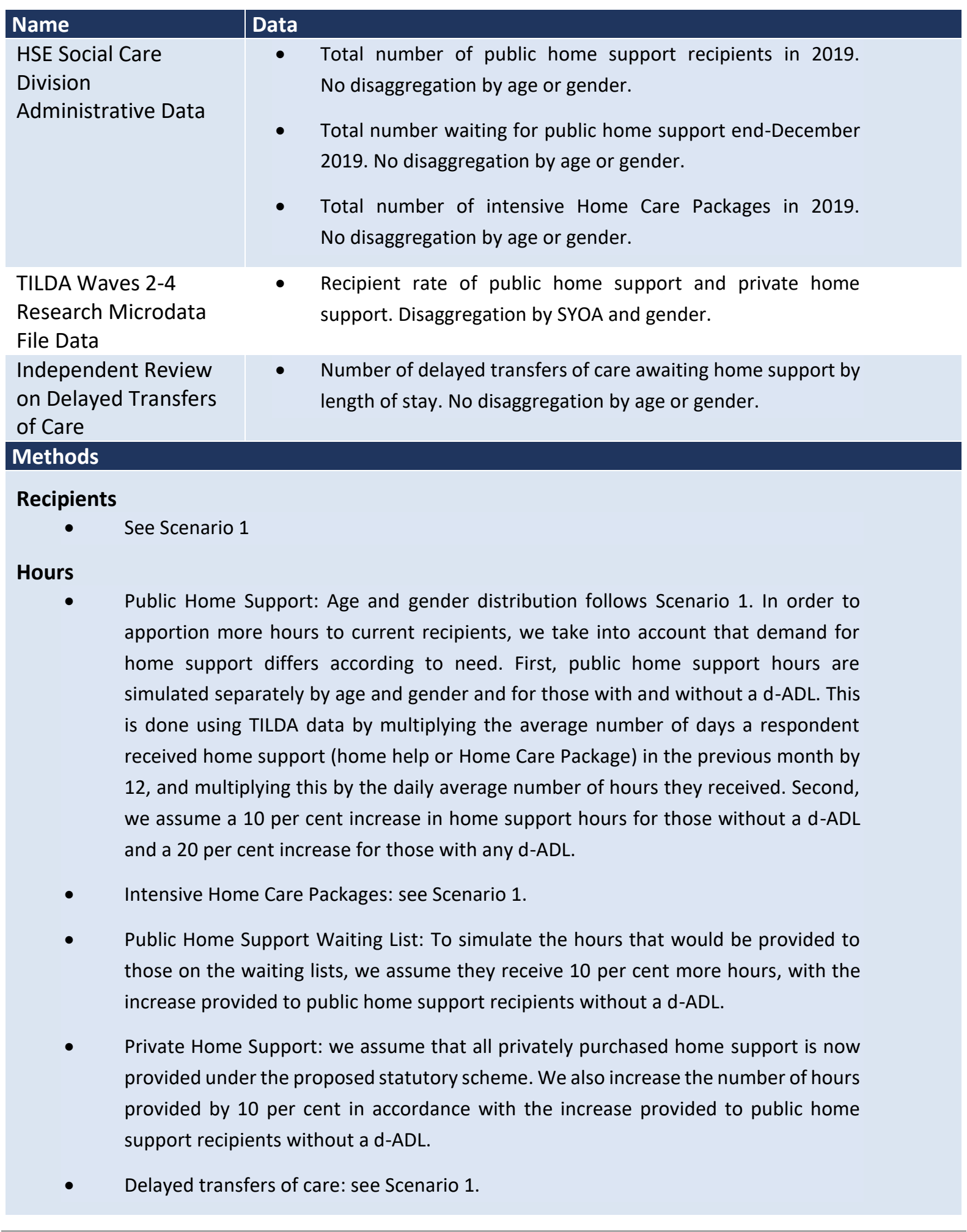




\subsubsection{Scenario 3 - Substitution for long-term residential care}

Demand Scenario 3 is based upon the assumption of model of care changes, with increased demand for home support resulting from reduced admission to LTRC. The assumptions build upon the increases in demand assumed in Demand Scenario 2.

Within this scenario, we do not assume that those within LTRC already will leave nursing homes and be cared for at home. Rather, our substitution assumptions are based on reducing the probability that those in receipt of home support will move to LTRC. This scenario is informed by the Winter Plan 2020/21 (HSE, 2020) which discusses increasing home support through increased community supports and reablement. In addition, the analysis builds upon recent evidence from Dublin North that examines the transition from home support into LTRC (Aspell et al., 2019). In their study, Aspell et al. (2019) find 8 per cent of all home support recipients followed in a 12-month period transitioned to LTRC. The key assumption in this scenario is that the rate of transition from home support to LTRC halves, from 8 per cent to 4 per cent. In order to meet the needs of these individuals, who would otherwise be admitted to LTRC, we assign the average number of home support hours of iHCP recipients based upon findings from Carter et al. (2019). Details of the assumptions are given in Table 4.3. 
TABLE 4.3 SCENARIO 3 (SUBSTITUTION FOR LONG-TERM RESIDENTIAL CARE): DATA AND METHODS

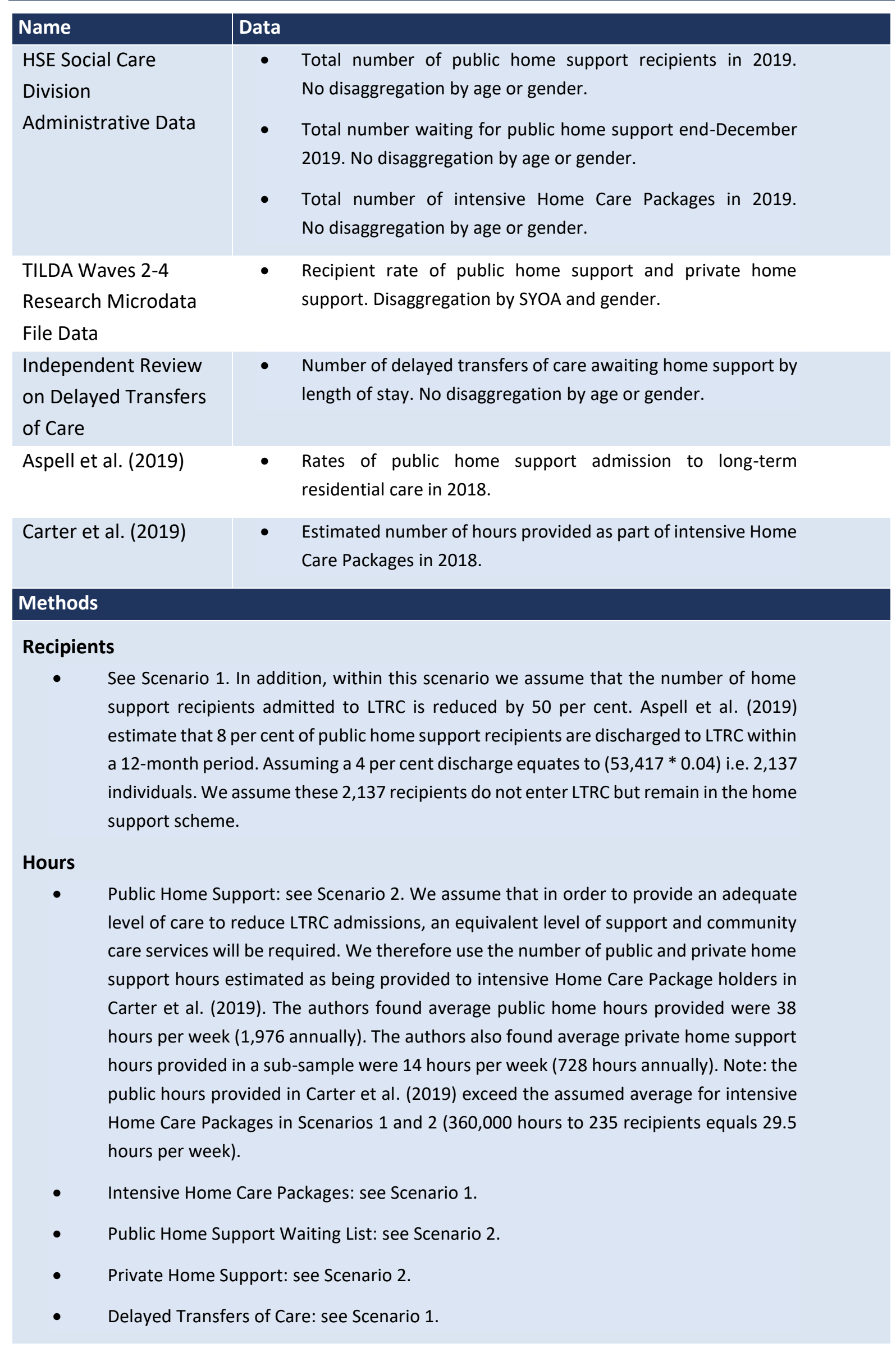




\subsubsection{Scenario 4 - Expansion of demand in community}

Demand Scenario 4 is based upon the assumption that the introduction of a statutory home support scheme will increase demand for home support for those who may have a need for home support, but who are currently not in receipt. The assumptions build upon the increases in demand assumed in Demand Scenario 3. The key assumption in this scenario is that establishment of a statutory home support scheme will increase demand from individuals who may previously have not expressed demand for home support services (public or private). For example, many individuals who currently receive unpaid care may seek formal support from a statutory scheme. We assume that increases in demand arise from the part of the population likely to have higher demand for support: those with a d-ADL. The scenario models the demand implications of a 50 per cent increase in demand from the population with a d-ADL across all age groups aged 65 years and older.

While a 50 per cent increase in demand amongst those with a d-ADL increases demand for home support significantly, it may also underestimate the demand that could emerge once a statutory scheme is established. Further study of the true demand that emerges following the introduction of the scheme will be required.

TABLE 4.4 SCENARIO 4 (EXPANSION OF DEMAND IN COMMUNITY): DATA AND METHODS

\begin{tabular}{|c|c|}
\hline Name & Data \\
\hline $\begin{array}{l}\text { HSE Social Care } \\
\text { Division } \\
\text { Administrative Data }\end{array}$ & $\begin{array}{l}\text { - Total number of public home support recipients in } 2019 . \\
\text { No disaggregation by age or gender. } \\
\text { - Total number waiting for public home support end-December } 2019 \text {. } \\
\text { - Total number of intensive Home Care Packages in } 2019 \text {. } \\
\text { No disaggregation by age or gender. }\end{array}$ \\
\hline $\begin{array}{l}\text { TILDA Waves 2-4 } \\
\text { Research Microdata } \\
\text { File Data }\end{array}$ & $\begin{array}{l}\text { - Recipient rate of public home support and private home support. } \\
\text { Disaggregation by SYOA and gender. }\end{array}$ \\
\hline $\begin{array}{l}\text { Independent Review } \\
\text { on Delayed Transfers } \\
\text { of Care }\end{array}$ & $\begin{array}{l}\text { - Number of delayed transfers of care awaiting home support by length } \\
\text { of stay. No disaggregation by age or gender. }\end{array}$ \\
\hline Aspell et al. (2019) & $\begin{array}{l}\text { - Rates of public home support admission to long-term residential care } \\
\text { in } 2018 .\end{array}$ \\
\hline Carter et al. (2019) & $\begin{array}{l}\text { - Estimated number of hours provided as part of intensive Home Care } \\
\text { Packages in } 2018 .\end{array}$ \\
\hline
\end{tabular}


Methods

\section{Recipients}

- See Scenario 3. In addition, we assume that the probability of home support being provided to those with a d-ADL increases by 50 per cent. This is to represent the potential increase in demand for those who do not receive public home support but who may demand support when a statutory scheme is established. This may represent an underestimate of actual demand as it does not take into account potential increases in demand from those with no d-ADL.

A 4 per cent admission to long-term residential care is assumed once more.

\section{Hours}

- Public Home Support: see Scenario 3. The additional recipients with a d-ADL that demand support are assumed to receive the same hours provided to those in their age and gender group with a d-ADL in Scenario 3.

- Intensive Home Care Packages: see Scenario 1.

- Public Waiting Lists: see Scenario 2.

- Private Home Support: see Scenario 2.

- Delayed transfers of care: see Scenario 1. 



\section{CHAPTER 5}

\section{Home support demand projections under statutory scheme}

This chapter provides simulations of the potential demand amongst the older population in Ireland under a statutory scheme. The demand simulations reflect the four scenarios outlined in the previous chapter, with discussion of results for each scenario presented separately. The final section in this chapter compares potential recipient numbers and home support hours across the scenarios.

\subsection{SUMMARY OF ASSUMPTIONS IN DEMAND SCENARIOS}

In this sub-section we outline the main assumptions behind each of the four demand scenarios used in the report, for convenience of reference when interpreting the results that follow.

- Scenario 1 - Baseline Estimation

This represents an estimate of the actual levels of professional home support utilisation and unmet demand in 2019.

- Scenario 2 - Increased Hours for Recipients

Starting with the position in Scenario 1, this scenario assumes that all home support hours are provided through a new statutory scheme. Private recipients of care are assumed to move into the public scheme. The scenario assumes an increase in home support for baseline recipients loosely based upon provisions of the Winter Plan 2020/21 and previous evidence from Care Alliance Ireland (2018). Increases of between 10 per cent and 20 per cent are apportioned to recipients, depending upon d-ADL status.

- Scenario 3 -Substitution for Long-Term Residential Care

In addition to the assumptions in Scenario 2, this scenario assumes there is a 50 per cent reduction in the number of people exiting public home support and entering LTRC (from 8 per cent to 4 per cent) using evidence from Aspell et al. (2019). The increased hours for those substituting from LTRC involves provision of an iHCP. Each of these individuals receives the equivalent of 52 home support hours per week based upon evidence from Carter et al. (2019).

- Scenario 4 - Expansion of Demand in Community

Building on the position in Scenario 3, this scenario further assumes that demand for home support amongst those with a d-ADL increases by 50 per cent following the introduction of a new statutory scheme. 


\subsection{SCENARIO 1 - BASELINE ESTIMATION}

Table 5.1 presents estimated home support demand in terms of numbers of recipients and home support hours in Ireland in 2019. These results reflect the number of people who received some form of home support in 2019 or who explicitly demanded home support but were placed on a waiting list.

We estimate that there were 65,246 people aged $65+$ in receipt of home support in 2019. This equates to 9.7 per cent of the population age 65 years and older living at home receiving home support in 2019. Public home support receipt was the largest component, with 53,417 people in receipt, and 235 in receipt of an iHCP. We estimate that there were 11,594 'private-only' recipients of care. In addition, there were 14,230 people who purchased private home support but who were also in receipt of public home support (public and private). These individuals are counted only within numbers of the public home support recipients, to avoid double counting. A further 5,436 were on the waiting list to receive public home support in December 2019. This results in an expressed demand for home support from 70,682 recipients (Scenario 1 total).

We also included home support hours for delayed transfers of care (delayed discharges) awaiting home support using information from an analysis of delayed transfers of care in public hospitals in 2017 and 2018 (Department of Health, 2018a). Assuming delayed transfers of care eventually became recipients (and thereby are not counted as additional recipients), in order to leave hospital earlier just over 39,000 home support hours would be required.

We estimate that in 2019 there were $\mathbf{2 4 . 7}$ million home support hours received across public and private home support. Most hours were provided through the public home support (18.2 million hours) or iHCP (0.36 million hours) schemes. We estimate that 6.1 million hours, which constitutes 24.9 per cent of home support supplied, were privately purchased. We estimate a further 1.5 million hours would have been provided if hours were provided to those on a waiting list, or to reduce delayed transfers of care for people awaiting home support. This results in an expressed demand for over 26.2 million home support hours in 2019 (Scenario 1 total). 
TABLE 5.1 BASELINE ESTIMATION (SCENARIO 1): RECIPIENTS AND HOME SUPPORT HOURS: AGES 65+

\begin{tabular}{|c|c|c|}
\hline & Recipients & Hours \\
\hline Public home support scheme & 53,417 & $18,200,000$ \\
\hline Public Intensive Home Care Packages & 235 & 360,000 \\
\hline Public Home Support total & 53,652 & $\underline{18,560,000}$ \\
\hline Private Home Support ${ }^{\mathrm{a}}$ & 11,594 & $6,147,389$ \\
\hline Total home support delivered in Ireland in 2019 & $\underline{65,246}$ & $\underline{24,707,389}$ \\
\hline Public Home Support Waiting List & 5,436 & $1,512,855$ \\
\hline Delayed Transfers of Care (public hospitals) ${ }^{b}$ & & 39,273 \\
\hline Scenario 1 Total Demand & $\underline{70,682}$ & $\underline{26,259,517}$ \\
\hline
\end{tabular}

Source: $\quad$ Authors' analysis of HSE data and TILDA Waves 2-4 Research Microdata File.

Notes: $\quad$ a Recipients includes 'private-only'. Hours includes privately purchased hours for private-only and public \& private recipients. b The number of recipients affected by delayed transfers of care (from public hospitals) is already counted in the public home support scheme.

Examining the baseline estimation in more detail, we provide an age and sex breakdown for home support use in 2019. The age and sex breakdown examined those who received public home support and private home support in Table 5.1. It was not possible to examine iHCP recipients due to a lack of information.

While the HSE collects data on overall number of recipients and hours of care received at national and LHO level each year, little information is available on the socioeconomic characteristics of home support recipients. However, the HSE collects information from six $\mathrm{LHOs}^{16}$ on the age of recipients. Figure 5.1 presents the percentage of home support recipients by age group and compares it to HSE data on six LHOs as well as North Dublin (CHO 9) estimates from Aspell et al. (2019).

Overall, the age distribution from TILDA estimates is very similar in these two sources. At older ages, the TILDA and HSE results are virtually identical; both data sources show 39 per cent of all home support recipients are aged 85 years and older. Aspell et al. (2019) report higher home support at the oldest ages (48 per cent). Some differences are seen at younger ages. This is due to approximately 10 per cent of home support hours for Older Persons actually being provided to those aged less than 65 years in these six LHOs. It is not known how representative these six LHOs are of national patterns, especially in terms of providing home support through the Older Persons' scheme to younger adults. ${ }^{17}$ Therefore, in this report we assume a cut-off of 65 years.

16 The six LHOs are: Kerry, North Cork, North Lee (Cork), South Lee (Cork), West Cork, Sligo/Leitrim.

17 There is evidence that intensive Home Care Packages (iHCPs) targeted at older people with dementia include some recipients under the age of 65. Keogh et al. (2018b) from Dublin North Central find that of those receiving a public HCP, 7 per cent had a cognitive impairment (O'Brien et al., 2019). 
FIGURE 5.1 PERCENTAGE OF HOME SUPPORT RECIPIENTS BY AGE GROUP: AGES 65+

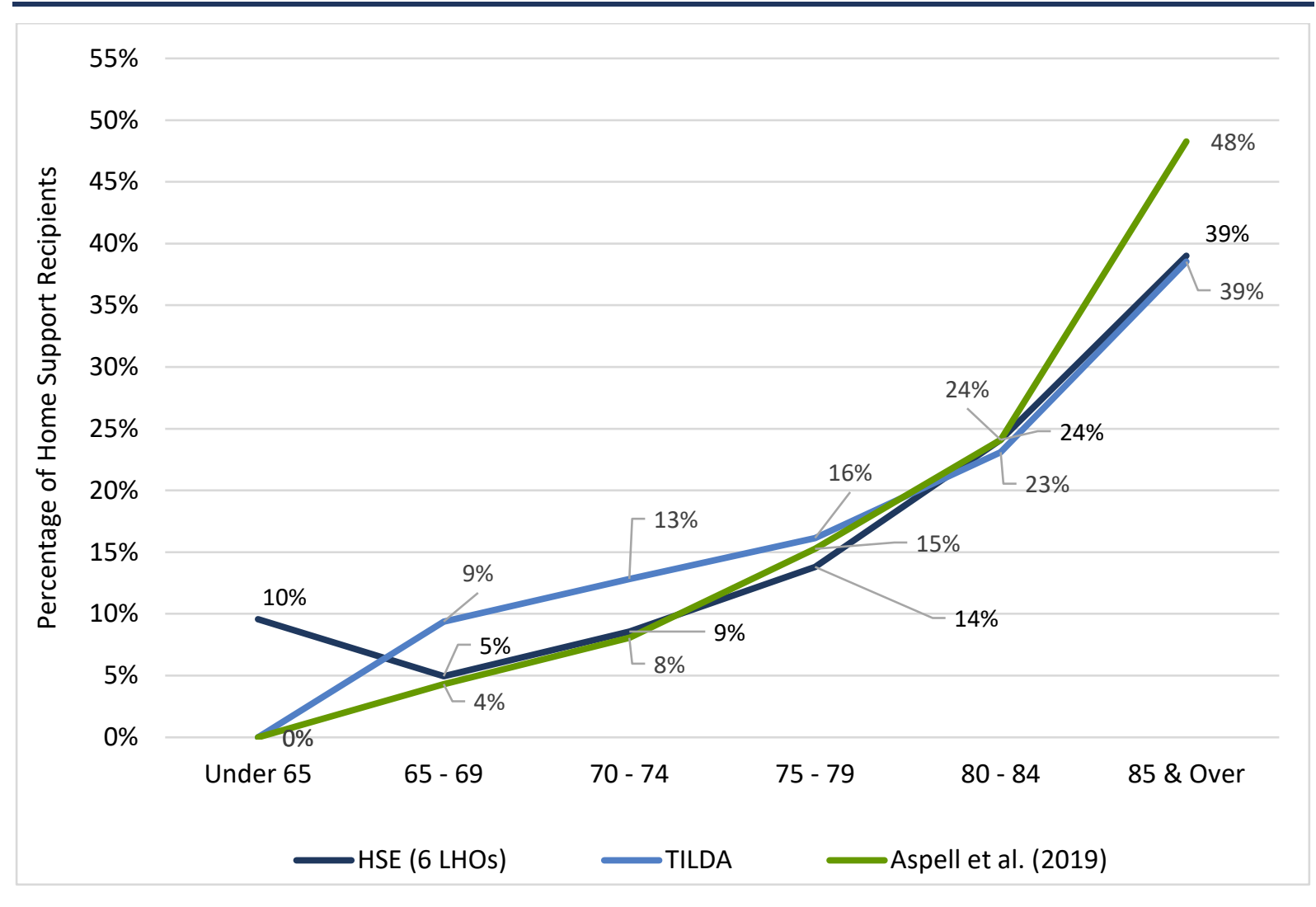

Source: $\quad$ Analysis of TILDA Waves 2-4 Research Microdata File; HSE Social Care Division; Aspell et al. (2019).

Notes: Includes: Home Help, Home Care Packages, and Personal Care Attendant. Survey weights applied.

Figure 5.2 illustrates home support utilisation rates by age group and sex. There is a clear age gradient in home support use. Results from Wren et al. (2017) find a similar gradient across age. Home support use is consistently higher amongst females, especially at the oldest ages. Over 50 per cent of females aged 90+ residing at home are in receipt of home support compared to 38 per cent of males. Some of the differences between males and females at older ages may be explained by older females being far more likely to be widowed compared to males. As spouses are often the primary carer at home, not having a spouse tends to reduce an individual's unpaid care support available and increase demand for professional home support. 


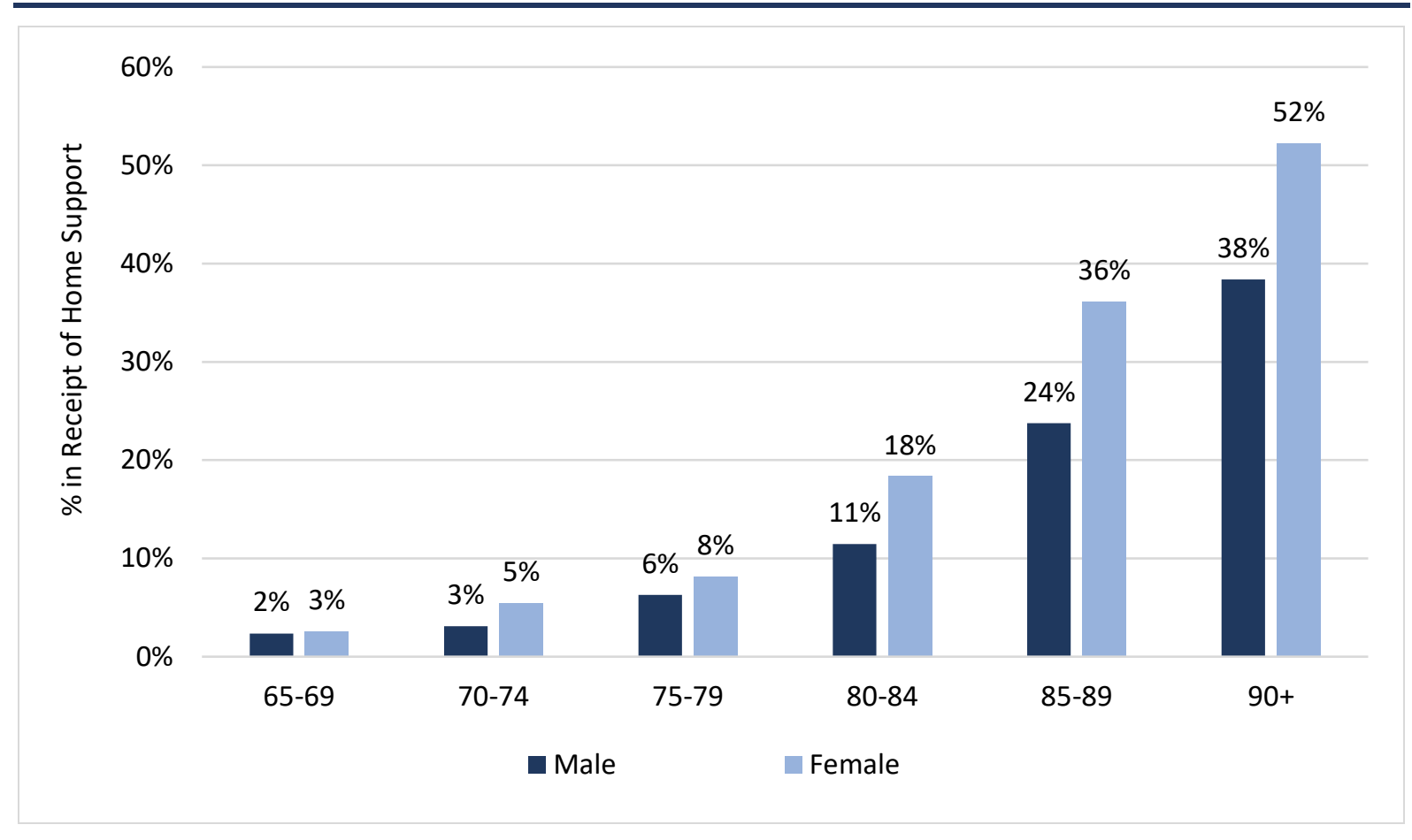

Figure 5.3 examines receipt of public and private home support by age group and sex. For both males and females, public home support receipt is more common than private home support. However, at younger ages, utilisation rates are similar. Higher rates of private home support at older ages may partly be a consequence of public supply not meeting demand. For males, 21 per cent of 85- to 89-year-olds and 28 per cent of those aged $90+$ are in receipt of public home support. Private support receipt in the 85-89 and 90+ age groups is 6 per cent and 19 per cent respectively. For females, 32 per cent of 85- to 89-year-olds and 45 per cent of those aged $90+$ are in receipt of public home support. Private support receipt in the $85-89$ and $90+$ age groups is 16 per cent and 20 per cent respectively. 
FIGURE 5.3 PUBLIC AND PRIVATE HOME SUPPORT RECEIPT RATES BY AGE AND SEX: AGES 65+

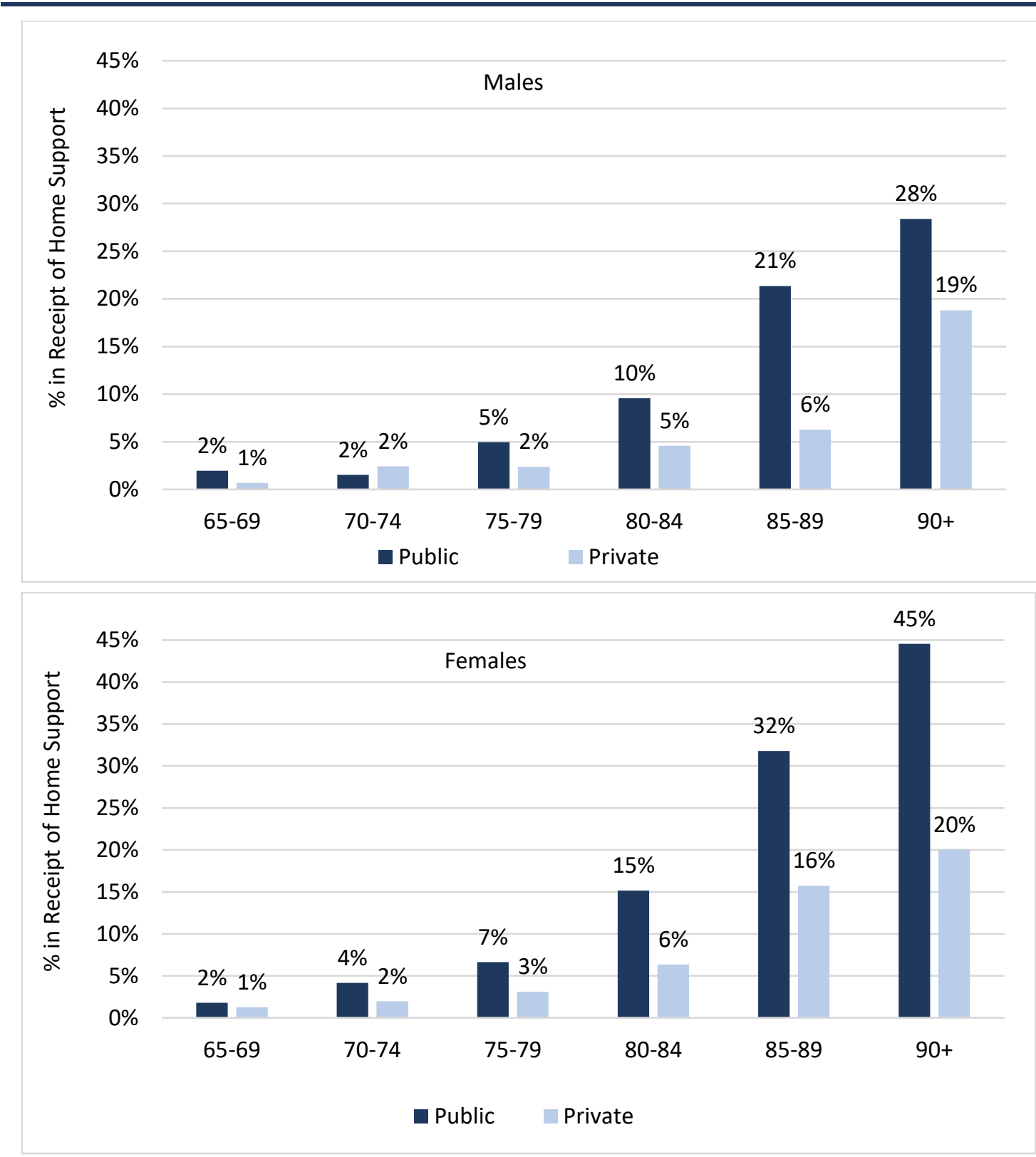

Source: $\quad$ Analysis of TILDA Waves 2-4 Research Microdata File.

Notes: $\quad$ Includes: Home Help, Home Care Packages, and Personal Care Attendant. Survey weights applied. TILDA respondents may be in receipt of both public and private home support.

Figure 5.4 also examines receipt of public and private home support by age group but expresses estimated numbers in receipt of home support including public home support, public and private home support, and private-only home support in each age group. While Figure 5.3 shows that receipt rates are lower at younger ages, due to the larger population at younger ages, the numbers in receipt are not as low at younger ages compared to older ages. The 80-84 and 85-89 age groups have the largest number of people in receipt of home support. The number of people in receipt of private-only home support is similar across all age groups. 


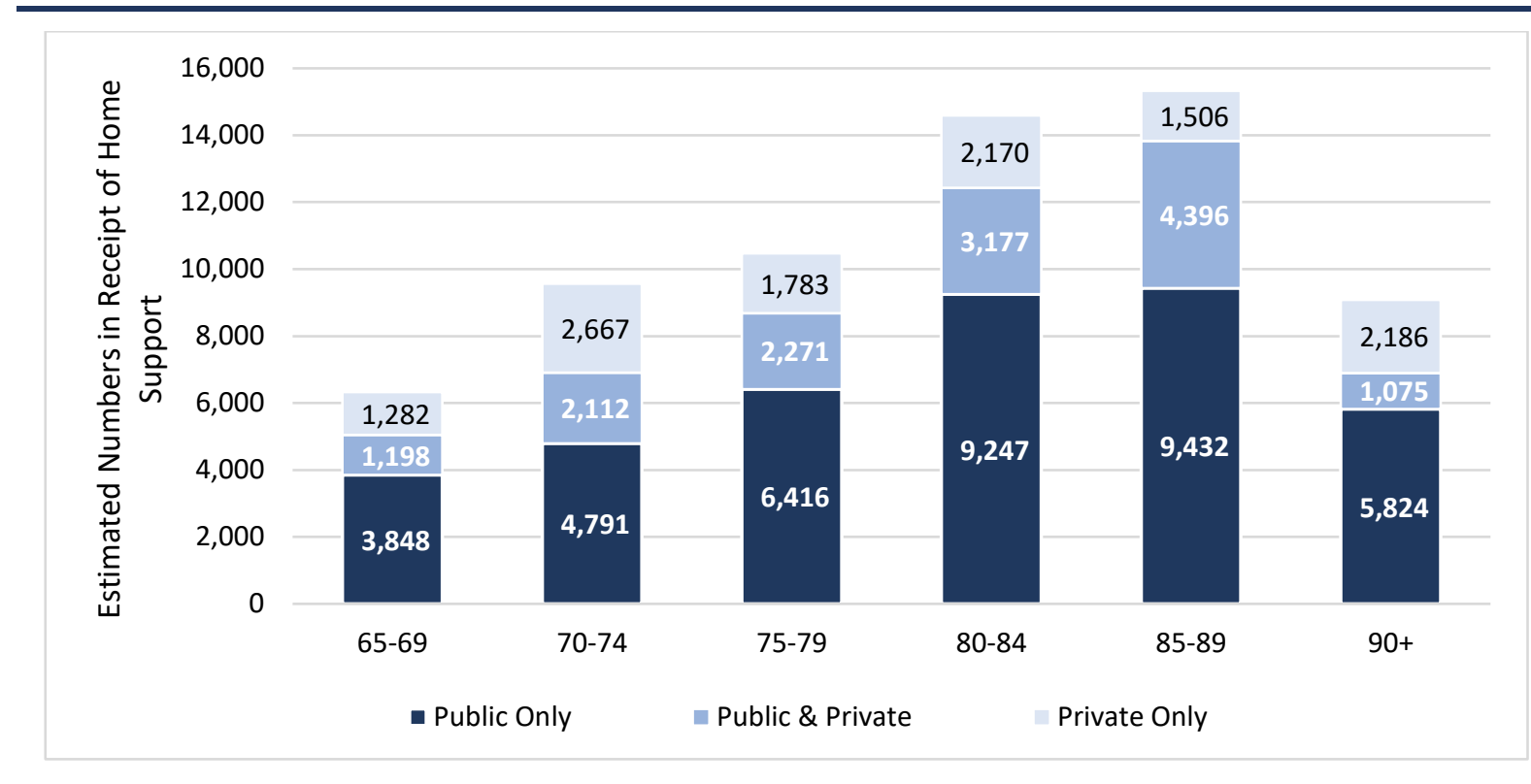

In Chapter 7, the health and healthcare utilisation profiles of home support recipients are estimated. In addition, Table A.4 and Table A.5 in the Appendix provide information on home support recipients across social supports (marital status and social connectedness score) and socioeconomic status (educational attainment and equivalised household income). These tables clearly show that being non-married or having poor social connectedness overall is linked with higher rates of home support receipt. In addition, lower educational attainment and lower (equivalised) household income is also clearly linked with higher rates of home support receipt.

Figure A.3 and Figure A.4 in the Appendix also show that there are opposing socioeconomic differences in receipt of public and private home support. For educational attainment in particular, while rates of public home support are much higher in lower education groups, the opposite is found for private home support. These socioeconomic factors will be important to understand when designing the planned statutory home support scheme.

\subsection{SCENARIO 2 - INCREASED HOURS FOR RECIPIENTS}

Table 5.2 presents the simulated home support demand under Scenario 2. This scenario begins with the assumption that all home support hours are provided through a new statutory scheme. It then incorporates an increase in home support for 'current' recipients based upon the goals of the Winter Plan 2020/21. Increases of between 10 per cent and 20 per cent based upon their d-ADL status are apportioned to recipients. 
The simulated total number of home support recipients (with people on a waiting list now included as recipients) in Scenario 2 is identical to Scenario 1 estimates. However, the number of recipients provided with home support by the State (i.e. through a statutory scheme) under this scenario increases from 53,652 (including iHCP recipients) to almost 70,700 , an increase of 30 per cent due to the assumed switch from private to the public home support scheme.

Given the assumptions made in Scenario 2, we simulate that in 2019 there would have been $\mathbf{2 9 . 7}$ million home support hours received through a statutory home support scheme. Mainly driven by private home support hours moving into public provision, this represents an increase of over five million hours, ${ }^{18}$ a 20.3 per cent increase compared to what we estimate was actually provided across public and private home support in 2019. As these hours would be delivered through the public system, this represents an increase of almost 11.2 million hours, ${ }^{19}$ a 45.2 per cent increase on what the HSE provided through the public home support and $\mathrm{HHCP}$ schemes in 2019.

\section{TABLE 5.2 SCENARIO 2: RECIPIENTS AND HOME SUPPORT HOURS: AGES 65+}

\begin{tabular}{|c|c|c|c|}
\hline & Recipients & Hours \\
\hline \multicolumn{2}{|c|}{ Public home support scheme } & 53,417 & $20,895,563$ \\
\hline \multicolumn{2}{|c|}{ Public Intensive Home Care Packages } & 235 & 360,000 \\
\hline \multicolumn{2}{|c|}{ Public Home Support Service, previously Private Home Support ${ }^{a, b}$} & 11,594 & $6,762,128$ \\
\hline \multicolumn{2}{|c|}{ Public Home Support Service previously on Waiting List } & 5,436 & $1,664,141$ \\
\hline \multicolumn{2}{|c|}{ Delayed Transfers of Care (public hospitals) ${ }^{c}$} & - & 39,273 \\
\hline \multicolumn{2}{|c|}{ Scenario 2 Total Demand } & $\underline{70,682}$ & $\underline{29,721,105}$ \\
\hline $\begin{array}{l}\text { Source: } \\
\text { Notes: }\end{array}$ & \multicolumn{3}{|c|}{$\begin{array}{l}\text { Authors' analysis of HSE data and TILDA Waves 2-4 Research Microdata File. } \\
\text { a Recipients includes 'private-only'. Hours includes privately-purchases hours for private-only and public \& private recipients. } \\
\text { b All private home support now assumed to be covered by the statutory scheme. } \\
\text { c The number of recipients affected by delayed transfers of care (from public hospitals) is already counted in the public home } \\
\text { support scheme. }\end{array}$} \\
\hline
\end{tabular}

\subsection{SCENARIO 3 - SUBSTITUTION FOR LONG-TERM RESIDENTIAL CARE}

Table 5.3 presents the simulated home support demand under Scenario 3. This scenario builds upon Scenario 2, and now assumes a 50 per cent reduction in the number of people exiting public home support and entering LTRC (from 8 per cent to 4 per cent in a 12-month period - see Aspell et al., 2019). This substitution from LTRC towards home support is intended to reflect the goals of the Winter Plan 2020/21. The increased hours for those substituting from LTRC involves provision of an $\mathrm{iHCP}$, as opposed to an average home support package. The scenario assumes 
that each of these individuals receives the equivalent of 52 home support hours per week, based on evidence from Carter et al. (2019) that average iHCPs included 38 public home support hours and 14 private home support hours.

The simulated number of recipients in Scenario 3 is 72,819 . This reflects the assumption that an additional 2,137 persons who would otherwise have transferred to LTRC are provided with iHCPs. The number of recipients provided with home support by the State (i.e. through a statutory scheme) under this scenario increases from 53,652 (including iHCP recipients) to almost 72,000, an increase of 34 per cent. Under Scenario 3, we simulate that in 2019 there would have been almost 34 million home support hours received through a statutory scheme. This represents an increase of over 9.2 million hours, ${ }^{20}$ a 37.4 per cent increase, on what we estimate was actually provided across public and private home support in 2019.

It is important to state that the healthcare and social care needs of people who would otherwise have been admitted to a LTRC home will be considerable and include significant unpaid care and also above-average healthcare utilisation. The care required will also differ across individuals and many people will require focused care for a specific condition, care for cognitive impairments, and assistance to help prevent falls. Aspell et al. (2019) indicate that for those individuals who transferred from the home support scheme into LTRC, having a cognitive impairment and falling were the two biggest driving factors. These results have been supported by findings clearly showing that people with dementia are much more likely to be admitted to LTRC than similar people without dementia (Carter et al., 2020). In addition, in their work examining iHCPs, Carter et al. (2019) clearly show GPs, public health nurses, occupational therapy, day centres, and respite care are key components of care packages for these individuals. Unpaid care demand will also increase substantially, and therefore it needs to be acknowledged that substituting home support for LTRC will tend to be associated with increased demands on unpaid and family caregivers. 
TABLE 5.3 SCENARIO 3: RECIPIENTS AND HOME SUPPORT HOURS: AGES 65+

\begin{tabular}{|l|r|r|}
\hline & Recipients & Hours \\
\hline Public home support scheme & 53,417 & $20,895,563$ \\
\hline Public Intensive Home Care Packages & 235 & 360,000 \\
\hline Public Home Support Service previously Private Home Support ${ }^{\text {a,b }}$ & 11,594 & $6,762,128$ \\
\hline Public Home Support Service previously on Waiting List & 5,436 & $1,664,141$ \\
\hline Delayed Transfers of Care (public hospitals) & & 39,273 \\
\hline Intensive Home Care Packages previously LTRC Admissions & - & $\mathbf{4 , 2 2 2 , 7 1 2}$ \\
\hline Scenario 3 Total Demand & $\mathbf{2 , 1 3 7}$ & $\mathbf{3 3 , 9 4 3 , 8 1 7}$ \\
\hline
\end{tabular}

Source: $\quad$ Authors' analysis of HSE data and TILDA Waves 2-4 Research Microdata File.

Notes: $\quad$ a Recipients includes 'private-only'. Hours includes privately purchased hours for private-only and public \& private recipients. b All private home support now assumed to be covered by the proposed statutory scheme.

c The number of recipients affected by delayed transfers of care (from public hospitals) is already counted in the public home support scheme.

\subsection{SCENARIO 4 - EXPANSION OF DEMAND IN THE COMMUNITY}

Table 5.4 presents the simulated home support demand under Scenario 4 . This scenario illustrates the effects if demand for home support amongst those with a d-ADL were to increase by 50 per cent (for example, if previously 10 per cent of 65- to 69-year-old males with a d-ADL received home support, we assume this increases to 15 per cent). This increases the number of recipients by 10,746 and the number of hours demanded by 6.4 million hours. Overall, Scenario 4 assumptions lead to an increase in hours demanded to almost 42 million hours, a 126 per cent increase, on what the HSE provided through the public home support and iHCP schemes in 2019.

TABLE 5.4 SCENARIO 4: RECIPIENTS AND HOME SUPPORT HOURS: AGES 65+

\begin{tabular}{|l|r|r|}
\hline & Recipients & Hours \\
\hline Public home support scheme & 53,417 & $20,895,563$ \\
\hline Public Intensive Home Care Packages & 235 & 360,000 \\
\hline Public Home Support Service previously Private Home Support ${ }^{\mathrm{a}, \mathrm{b}}$ & 11,594 & $\mathbf{8 , 6 3 0 , 1 7 6}$ \\
\hline Public Home Support Service previously on Waiting List & 5,436 & $\mathbf{1 , 6 6 4 , 1 4 1}$ \\
\hline Delayed Transfers of Care (public hospitals) & - & 39,273 \\
\hline Intensive Home Care Packages previously LTRC Admissions & $\mathbf{2 , 5 6 6}$ & $\mathbf{5 , 0 7 0 , 4 1 6}$ \\
\hline 50\% increase in Pop with d-ADLs demanding care & 10,746 & $5,259,376$ \\
\hline Scenario 4 Total Demand & $\mathbf{8 3 , 9 9 4}$ & $\mathbf{4 1 , 9 1 8 , 9 4 5}$ \\
\hline
\end{tabular}

Source: Authors' analysis of HSE data and TILDA Waves 2-4 Research Microdata File.

Notes: a Recipients includes 'private-only'. Hours include privately purchased hours for private-only and public $\&$ private recipients. b All private home support now assumed to be covered by the statutory scheme.

c The number of recipients affected by delayed transfers of care (from public hospitals) is already counted in the public home support scheme.

$\mathrm{d}-\mathrm{ADL}=$ difficulties with activities of daily living. 


\subsection{SCENARIO COMPARISONS}

Table 5.5 and Table 5.6 illustrate the potential demand across the four scenarios discussed above. In Scenario 4, after modelling the addition of private purchasers, reducing admissions into LTRC and modelling increased demand in the community, we estimate an additional 30,000 people being supported by the proposed statutory scheme. Were this to occur, we project that this would result in 12.5 per cent of all over-65s living at home ${ }^{21}$ in Ireland receiving home support through the new statutory scheme.

However, the largest increases in demand are mainly seen in hours. Across the four scenarios, the simulated number of hours provided through public home support schemes increase from 18.56 million hours (18.2 million through home support and 360,000 through iHCPs) to almost 42.4 million hours. This represents a 70 per cent increase in home support provided in 2019, and a 126 per cent increase on what the HSE provided through the public home support and iHCP schemes in 2019.

TABLE 5.5 ESTIMATED AND SIMULATED DEMAND FOR HOME SUPPORT ACROSS SCENARIOS RECIPIENTS: AGES 65+

\begin{tabular}{|c|c|c|c|c|c|}
\hline & $\begin{array}{l}\text { Baseline Estimation } \\
\text { (Scenario 1) }\end{array}$ & Scenario 2 & Scenario 3 & Scenario 4 \\
\hline \multicolumn{2}{|c|}{ Public home support scheme } & 53,417 & 53,417 & 53,417 & 53,417 \\
\hline \multicolumn{2}{|c|}{ Public Intensive Home Care Packages } & 235 & 235 & 235 & 235 \\
\hline \multicolumn{2}{|c|}{ Reductions in Admissions to LTRC } & & & $\underline{2,137}$ & 2,566 \\
\hline \multicolumn{2}{|c|}{$\begin{array}{l}50 \% \text { increase in Pop with d-ADLs } \\
\text { demanding care }\end{array}$} & & & & $\underline{10,746}$ \\
\hline \multicolumn{2}{|c|}{ Total public home support delivered } & 53,652 & & & \\
\hline \multicolumn{2}{|c|}{ Private Home Support ${ }^{\mathrm{a}}$} & 11,594 & & & \\
\hline \multicolumn{2}{|c|}{ Home support moved from private to public $^{b}$} & & $\underline{11,594}$ & 11,594 & 11,594 \\
\hline \multicolumn{2}{|c|}{ Total home support delivered } & 65,246 & & & \\
\hline \multicolumn{2}{|c|}{ Public Home Support Waiting List } & 5,436 & 5,436 & 5,436 & 5,436 \\
\hline \multicolumn{2}{|c|}{ Scenario Total' } & $\underline{70,682}$ & $\underline{70,682}$ & $\underline{72,819}$ & $\underline{83,994}$ \\
\hline $\begin{array}{l}\text { Source: } \\
\text { Notes: }\end{array}$ & \multicolumn{5}{|c|}{$\begin{array}{l}\text { Authors' analysis of HSE data and TILDA Waves 2-4 Research Microdata File. } \\
\text { a Recipients includes 'private-only'. Hours includes privately purchased hours for private-only and public \& private recipients. } \\
\text { b All private home support now assumed to be covered by the statutory scheme. } \\
\text { c The number of recipients affected by delayed transfers of care (from public hospitals) is already counted in the public home } \\
\text { support scheme. } \\
\text { d-ADL = difficulties with activities of daily living. }\end{array}$} \\
\hline
\end{tabular}

21 This equates to 12 per cent of all those aged 65+ in Ireland in 2019. 
TABLE 5.6 ESTIMATED AND SIMULATED DEMAND FOR HOME SUPPORT ACROSS SCENARIOS HOURS: AGES 65+

\begin{tabular}{|c|c|c|c|c|}
\hline & $\begin{array}{c}\text { Baseline } \\
\text { Estimation } \\
\text { (Scenario 1) }\end{array}$ & Scenario 2 & Scenario 3 & Scenario 4 \\
\hline Public home support scheme & $18,200,000$ & $20,895,563$ & $20,895,563$ & $20,895,563$ \\
\hline Public Intensive Home Care Packages & 360,000 & 360,000 & 360,000 & 360,000 \\
\hline Reductions in Admissions to LTRC & & & $\underline{4,222,712}$ & $5,070,416$ \\
\hline $\begin{array}{l}50 \% \text { increase in Pop with d-ADLs } \\
\text { demanding care }\end{array}$ & & & & $\underline{5,259,376}$ \\
\hline Total public hours delivered & $18,560,000$ & & & \\
\hline Private Home Support ${ }^{a}$ & $6,147,389$ & & & \\
\hline Home support moved from private to public ${ }^{b}$ & & $\underline{6,762,128}$ & $6,762,128$ & $8,630,176$ \\
\hline Total hours delivered & $24,707,389$ & & & \\
\hline Public Home Support Waiting List & $1,512,855$ & $1,664,141$ & $1,664,141$ & $1,664,141$ \\
\hline Delayed Transfers of Care (public hospitals) & 39,273 & 39,273 & 39,273 & 39,273 \\
\hline Scenario Total & $\underline{26,259,517}$ & $\underline{29,721,105}$ & $\underline{33,943,817}$ & $\underline{41,918,945}$ \\
\hline
\end{tabular}

Source: $\quad$ Authors' analysis of HSE data and TILDA Waves 2-4 Research Microdata File.

Notes: a Recipients includes 'private-only'. Hours includes privately purchased hours for private-only and public \& private recipients.

b All private home support now assumed to be covered by the statutory scheme.

$\mathrm{d}-\mathrm{ADL}=$ difficulties with activities of daily living. 


\section{CHAPTER 6}

\section{Home support recipients' use of healthcare and social care services}

This Chapter uses data from TILDA (Waves 2-4) to profile home support recipients aged 65 years and older in Ireland. The scope of a new statutory scheme may extend not only to home support recipients who currently receive services through the public system, but also those who purchase private home support. Therefore, in most analyses we examine all home support use by combining both publicly provided and privately purchased home support. Where applicable and sample size allows, we examine public and private home support recipients separately.

\subsection{HEALTH}

\subsubsection{Difficulties with activities of daily living (d-ADL)}

Figure 6.1 illustrates the prevalence of home support for males and females by $d$-ADL status. Both males and females with at least one $d-A D L$ have higher rates of home support. Only 5 per cent of males without a d-ADL are in receipt of home support, while 20 per cent of those with one d-ADL and 37 per cent of those with at least two d-ADL are in receipt of home support. Similarly, only 8 per cent of females without a d-ADL are in receipt of home support, with 28 per cent of those with one d-ADL and 48 per cent of those with at least two d-ADL in receipt of home support.

\section{FIGURE 6.1 HOME SUPPORT RECEIPT BY D-ADL AND SEX: AGES 65+}

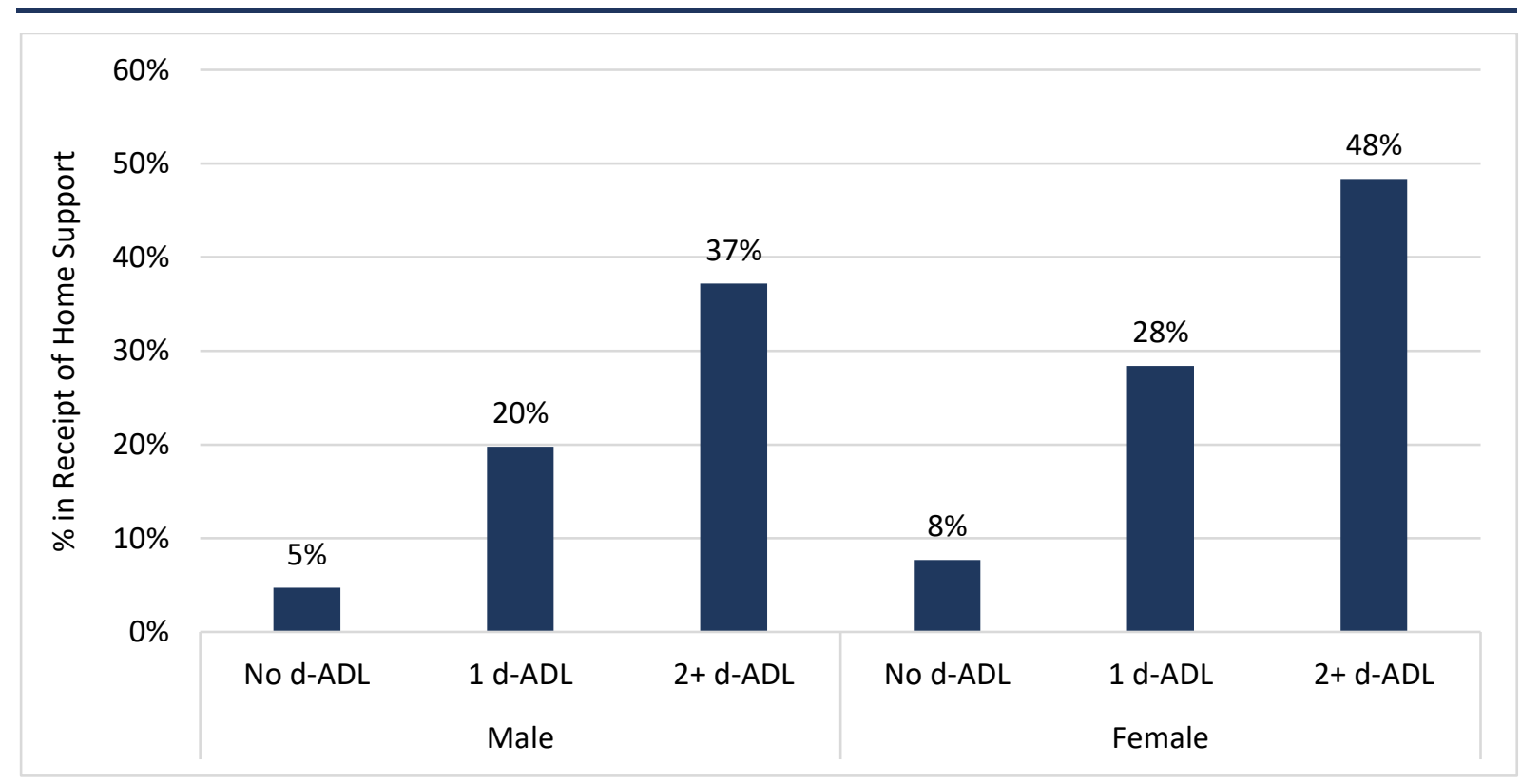

Source: $\quad$ Analysis of TILDA Waves 2-4 Research Microdata File.

Notes: Home Support includes: Home Help, Home Care Packages, and Personal Care Attendant. Survey weights applied. 
Figure A.5 in the Appendix also shows that for individuals with any d-ADL, public home support was the main type of home support used.

Figure 6.2 illustrates home support receipt for males and females across age groups for those with any $d-A D L$ (combining one $d-A D L$ and $2+d-A D L$ ) or no $d-A D L$. The age gradient in home support receipt is clearer for those with no d-ADL. Home support receipt rates are relatively high for younger people with any $d-A D L$, and the increase across age is less consistent. For males, 24 per cent of 65- to 69-yearolds with any d-ADL are in receipt of home support, and this increases to 49 per cent in the 90+ age group. For females, 17 per cent of 65- to 69-year-olds with any d-ADL are in receipt of home support, and this increases to 61 per cent in the 85-89 age group.

The lack of a clear age gradient for $d-A D L$ may be due to the lack of substantial support in the community requiring many older people with $d$-ADL to enter residential care facilities in order to be provided with sufficient support. 


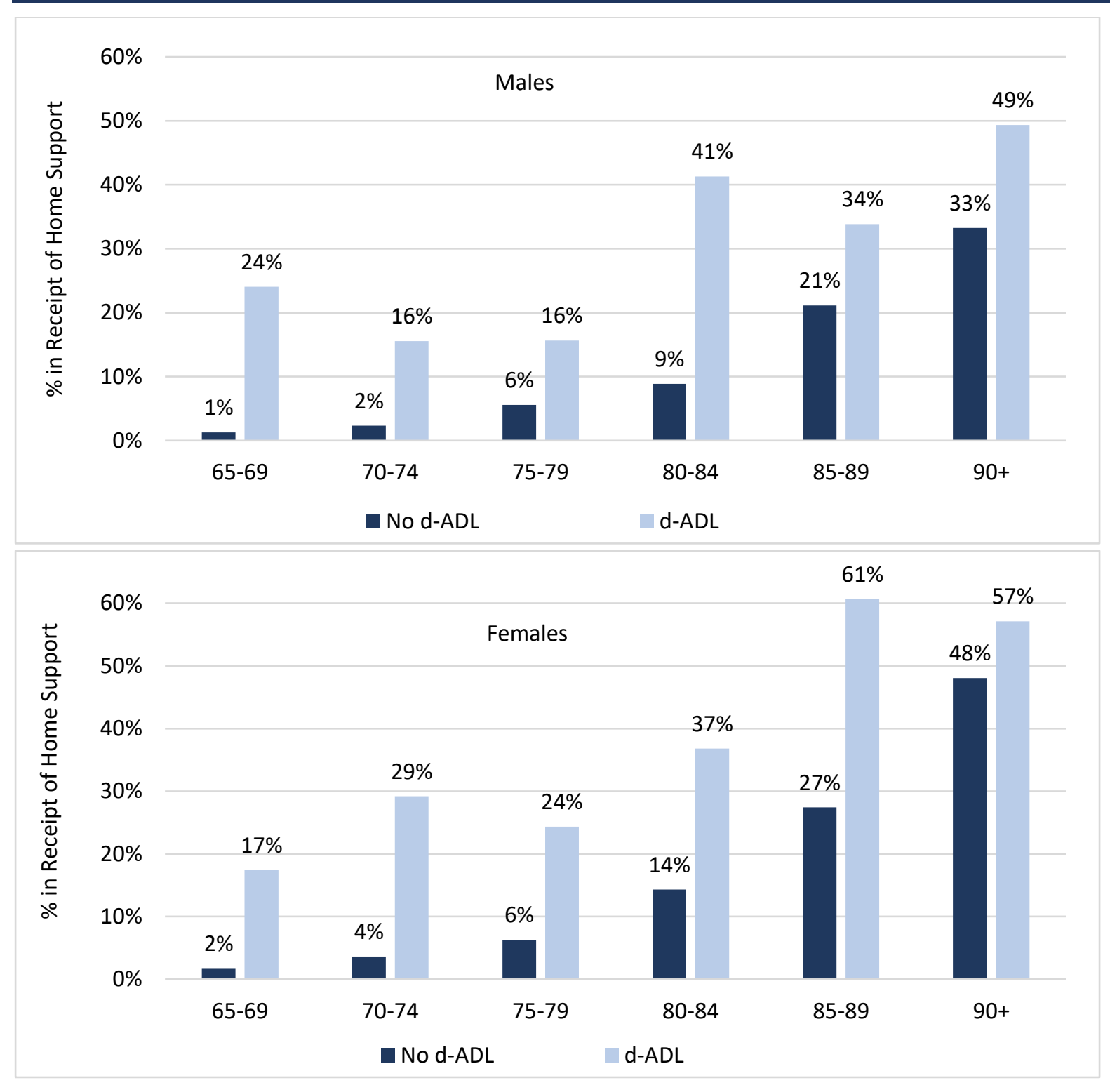

Notes: Home Support includes: Home Help, Home Care Packages, and Personal Care Attendant. Survey weights applied.

\subsubsection{Difficulties with instrumental activities of daily living (d-iADL)}

Figure 6.3 shows the prevalence of receiving home support for males and females by $d$-iADL status. Both males and females with d-iADL have higher rates of home support. Only 4 per cent of males without a d-iADL are in receipt of home support, while 28 per cent of those with one d-iADL and 40 per cent of those with at least two d-iADL are in receipt of home support. Similarly, only 6 per cent of females without a d-iADL are in receipt of home support, with 32 per cent of those with one d-iADL and 46 per cent of those with at least two d-iADL in receipt of home support. Overall, the results are similar to the $d-A D L$ results in the previous section.

Figure A.6 in the Appendix also shows that for individuals with any d-iADL, public home support was by far the main type of home support used. 
FIGURE 6.3 HOME SUPPORT RECEIPT BY D-IADL AND SEX: AGES 65+

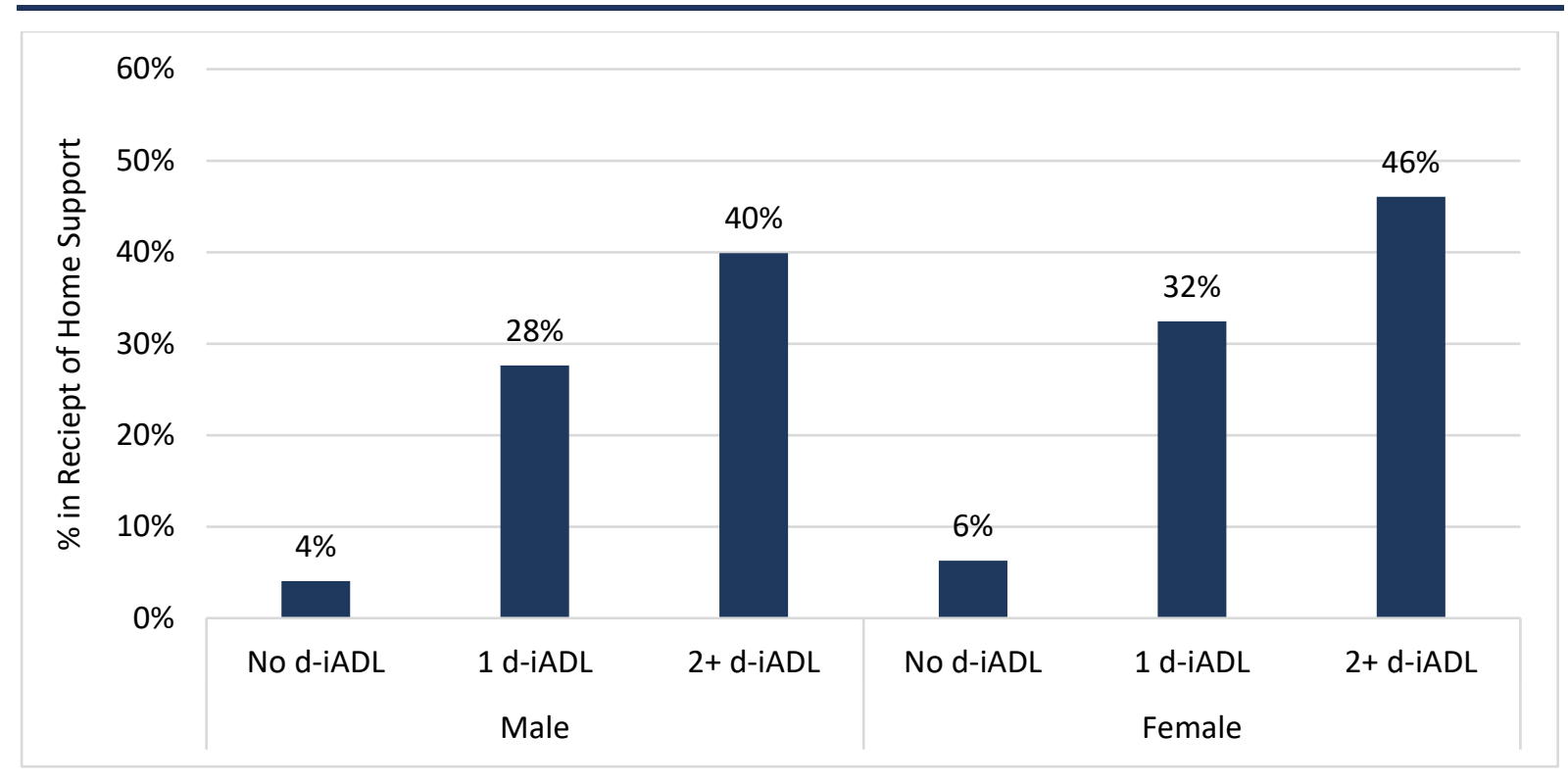

Source: $\quad$ Analysis of TILDA Waves 2-4 Research Microdata File.

Notes: Home Support includes: Home Help, Home Care Packages, and Personal Care Attendant. Survey weights applied.

Figure 6.4 illustrates home support receipt for males and females across age groups by any d-iADL (combining one d-iADL and $2+d-i A D L$ ) status. The age gradient in home support receipt is clearer for those with no d-iADL. Home support receipt rates are very high for younger people with any d-iADL, and the increase across age is not linear, especially amongst males. For males, 35 per cent of 65 - to 69-year-olds with any d-iADL are in receipt of home support and this increases to 46 per cent and 40 per cent in the 85-89 and 90+ age groups respectively. For females, there is a pronounced age gradient, as 19 per cent of 65- to 69-year-olds with any d-iADL are in receipt of home support increasing to 60 per cent in the $90+$ age group.

Similar to the results for $d-A D L$, the lack of a clear age gradient for d-iADL may partly be due to the lack of substantial support in the community requiring many older people with d-iADL to enter residential care facilities in order to be provided with sufficient help with everyday activities. 


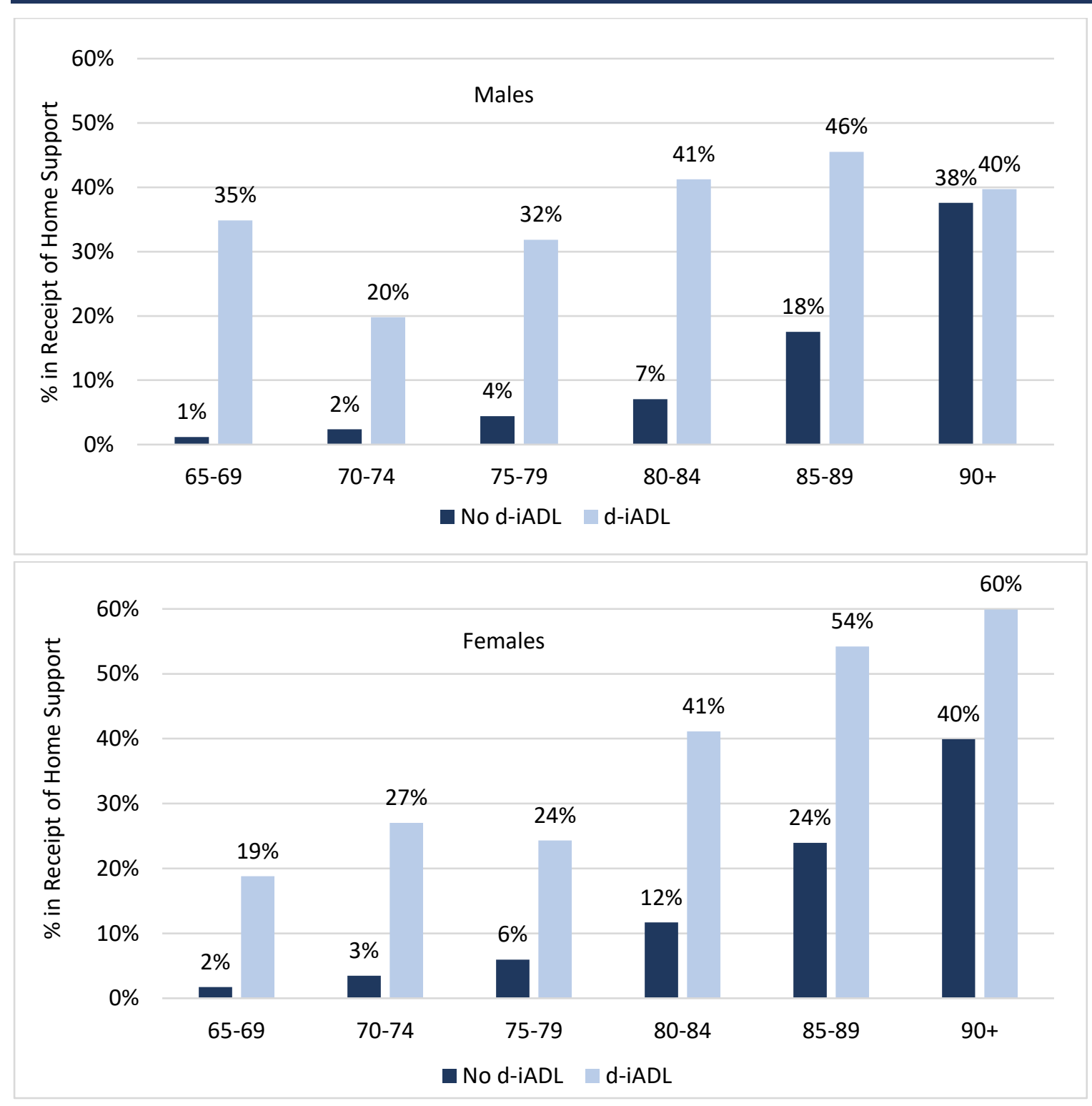

Source: $\quad$ Analysis of TILDA Waves 2-4 Research Microdata File.

Notes: $\quad$ Home Support includes: Home Help, Home Care Packages, and Personal Care Attendant. Survey weights applied.

\subsubsection{Falls}

Work by Aspell et al. (2019) has shown that falls are a significant threat to the wellbeing of older people. The authors found a large proportion of home support recipients experience falls, and that having a fall is a key factor in admission to residential care; 71 per cent of recipients admitted to residential care were at risk of falls (Aspell et al., 2019). We therefore examine falls among older people residing at home. Figure 6.5 shows that a larger percentage of people who receive home support experienced a fall in the previous 12 months compared to those without a fall; 37 per cent of males and 46 per cent of females with home support reported a fall. 
FIGURE 6.5 PERCENTAGE WITH FALLS IN PREVIOUS 12 MONTHS BY HOME SUPPORT RECEIPT STATUS: AGES 65+

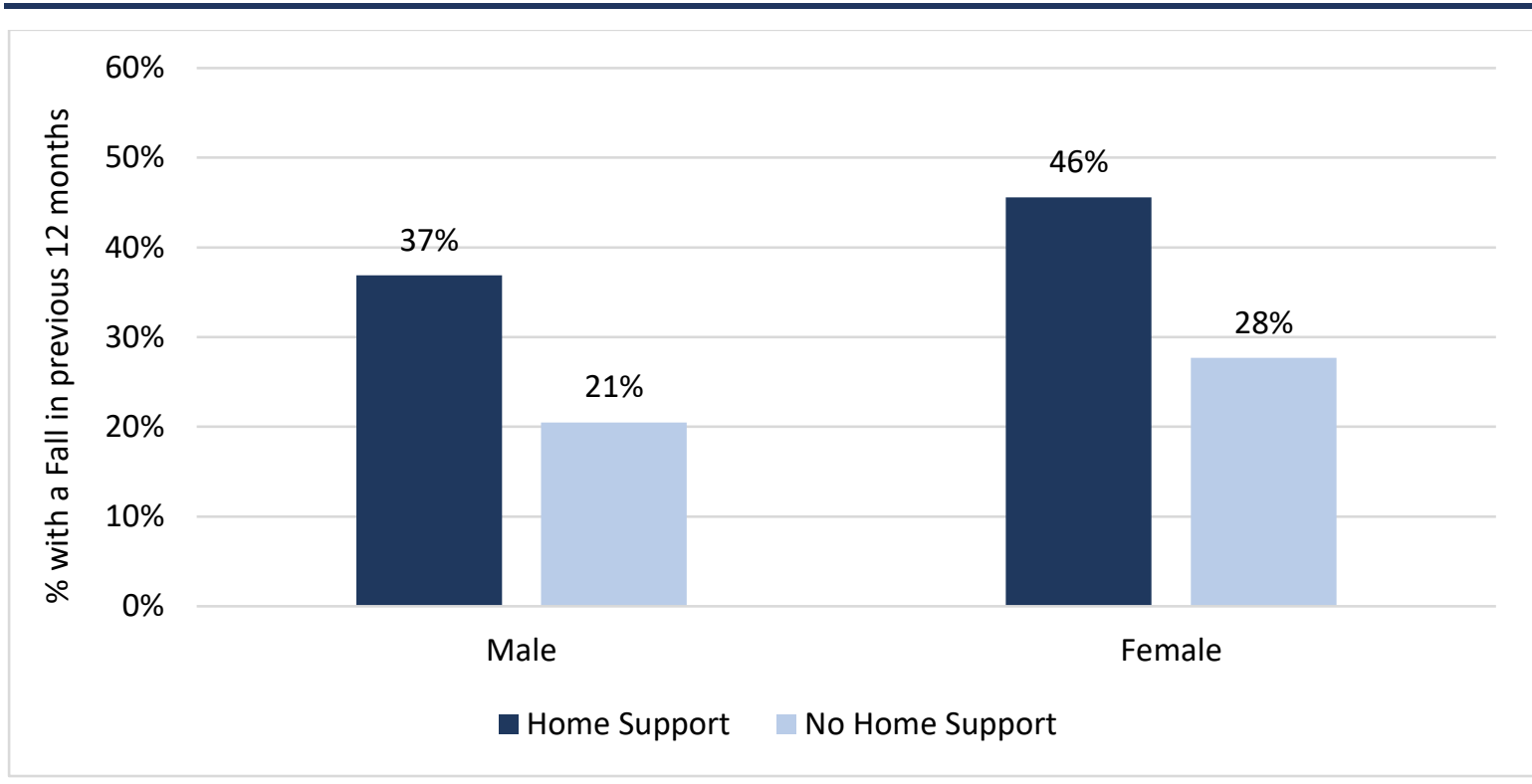

Source: $\quad$ Analysis of TILDA Waves 2-4 Research Microdata File.

Notes: Home Support includes: Home Help, Home Care Packages, and Personal Care Attendant. Survey weights applied.

Figure 6.6 displays the shares of the population receiving home support, distinguishing between those who reported a fall or did not report a fall in the previous 12 months for males and females and by age group. Males at younger ages reporting a fall were much more likely to be in receipt of home support than those without a fall. The pattern is less consistent at older ages. Similarly, for females, at younger ages, those reporting a fall had higher rates of home support receipt than those without a fall. The gap narrows at older ages. This 'switch' or narrowing at older ages is likely due to older people who are prone to falls being more likely to be admitted to LTRC. 
FIGURE 6.6 HOME SUPPORT RECEIPT BY FALLS STATUS IN PREVIOUS 12 MONTHS, AGE AND SEX: AGES 65+

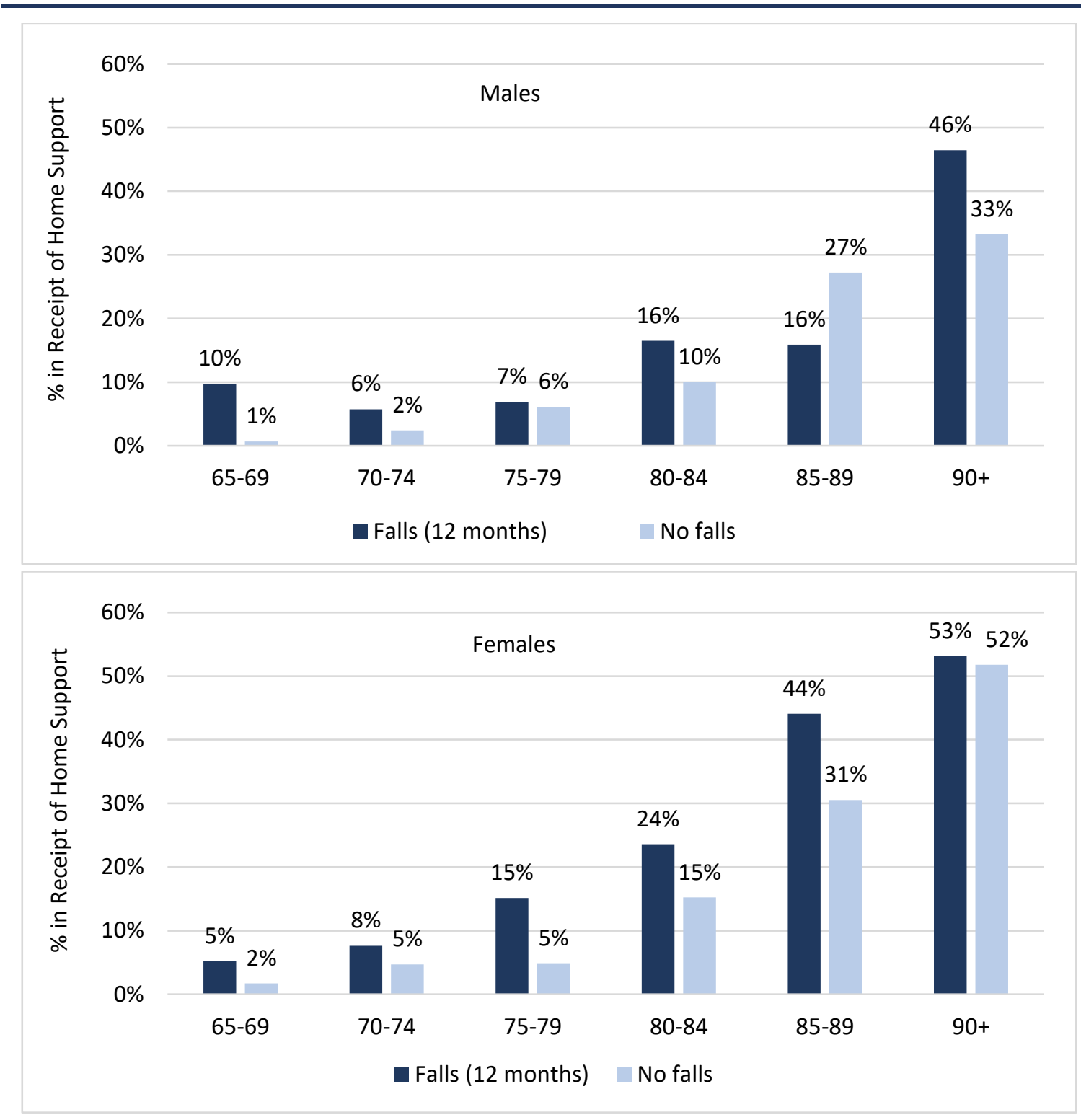

Source: $\quad$ Analysis of TILDA Waves 2-4 Research Microdata File.

Notes: Home Support includes: Home Help, Home Care Packages, and Personal Care Attendant. Survey weights applied.

\subsubsection{Cognitive impairment}

Aspell et al. (2019) also emphasises that cognitive impairment ('cognitive dysfunction'; dementia or suspected cognitive impairment) is a significant issue for home support recipients. The authors found a large proportion of home support recipients have moderate or severe cognitive impairment and that this is a key factor in admission to residential care; 61 per cent of recipients admitted to residential care had moderate or severe cognitive impairment (Aspell et al., 2019). Further evidence from Dublin North Central finds that of those receiving public home support, 37 per cent had dementia and 9 per cent had a suspected cognitive impairment (O'Brien et al., 2019). We therefore examine cognitive impairment among older people residing at home. Cognitive impairment is measured using the total score on the Mini Mental State Examination (MMSE) variable in TILDA. This 
total score is calculated by summing scores from 11 questions on cognition. ${ }^{22} \mathrm{~A}$ Moderate/Severe cognitive impairment is defined as having a score of 26 to 30 (on a 30-point scale).

Figure 6.7 shows that a higher percentage of people who receive home support had a moderate/severe cognitive impairment than those who did not receive support: 31 per cent of males and 35 per cent of females with home support reported a having a moderate/severe cognitive impairment.

\section{FIGURE 6.7 PERCENTAGE WITH MODERATE/SEVERE COGNITIVE IMPAIRMENT BY HOME SUPPORT} RECEIPT STATUS: AGES 65+

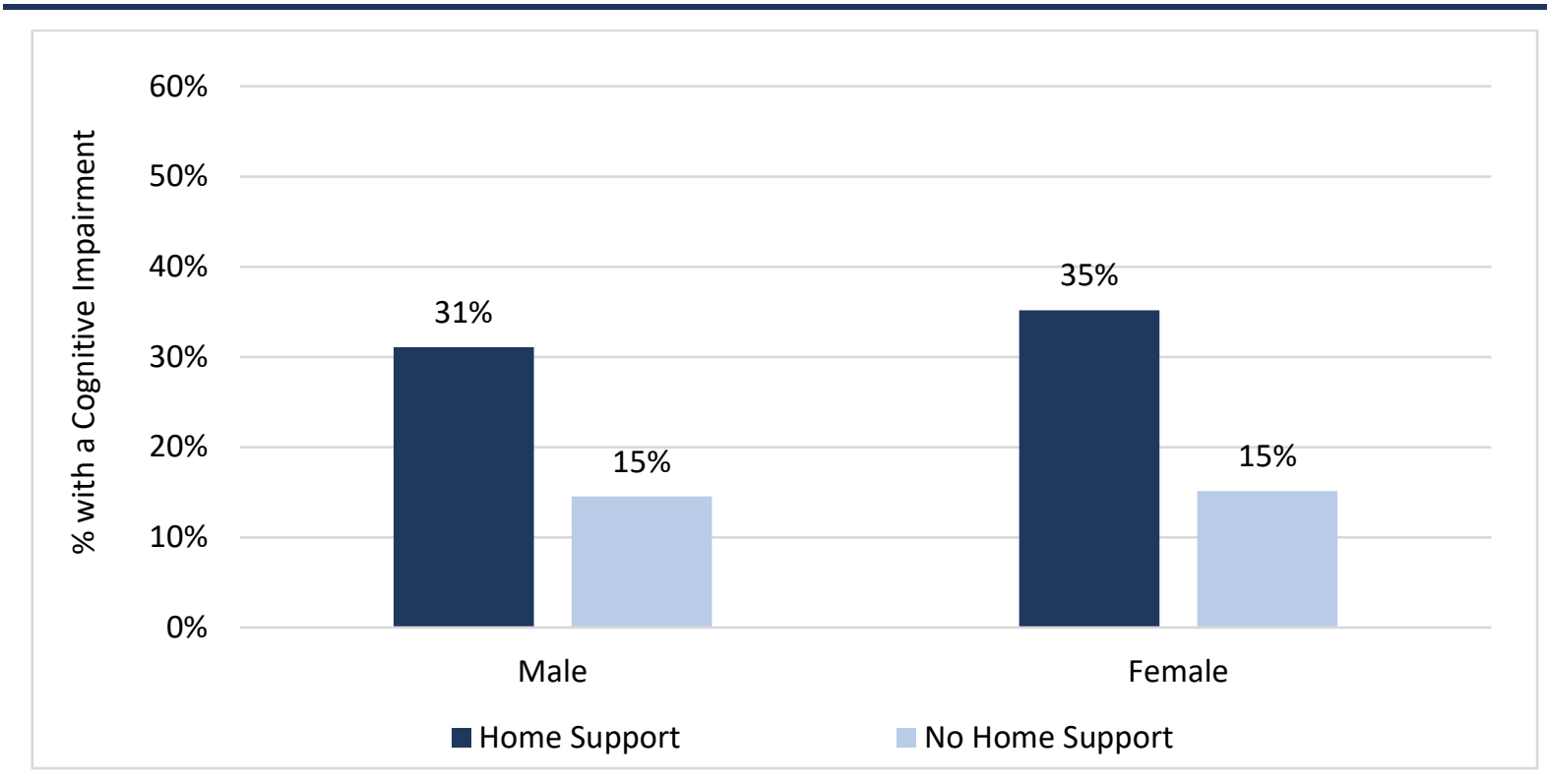

Source: $\quad$ Analysis of TILDA Waves 2-4 Research Microdata File.

Notes: $\quad H o m e$ Support includes: Home Help, Home Care Packages, and Personal Care Attendant. Survey weights applied. Cognitive impairment is measured using the total score on the Mini Mental State Examination (MMSE).

Figure 6.8 shows the receipt of home support among those who reported having a moderate/severe cognitive impairment or no impairment, split by sex and by age group. There is a clear age gradient in home support receipt across cognitive impairment status. For males, at younger ages, those reporting a cognitive impairment had much higher home support receipt rates than those without a cognitive impairment. The pattern is less consistent at older ages for males and females, which may partly reflect higher rates of admission to LTRC among cognitively impaired people at older ages. Note, however, that many cognitively impaired people also have other morbidities, and they may be subject to varying age and sex profiles. Home support requirements are subject to a more complex pattern of needs across age and sex than a simple comparison like this can show.

22 A list of the 11 cognitive questions that are used to quantify respondents MMSE score can be found here https://tilda.tcd.ie/data/documentation/doc/wave4/Derived\%20Variables\%20Codebook_wave\%204\%20v4.0.pdf. 
FIGURE 6.8 HOME SUPPORT RECEIPT BY MODERATE/SEVERE COGNITIVE IMPAIRMENT STATUS, AGE AND SEX: AGES 65+

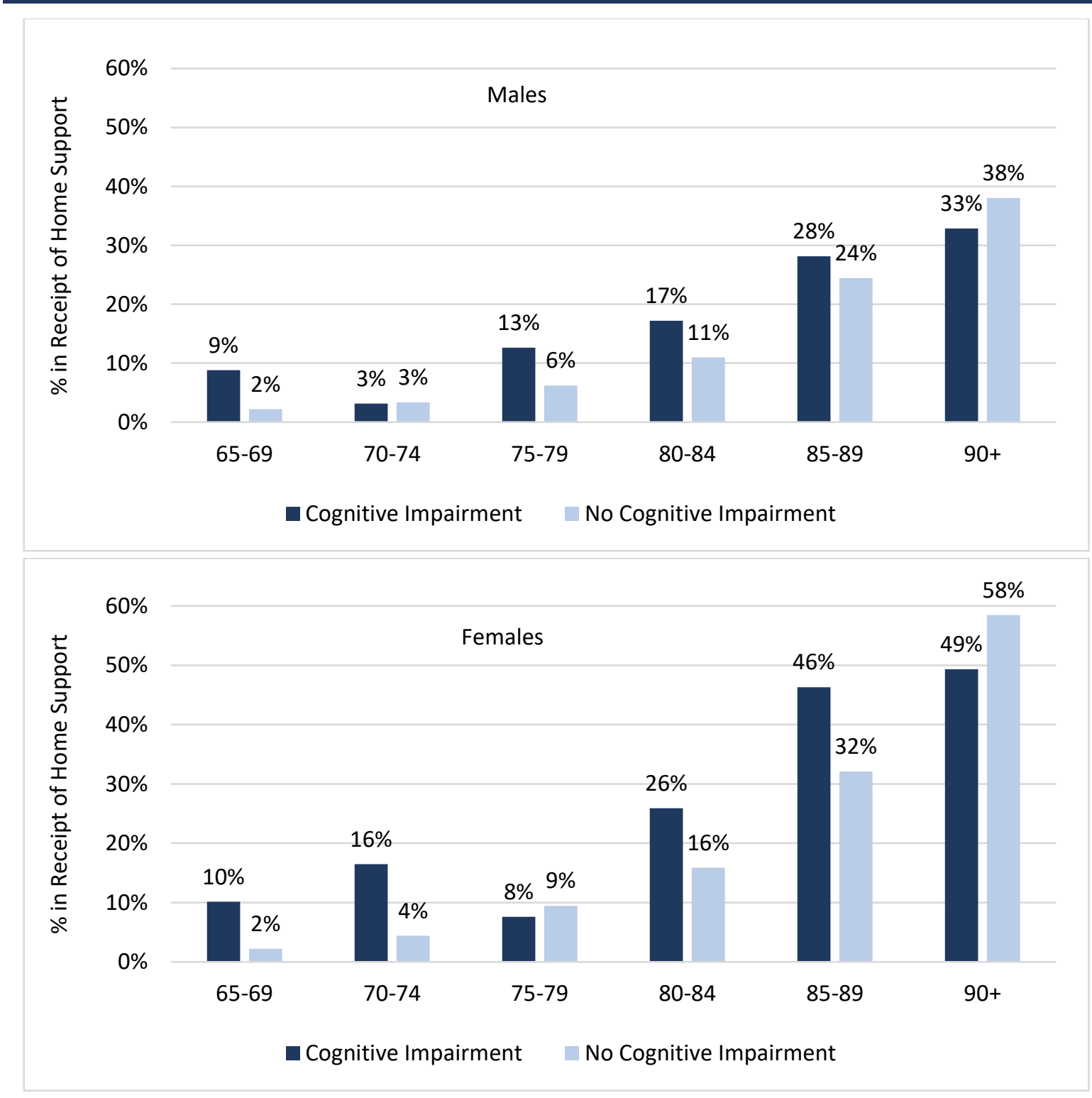

Source: $\quad$ Analysis of TILDA Waves 2-4 Research Microdata File.

Notes: Home Support includes: Home Help, Home Care Packages, and Personal Care Attendant. Survey weights applied. Cognitive impairment is measured using the total score on the Mini Mental State Examination (MMSE).

\subsection{HEALTHCARE UTILISATION}

This section examines overall healthcare and social care use by people in receipt of home support. While this report is mainly concerned with the potential demand implications on home support from introducing a statutory scheme, the needs of recipients will be far broader than home support. Therefore this section seeks to highlight how much more healthcare and social care is used by home support recipients compared to the older population not in receipt of home support. The results do not draw a causal inference between home support and healthcare utilisation. A major health shock may result in hospitalisation which in turn will require home support post-discharge. In addition, the expansion of home support, allowing people to live at home for longer, will increase the demand for healthcare 
and social care services provided in the community. Using data from TILDA, in the following figures we estimate levels of healthcare and social care use in the previous 12 months across a range of services. We present results across three Figures: Figure 6.9 presents findings from GP and inpatient hospital care; Figure 6.10 presents findings on allied health professional care; Figure 6.11 presents findings from social care services.

Figure 6.9 shows the shares of the population with high GP use (5+ visits) and inpatient hospital care use (any inpatient stay) in the previous 12 months for groups with and without home support. Those in receipt of home support are 10 percentage points more likely to have a high number of GP visits $(5+)$ annually. However, overall high GP visiting rates are high across both groups. In the previous 12 months, 22 per cent of home support recipients had at least one inpatient stay in hospital compared to 13 per cent of home support non-recipients.

FIGURE 6.9 GP VISITS AND INPATIENT STAYS BY HOME SUPPORT RECEIPT STATUS: AGES 65+

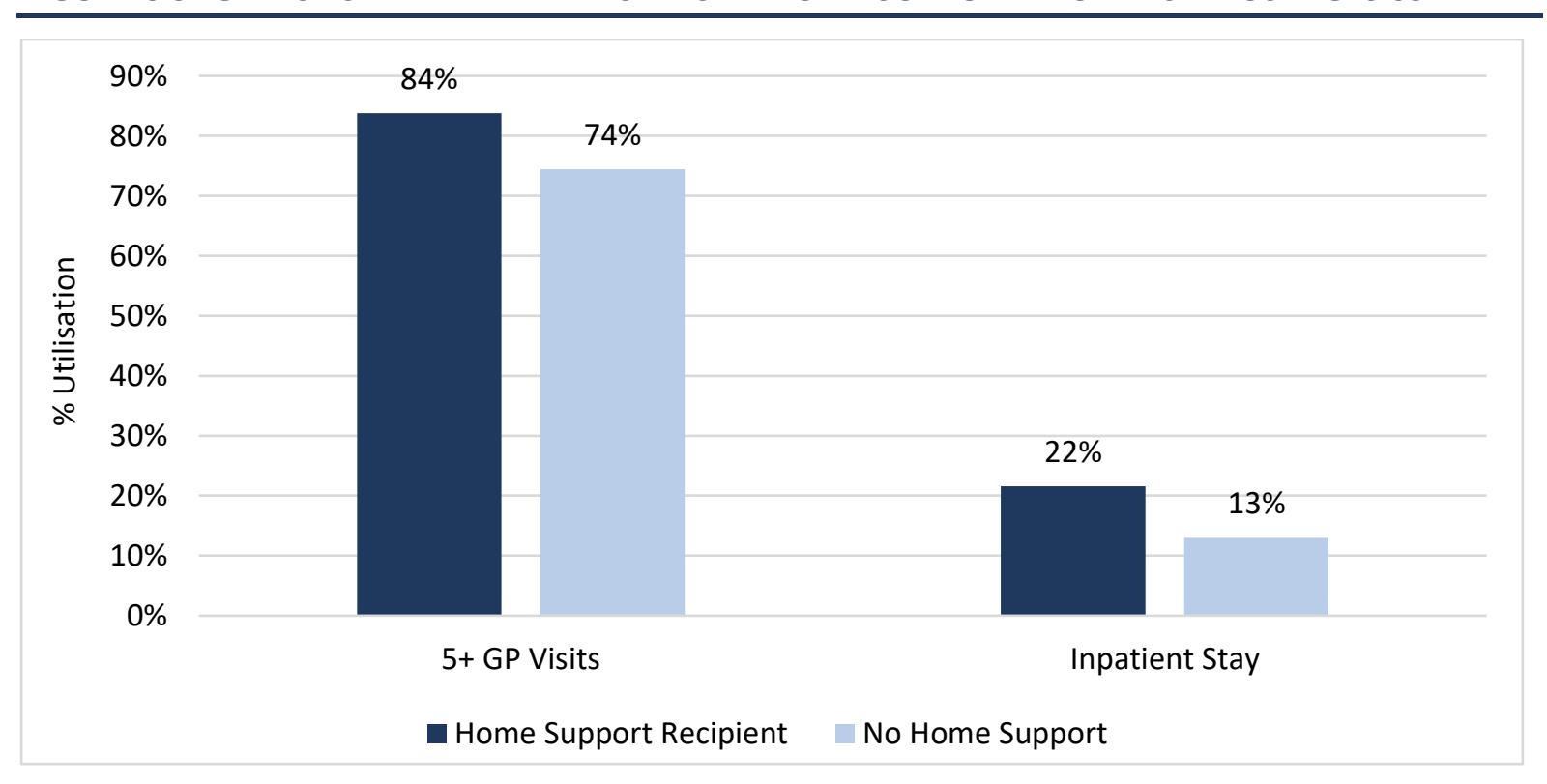

Source: $\quad$ Analysis of TILDA Waves 2-4 Research Microdata File.

Notes: Home Support includes: Home Help, Home Care Packages, and Personal Care Attendant. Survey weights applied.

Figure 6.10 illustrates use of allied health professionals in the previous 12 months for recipients and non-recipients of home support. Public health nurses (PHN), occupational therapists (OT) and physiotherapists are key providers of care and support to older people and those in receipt of home support. Of individuals in receipt of home support, 35 per cent had a PHN visit in the previous 12 months, as compared to only 5 per cent of non-recipients. In the previous 12 months, 9 per cent of home support recipients had an OT visit, compared to 1 per cent of non-recipients. Results are not as divergent for physiotherapy visits, with 15 per cent of home support recipients having a physiotherapist visit in the previous 12 months, compared to 5 per cent of non-recipients. The large difference in PHN and 
OT utilisation for those in receipt of home support may be explained in part by the key role played by these professionals making assessments prior to the granting of support, but it also reflects care provided alongside home support packages.

\section{FIGURE 6.10 PUBLIC HEALTH NURSE, OCCUPATIONAL THERAPY, PHYSIOTHERAPY VISITS BY HOME SUPPORT RECEIPT STATUS: AGES 65+}

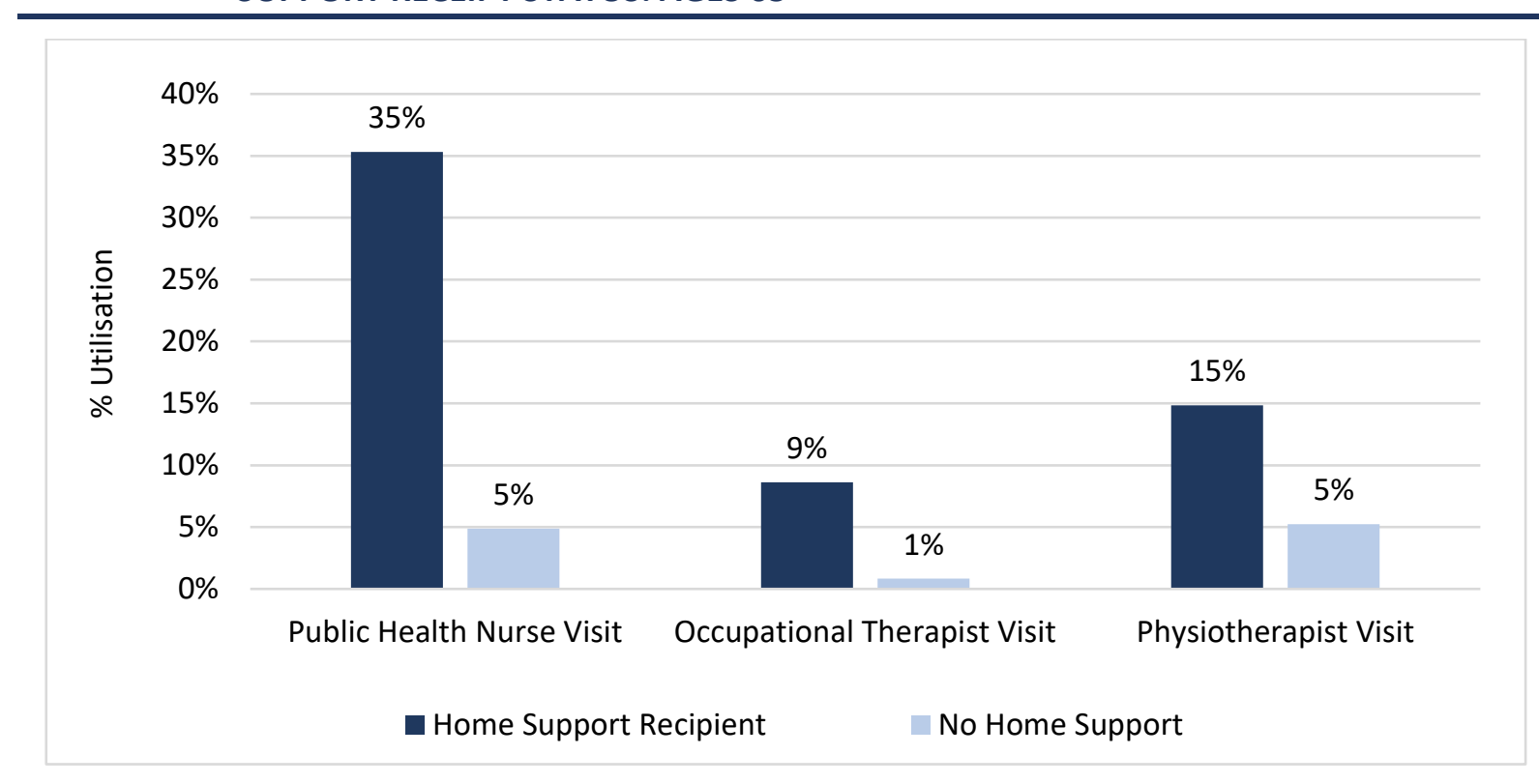

Source: $\quad$ Analysis of TILDA Waves 2-4 Research Microdata File.

Notes: $\quad H o m e$ Support includes: Home Help, Home Care Packages, and Personal Care Attendant. Survey weights applied.

Figure 6.11 shows how use of social care services in the previous 12 months varies between recipients and non-recipients of home support. While unpaid and professional home supports are the key components of aiding people with a d-ADL to live at home for as long as possible, other types of social care are also vital to many home support recipients and their unpaid carers and families. Day centre, respite care, and convalescent (often short-term nursing home care) are significant sources of demand. Overall, many home support recipients use other social care services; 9 per cent of home support recipients used day centre care in the previous 12 months, compared to only 2 per cent of non-recipients. Respite care use was low overall, with just 3 per cent of recipients using respite care in the previous 12 months. Finally, 10 per cent of home support recipients spent some time in a nursing or convalescent home. This compares to just 2 per cent of non-recipients. 
FIGURE 6.11 DAY CENTRE, RESPITE CARE, AND CONVALESCENT CARE BY HOME SUPPORT RECEIPT STATUS: AGES 65+

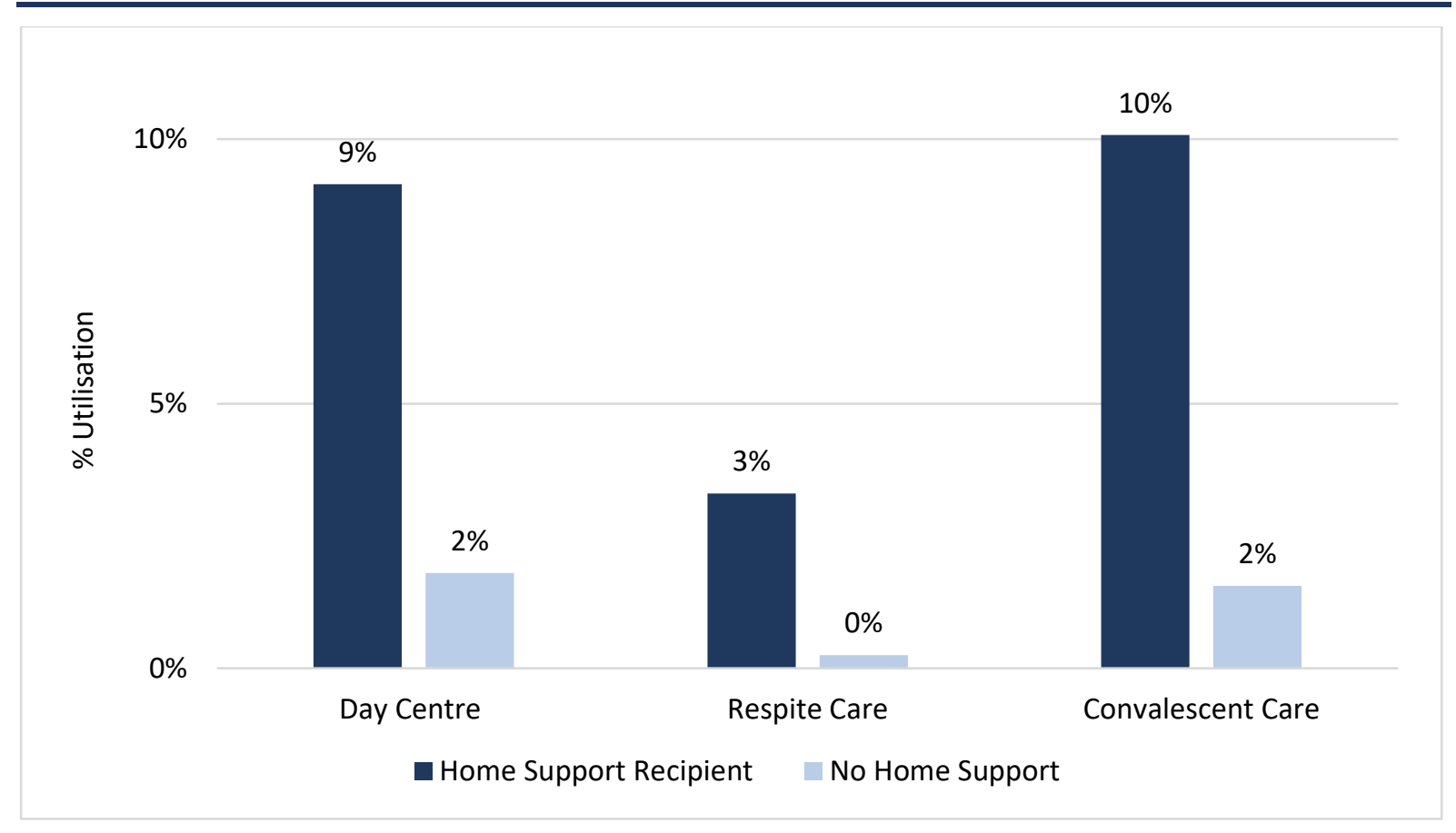

Source: $\quad$ Analysis of TILDA Waves 2-4 Research Microdata File.

Notes: Home Support includes: Home Help, Home Care Packages, and Personal Care Attendant. Survey weights applied. 


\section{CHAPTER 7}

\section{Home support supply}

\subsection{INTRODUCTION}

The results reported in Chapter 5 indicate that demand for home support is likely to increase significantly on foot of the introduction of a statutory scheme. Our simulations indicate that the potential demand for home support may increase to

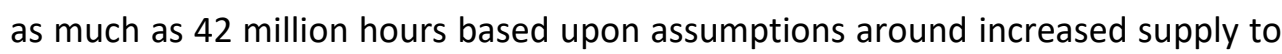
current recipients, increased substitution away from LTRC and increased demand from those not currently in the scheme. The 42 million hours estimated in Scenario 4 would represent a 71 per cent increase in demand for home support hours, and therefore require a proportionate increase in supply, potentially in a short period of time.

As these demand scenarios are modelled based on the 2019 population, they do not account for the rise in demand for home support that will occur, even in the absence of a statutory scheme, as the older population grows (Wren et al., 2017). Providing significantly increased levels of service implies increases in costs. We intend to explore ways of meeting the potential cost of a new statutory scheme and options for meeting it in subsequent research. However, public and private providers of professional care will also face significant challenges in meeting growing demand even if resources are made available. This chapter discusses the supply of home support in Ireland, regional differences in supply, and the role played by non-HSE provision.

\subsection{WHO SUPPLIES HOME SUPPORT?}

Home support in Ireland is provided by staff drawn from the HSE, voluntary organisations, and for-profit organisations. There is no definitive database of who provides home support in Ireland. In this section, combining information from the HSE with data from private purchasers (and providers) of care, we estimate the proportion of home support provided by HSE and non-HSE staff nationally and across regions in Ireland.

Figure 7.1 provides estimates of the number of home support hours provided by HSE and non-HSE staff in 2019. These estimates are based upon the baseline public and private home support hours (24.7 million) estimated in Chapter 5. First, using data from the HSE just over 8.2 million home support hours were provided by HSE staff in 2019. This represents 44 per cent of all public home support, and 33.4 per cent of all home support provided. 
Due to limited available data, it is difficult to split non-HSE home support provision between voluntary organisations and for-profit organisations. Recent research has found that there is a 4:1 split between for-profit and voluntary organisations in public home support expenditure (Mercille and O'Neill, 2020). If we assume similar costs per home support hour between for-profit and voluntary organisations, based on Figure 7.1, this would imply that about 33.4 per cent of home support was provided by HSE staff ( 8.24 million hours); 8.4 per cent provided by voluntary organisations ( 2.06 million hours), and 58.3 per cent provided by for-profit organisations (14.4 million hours).

FIGURE 7.1 HOME SUPPORT FOR OLDER PERSONS: PROVISION BY HSE AND NON-HSE STAFF IN 2019

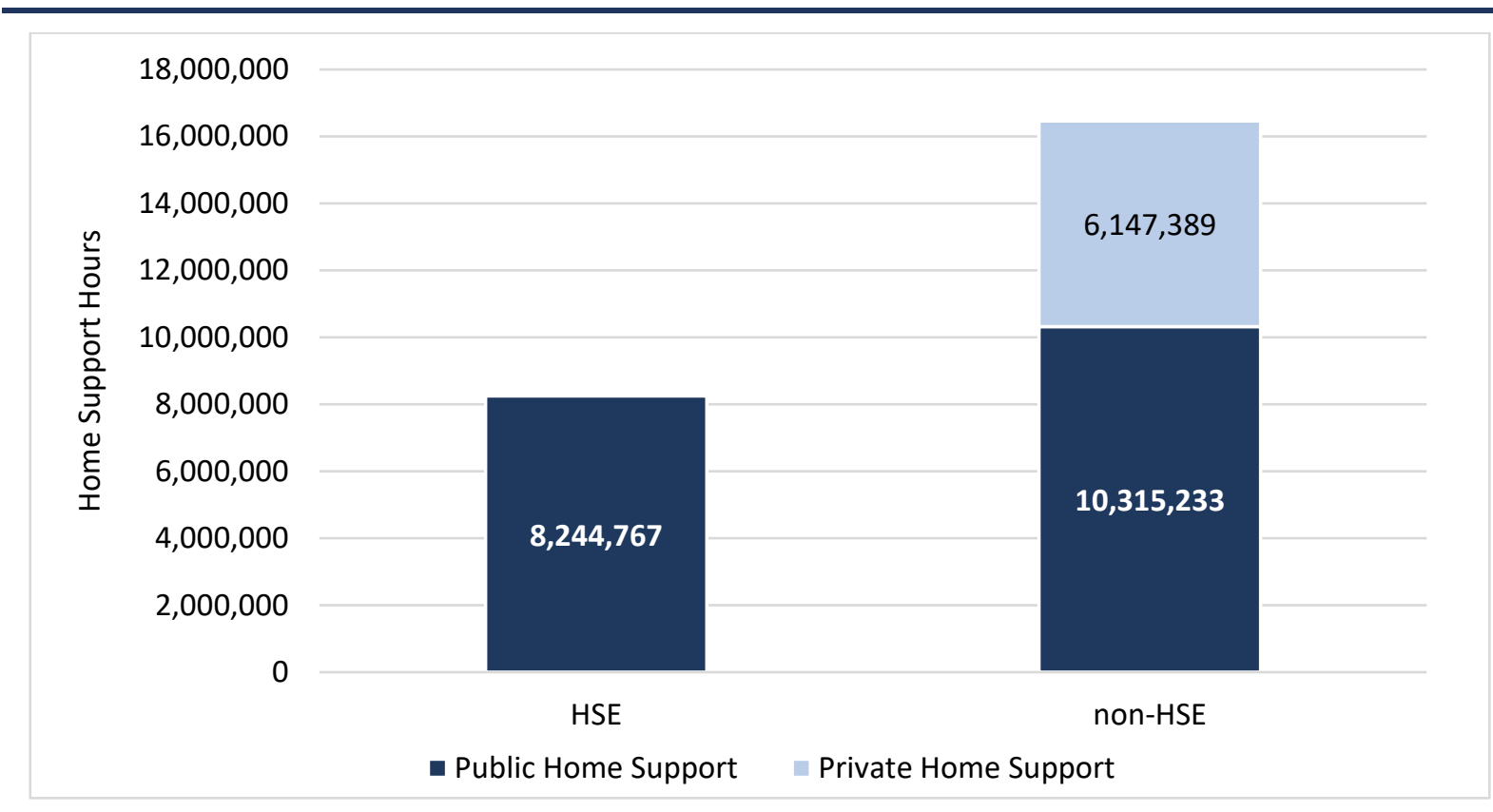

Source: HSE Social Care Division; analysis of TILDA Waves 2-4 Research Microdata File.

Notes: Non-HSE includes home support provided by voluntary organisations and for-profit organisations. Private home support estimated from TILDA data.

While most home support is provided by non-HSE staff, the share varies across regions in Ireland. While we do not have information on regional variation in private home support, Figure 7.2 illustrates the breakdown of public home support by HSE and non-HSE staff across regions in 2019. There is considerable variation in the percentage of home support provided by non-HSE staff, ranging from 11 per cent in South Tipperary to 100 per cent in Dublin, Clare, and Wicklow.

While it is likely that the bulk of non-HSE provided public home support is provided by for-profit organisations, we know that in some areas with a significant percentage of non-HSE provision, voluntary organisations are large contributors. Therefore, it is not necessarily the case that in regions with a large percentage of non-HSE public home support provision that for-profit organisations provide substantially more than voluntary organisations. For example, Clarecare, a 
voluntary organisation, provides most home support in county Clare. In addition, voluntary organisations provide a substantial number of hours in Dublin North, while the Alzheimer Society of Ireland provides public home support across regions. ${ }^{23}$ Nevertheless, in most regions where non-HSE provision is large, forprofit organisations are likely to be the main providers of public home support.

FIGURE 7.2 PUBLIC HOME SUPPORT FOR OLDER PERSONS BY LHO: PROVISION BY HSE AND NONHSE STAFF IN 2019

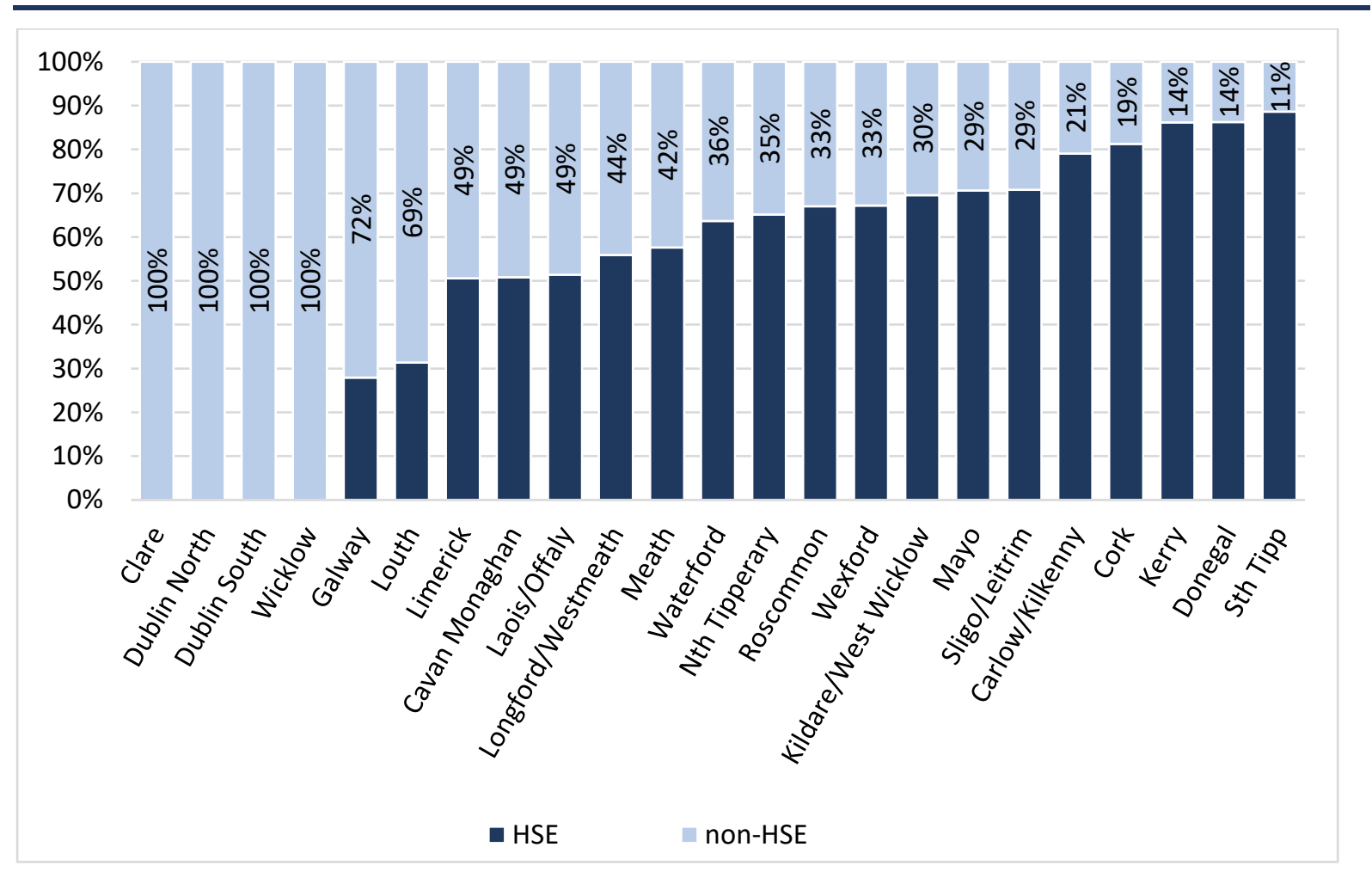

Source: HSE Social Care Division.

\subsubsection{For-profit organisations}

Mercille and O'Neill (2020) discuss the increasing role played by for-profit organisations in the home support sector in Ireland. In recent years, the State has increased spending on for-profit organisations to provide home support in Ireland. In 2006, only $€ 3$ million was spent on for-profit organisations. In 2019, this figure was $€ 176$ million (Mercille and O'Neill, 2020).

While the total number of for-profit organisations that provide home support in Ireland is not known, the $\mathrm{HCCl}$, the representative organisation for private home care organisations, state that 90 per cent of home support hours provided under

23 The 2017 HSE Social Care Division Operational Plan lists voluntary organisations and for-profit organisations that receive the most funding to provide services for the HSE's Social Care Older Peoples Division. https://www.hse.ie/eng/services/publications/serviceplans/service-plan-2017/operational-plans-2017/social-careoperational-plan-2017.pdf. 
the home support scheme by for-profit providers is provided by their members ( $\mathrm{HCCl}, 2019 a)$. These 70 members directly employ 14,000 carers. Many for-profit organisations in Ireland operate franchise arrangements. Therefore, while the $\mathrm{HCCl}$ represents 70 members, many members are franchisees of large providers, often independently owned. In a recent study of home support during COVID-19, it was found that five private providers (Home Instead, Bluebird Care, Comfort Keepers, Irish Homecare, and Caremark Ireland) were the main providers of care through the home support scheme. In 2019, these five providers received almost $€ 130$ million to provide public home support (Delaney, 2020).

The State relies heavily upon the for-profit sector to provide home support in Ireland. It is not clear at this stage how the introduction of a statutory scheme will affect the public-private mix of services. If the new scheme leads to an increased dependence on for-profit organisations to support its implementation, this change is likely to require significant work on planning, negotiation and regulation. There is relatively little information on how many carers are employed in for-profit organisations, the skills of these carers, and the scope to increase carer numbers. Privately purchased home support is not regulated in terms of who provides the support - and the quality of care provided - in the same manner as public home support.

\subsubsection{Voluntary organisations}

Even less is known about voluntary home support organisations than about forprofit home support organisations. While the voluntary sector was a key provider of home support in the past, in recent years the voluntary sector has provided a decreasing proportion of home support (Mercille and O'Neill, 2020). A significant change occurred in 2016, when all home support to be provided by non-HSE staff was switched to competitive tendering (Mercille and O'Neill, 2020). This means that voluntary organisations competed with for-profit organisations within the same tendering process. Previously these voluntary organisations were funded in part by Section 39 service agreements.

We are not aware of any comprehensive list of voluntary organisations providing home support in Ireland. However, in recent years, the HSE listed those organisations that were provided with more than $€ 1$ million per annum to provide social care, with many of these largely providing home support. ${ }^{24}$ The National Community Care Network (NCCN) is the representative body for many voluntary

24 For example, the HSE Social Care Operational Plan 2017 provides details on 30 voluntary organisations that received funding of at least $€ 1$ million through Services for Older People, at an overall cost of $€ 79.3$ million. Most of the organisations listed are home care (support) providers.

https://www.hse.ie/eng/services/publications/serviceplans/service-plan-2017/operational-plans-2017/social-careoperational-plan-2017.pdf. 
home support organisations in Ireland. It currently represents 22 non-profit home support organisations (Gov.ie, 2019).

\subsection{PROFESSIONAL CARERS}

The sustainability of home support in Ireland and the effectiveness of a new statutory scheme is dependent upon securing an adequate supply of carers with the skills required to meet the needs of their clients. These carers will work across the HSE, voluntary organisations, and for-profit organisations. The NCCN has stated that the recruitment of carers and their retention is 'undoubtedly the single biggest challenge for all providers' in the home care profession (NCCN, 2017). It is clear that significant increases in service provision such as in the scenarios outlined in Chapter 5 would require correspondingly large increases in the supply of hours provided by carers.

There is little published information on home carers in Ireland. Currently, outside of the HSE, little is known about home carers in Ireland, including the total number of carers employed. There is no central register of carers and little information is available on employees within voluntary and for-profit home care organisations. While carers employed by the HSE and voluntary organisations are commonly contracted, within for-profit organisations carers may not be salaried. Within forprofit organisations, carer pay is often tied to hours of care provided.

At present, there are no legal requirements for home carers or healthcare assistants outside of the public sector to have full formal training except under the HSE's tendering process (Conyard et al., 2020). Within the for-profit sector, it is unknown how many carers have Level 5 qualifications (Healthcare Support Assistant (General) - Major Award Level 5 or equivalent), and therefore may be best suited to meeting the needs of more complex recipients. In a recent survey of home carers in Ireland, 16 per cent reported not having full formal qualifications in caring, and only three-quarters of respondents reported having training in ADL and using these skills in practice (Conyard et al., 2020). Similarly, for patients with dementia or other cognitive impairment, it is essential that appropriate care can be identified and provided. Evidence shows that less than half of carers in Ireland have reported training in dementia care and using those skills in their job (Conyard et al., 2020).

As of October 2020, both HCAs and Health Care Support Assistants (HCSAs), formerly home helps, employed by the HSE earn salaries of between $€ 29,062$ (point 1 on salary scale) and $€ 37,600$ (point 9 on salary scale). ${ }^{25} \mathrm{HCAs}$ employed by 
voluntary organisations are assumed to receive similar salaries. However, until recently, many of the payment cuts that were enacted through various Financial Emergency Measures in the Public Interest (FEMPI) Acts, were enforced for longer periods for voluntary sector staff. To provide an insight into private home carer salaries in Ireland, we examined 'healthcare assistant' job advertisements on the Indeed job search engine. The advertised salaries for July-August 2020 ranged from $€ 11$ to $€ 14$ per hour, or $€ 22,308$ to $€ 28,392$ per annum (Indeed, 2020). This figure corresponds to other evidence highlighting carers payment of approximately $€ 12$ per hour (Delaney, 2020), and a 2019 submission by the $\mathrm{HCCl}$ to the Oireachtas Joint Committee on Business, Enterprise and Innovation of average reported hourly rate for a $\mathrm{HCA}$ employed by a $\mathrm{HCCl}$ member as $€ 12.14$, with ranges from $€ 10.60$ to $€ 17.00$ per hour ( $\mathrm{HCCl}, 2019 b)$.

\subsubsection{Information on professional carers}

Ireland does not have a comprehensive, up-to-date source of data on the demography, employment, experience and skills of care staff. The lack of this type of data makes it difficult to estimate the numbers of carers employed, with up-todate training or particular skills, which makes workforce planning difficult (HSE, 2018). As an example of what is possible, the Adult Social Care (ASC) Workforce database ${ }^{26}$ in England (previously called the National Minimum Data Set for Social Care) is an online database that collects and collates workforce information for the adult social care sector. This database includes information from NHS-employed, local authority-employed, voluntary sector-employed, and privately employed workers. It is a good example of how data from both public and private organisations can be collated and subsequently used to understand and plan the social care sector. A database with similar coverage in Ireland would be of value not only to policymakers, but also to employers and carers themselves. As care for older people becomes more centred around peoples' homes and communities, the complexity of care will increase, and the challenges associated with assembling data on carers from disparate sources will become even greater.

There are essentially two ways to collect data of this kind: by maintaining a centralised source of administrative data on care staff, e.g. a carer's register, or conducting regular sample surveys with sufficient scale, granularity and representativeness to cover the full sector. The authors of this report are not aware of any plans to enact registration of carers in the context of the new statutory home support scheme. A 2018 HSE report highlighted the benefits of a potential registration body for home carers (HSE, 2018), but the appropriate form of regulation for care staff in Ireland is beyond the scope of this report. If carer registration were to be introduced in the longer term, maintaining a high-quality register and making the data in it available to stakeholders could facilitate 
workforce planning and help identify gaps in knowledge and skills. In the absence of an administrative data source, it is worth considering use of sample surveys to improve the data available on carers.

\subsubsection{Profile of professional carers in Ireland}

This section provides a short profile of carers in Ireland using information available from various sources.

Table 7.1 provides information on 'patient and client' carers employed by the HSE Social Care Division to provide care to older people in the community in December 2019. Overall, there were 5,703 carers employed by the HSE in December 2019 to provide care to older people in the community who we categorise as home carers. The majority of carers $(5,313)$ were defined as healthcare support assistants (HCSAs - previously called home helps), with a small number being other types of carers such as healthcare assistants (HCAs). There were overall 3,755 carer WTEs, with 3,444 WTEs beings HCSAs. Across all types of carer, the vast majority of WTEs were female ( 96.5 per cent) highlighting that this is a sector that is heavily dependent on the female workforce.

TABLE 7.1 PROFILE OF HSE SOCIAL CARE DIVISION OLDER PEOPLES CARE (COMMUNITY) EMPLOYED CARERS, DECEMBER 2019

\begin{tabular}{|c|c|c|c|c|}
\hline & WTE & Headcount & $\begin{array}{l}\text { Headcount: } \\
\text { WTE Ratio }\end{array}$ & $\%$ Female \\
\hline Healthcare Assistants & 216 & 286 & 1.32 & 92.7 \\
\hline $\begin{array}{l}\text { Healthcare Support Assistants } \\
\text { (previously Home Helps) }\end{array}$ & 3,444 & 5,313 & 1.54 & 96.9 \\
\hline Other carers & 95 & 104 & 1.10 & 83.7 \\
\hline Overall Patient \& Client Carers & 3,755 & 5,703 & 1.52 & 96.5 \\
\hline
\end{tabular}

Sources: $\quad$ Health Service Personnel Census December 2019.

Notes: $\quad$ WTE $=$ Whole Time Equivalents. Headcount is the total number of workers. These data do not include carers employed in HSE residential care facilities.

There is less information available on carers working in voluntary organisations and for-profit organisations. We do not try and estimate privately employed carer numbers in this report due to gaps in coverage and questions surrounding the reliability of data that are available. First, no information is available about carers working within voluntary organisations. Second, while there is some information on carer numbers in for-profit organisations from the $\mathrm{HCCl}$, there are questions about its reliability, especially in terms of carer WTE. According to the $\mathrm{HCCl}$ there are approximately 14,000 workers across its member organisations, and 4,553 WTEs (compared to 3,755 HSE employed WTEs). The implied low ratio of WTEs to workers makes us uncertain about what these estimates are measuring. The low ratio is likely driven, in part, by carers working across multiple organisations. In England, where there is a centralised carer database, there are 129 jobs per 100 
headcount, with many carers holding more than one job (Skills For Care, 2020). Therefore, the headcount numbers may also be skewed by as much as a third (based on the English evidence) if carers are double-counted as they work across different organisations.

There is also very little information about the socio-demographic characteristics of carers. In March 2020, researchers from UCD in collaboration with HCA and Carers Ireland provided an analysis of qualified carers and healthcare assistants (Conyard et al., 2020). The analysis examined the function, wellbeing, and satisfaction of carers in Ireland, and surveyed almost 2,000 carers. The report found that 16 per cent of carers had no professional caring qualification and over half had no training in dementia care (Conyard et al., 2020). The Conyard et al. (2020) analysis found that the vast majority of carers reported at least average satisfaction with their career. Recent analysis has highlighted that amongst all workers in Ireland, those in the caring professions had amongst the highest risk to COVID-19 (Walsh et al., 2020b).

In order to provide further detail on carers in Ireland, we analysed the Healthy Ireland Survey (HIS), Waves 1-4. Carers were defined as those with an occupation as a 'care worker or home carer' who cared for people in residential facilities or in their own home. Therefore, this sample of carers will include those who work in residential care facilities. Table 7.2 provides demographic information on carers $(\mathrm{N}=513)$ in Ireland and compares carers to nurses and all other healthcare workers. Carers are predominantly female (84.8 per cent, less than HSE-employed carers in Table 7.1), though less so than nurses. Carers tend to be slightly older on average than nurses. Almost 22 per cent of carers were born outside of Ireland, slightly less than nurses. A high percentage of carers live in the most deprived areas, concentrated in these areas to a much greater extent than nurses are. Lower average incomes and educational attainment among carers compared to other healthcare workers may explain the higher share living in deprived areas. Previous research using the HIS found that, compared to other occupational groups in Ireland, the caring profession has amongst the highest percentage of workers living in the most deprived quintile of areas (i.e. the most deprived 20 per cent) (Walsh et al., 2020b). Over 36 per cent of carers live in rural areas. While almost half of carers have a Medical Card, only 30 per cent have private health insurance, less than half the rate of nurses and other healthcare workers. 


\section{TABLE 7.2 SOCIO-DEMOGRAPHIC CHARACTERISTICS OF CARERS, NURSES AND OTHER HEALTHCARE WORKERS IN IRELAND}

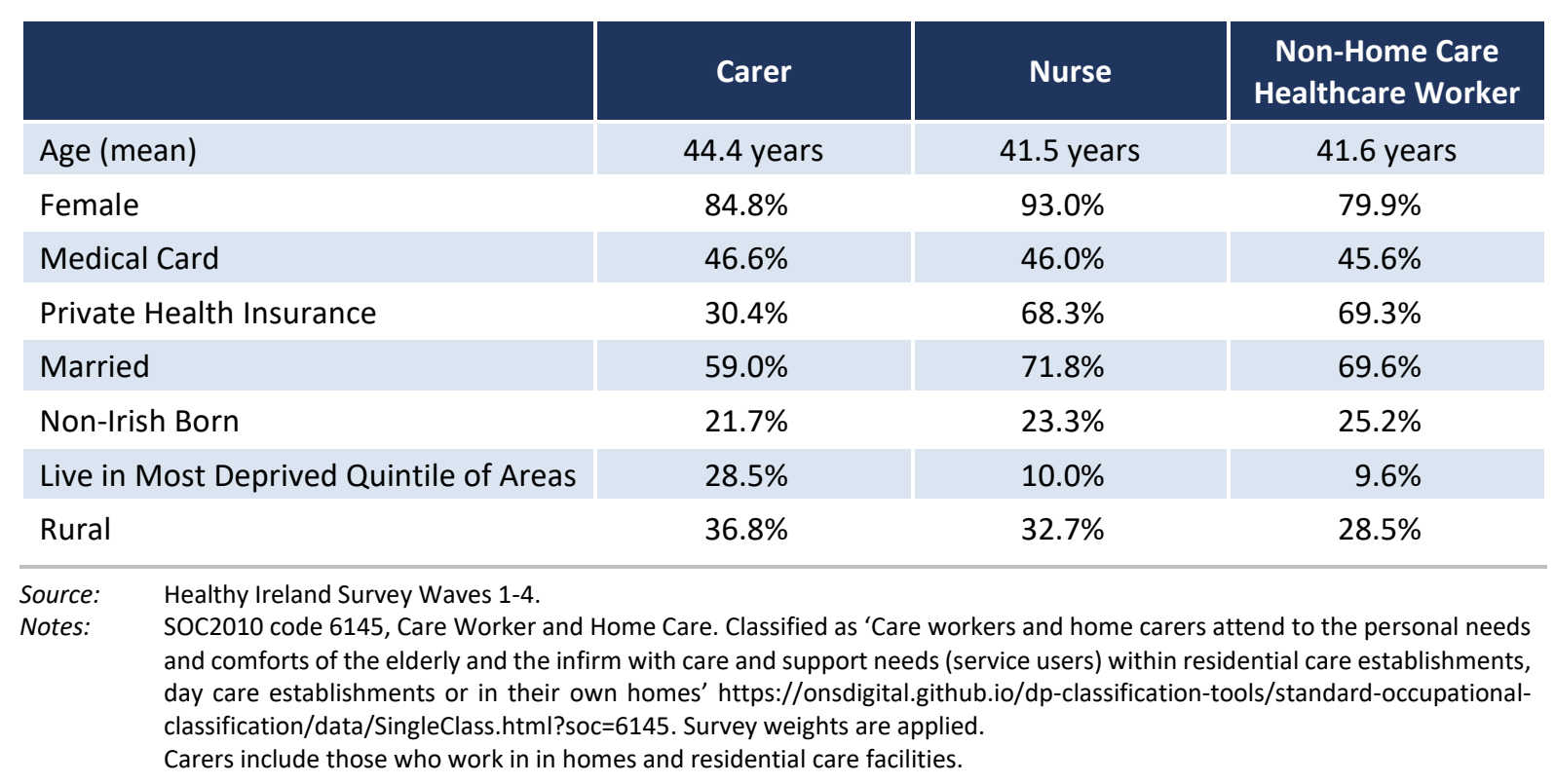

In summary, relatively little is known in Ireland about numbers of carers, their socioeconomic characteristics, their working conditions, or their skillsets. Even the most basic information such as the number of carers that provide care through the public home support scheme is not known. Improved collection of data on carers could assist the future development and evaluation of home support services. 



\section{CHAPTER 8}

\section{Conclusions}

\subsection{INTRODUCTION}

A new statutory home support scheme was proposed in the 2017 Sláintecare report (Houses of the Oireachtas Committee on the Future of Healthcare, 2017), and was included in the 2020 'Programme for Government' document (Department of the Taoiseach, 2020). This report simulates the potential service demand amongst the older population that may arise under a planned statutory home support scheme. Four scenarios are included, starting with baseline estimates of actual activity in 2019 and successively extending the possible sources of additional demand for public home support. The report also discusses a range of factors likely to impact demand and supply of home support, provides a profile of home support recipients, and includes brief overviews of home support supply arrangements and the data available on home carers in Ireland.

The report sets out a baseline scenario that can be compared with subsequent scenarios describing possible effects of introducing a statutory scheme. The baseline represents estimated demand for home support amongst the population of Ireland aged 65+ in 2019. The report then examines three policy scenarios focusing on different channels through which demand is likely to change. The scenarios are assembled in an additive manner. In the next sub-section we summarise the simulation results for each scenario.

\subsubsection{Baseline scenario}

Table 8.1 presents the estimated home support demand in Ireland in 2019 ('Scenario 1'). There were 65,246 people aged 65+ in receipt of home support in 2019. In total, 53,417 people were in receipt of public home support, and 235 people received an iHCP. Of these, an estimated 14,230 public home support recipients also purchased private home support. We estimate that over 11,500 people purchased private home support only. An estimated 24.7 million home support hours were received across public and private home support in 2019. Of these, the majority were provided through the public home support (18.2 million hours) or iHCP (0.36 million hours) schemes. An estimated 6.1 million hours, or 24.9 per cent of all home support received, were privately purchased. This finding is similar to previous research examining home support in Ireland (Wren et al., 2017). 
There were 5,436 people were on the waiting list for any public home support in December 2019. ${ }^{27}$ Assuming those on a waiting list receive average home support hours, we estimate a 'demand' for an additional 1.5 million hours in 2019. Finally taking delayed transfers of care into account $(39,000$ hours required to allow for earlier discharge home) the overall estimated baseline of home support demanded in 2019 was just over 26.2 million hours.

TABLE 8.1 BASELINE ESTIMATION (SCENARIO 1): RECIPIENTS AND HOME SUPPORT HOURS: AGES 65+

\begin{tabular}{|l|r|r|}
\hline & Recipients & \multicolumn{1}{c}{ Hours } \\
\hline Public home support scheme & 53,417 & $18,200,000$ \\
\hline Public Intensive Home Care Packages & 235 & 360,000 \\
\hline Public Home Support total & $\mathbf{5 3 , 6 5 2}$ & $\underline{\mathbf{1 8 , 5 6 0 , 0 0 0}}$ \\
\hline Private Home Support $^{\mathrm{a}}$ & 11,594 & $\mathbf{6 , 1 4 7 , 4 0 0}$ \\
\hline Total care delivered in Ireland in 2019 & $\underline{\mathbf{2 4 , 7 0 7 , 4 0 0}}$ \\
\hline Public Home Support Waiting List & 5,436 & $\mathbf{1 , 5 1 2 , 9 0 0}$ \\
\hline Delayed Transfers of Care (public hospitals) & & 39,300 \\
\hline Scenario 1 Total & $\underline{\mathbf{7 0 , 7 0 0}}$ & $\underline{\mathbf{2 6 , 2 5 9 , 5 0 0}}$ \\
\hline
\end{tabular}

Source: $\quad$ HSE Social Care Division; Analysis of TILDA Waves 2-4 Research Microdata File.

Notes: $\quad$ a Recipients includes 'private-only'. Hours includes privately purchased hours for private-only and public \& private recipients. $b$ The number of recipients affected by delayed transfers of care (from public hospitals) is already counted in the public home support scheme.

Further examining public and private home support utilisation presented in Table 8.1, the results in Figure 8.1 present a breakdown of home support use (public or private) across age groups for males and females. There is a clear age gradient in home support utilisation. Results from Wren et al. (2017) find a similar gradient across age. Home support use is also consistently higher amongst females, especially at the oldest ages. Over 50 per cent of females aged $90+$ residing at home are in receipt of home support compared to 38 per cent of males. 


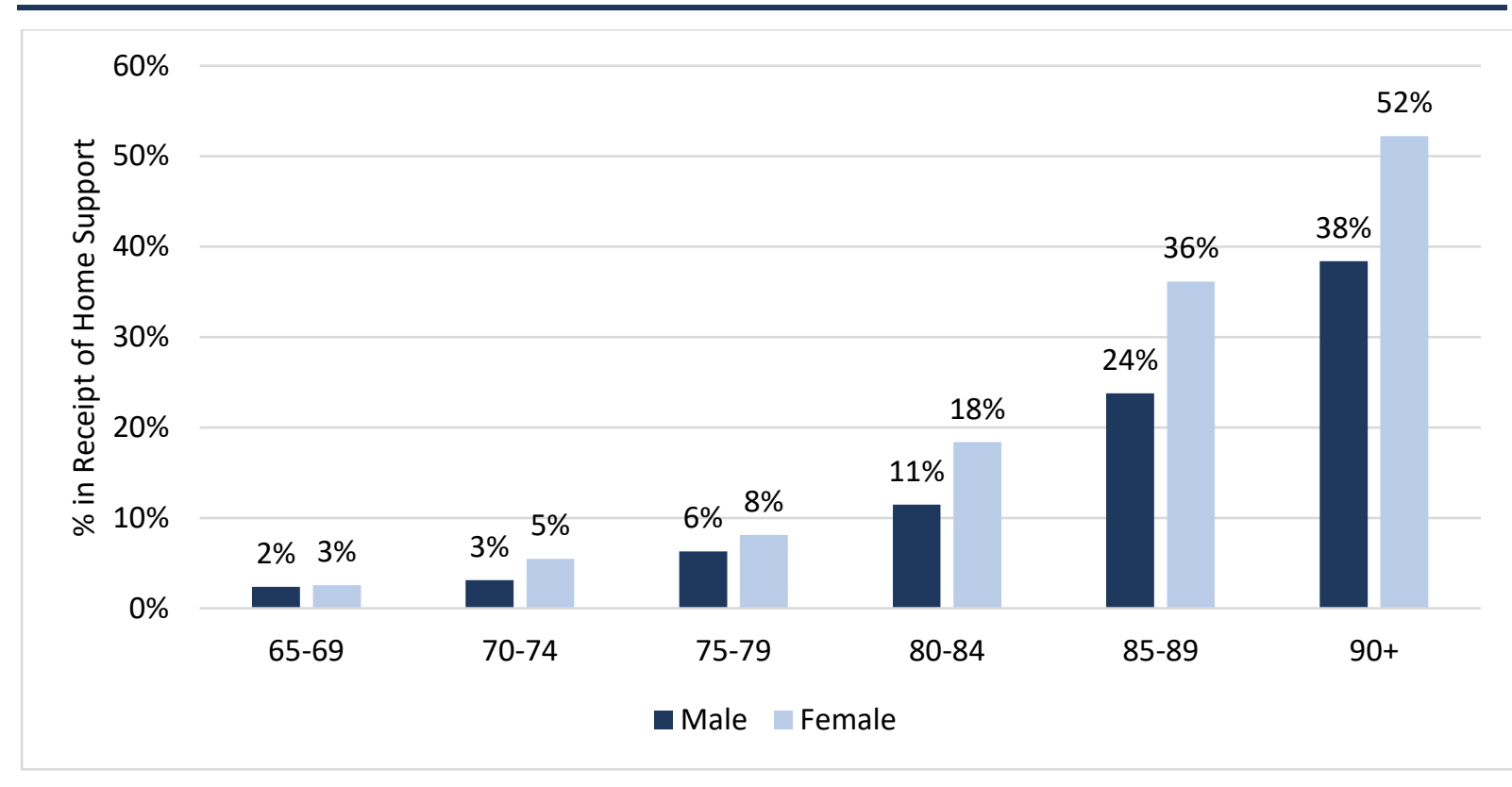

Source: $\quad$ HSE Social Care Division; Analysis of TILDA Waves 2-4 Research Microdata File.

Notes: Includes: Home Help, Home Care Packages, and Personal Care Attendant. Survey weights applied.

\subsubsection{Demand scenarios}

We modelled three additional demand scenarios for a statutory scheme based upon evidence discussed in Chapter 4 and Winter Plan 2020/21. Each of the three scenarios (Scenarios 2 to 4 ) was based upon the baseline scenario with additional assumptions included in an additive manner thereafter.

- Scenario 2 - Increased Hours for Recipients

This scenario modelled increases in home support hours to be provided to those currently in receipt of home support. This scenario also assumed that all home support that was privately purchased prior to the introduction of a statutory scheme would be publicly provided in future.

- Scenario 3 -Substitution for Long-Term Residential Care

This scenario modelled the impact of reducing by half the number of home support recipients previously leaving home support and being admitted into LTRC homes. A key assumption of this scenario is that all those individuals (2,137 in 2019) no longer being admitted into LTRC would instead receive an iHCP of 52 hours per week.

\section{- Scenario 4 - Expansion of Demand in Community}

This scenario modelled the impact of meeting greater demand from people living at home but who had not yet demanded professional home support. This is modelled by assuming that the probability of home support being provided to those with a d-ADL increases by 50 per cent. 
Table 8.2 and Table 8.3 illustrate the potential demand across the scenarios discussed above. In terms of recipients, while an estimated 65,246 people were in receipt of home support in 2019 under the current system, our simulations indicate that this could have been as high as almost 84,000 recipients when all scenarios are modelled. This equates to an increase of 28.7 per cent in recipient numbers. As all these recipients would be covered by the proposed statutory scheme, this increase in recipients equates to a 54.4 per cent increase in recipients receiving funding through the public system. Currently we estimate that 9.7 per cent of those aged 65 years and older living at home are in receipt of home support. This would increase to 12.5 per cent under the highest level simulated.

Our simulations indicate that larger proportional increases in demand could be seen for home support hours. An estimated 24.7 million hours were provided in 2019 in the current system across public and private home support. Our simulations indicate that this could rise to almost 42 million hours under the demand projection scenarios modelled. This equates to an increase of 70 per cent of hours (17.2 million hours). If all hours were provided through a statutory home support scheme, this increase would equate to a 126 per cent increase in hours (23.4 million hours) delivered through a public home support scheme.

Across the demand scenarios modelled, Scenario 3 (Substitution for Long-Term Residential Care) and Scenario 4 (Expansion of Demand in the Community) have the largest impact on increased projected demand for home support hours.

TABLE 8.2 ESTIMATED AND SIMULATED DEMAND FOR HOME SUPPORT ACROSS SCENARIOS RECIPIENTS: AGES 65+

\begin{tabular}{|c|c|c|c|c|}
\hline & $\begin{array}{c}\text { Baseline } \\
\text { Estimation } \\
\text { (Scenario 1) }\end{array}$ & Scenario 2 & Scenario 3 & Scenario 4 \\
\hline Public home support scheme & 53,417 & 53,417 & 53,417 & 53,417 \\
\hline Public Intensive Home Care Packages & 235 & 235 & 235 & 235 \\
\hline Reductions in Admissions to LTRC & & & $\underline{2,137}$ & 2,566 \\
\hline $\begin{array}{l}50 \% \text { increase in Pop with d-ADLs } \\
\text { demanding care }\end{array}$ & & & & $\underline{10,700}$ \\
\hline Total public home support delivered & 53,652 & & & \\
\hline Private Home Support ${ }^{\mathrm{a}}$ & 11,594 & & & \\
\hline $\begin{array}{l}\text { Home support moved from private to } \\
\text { public }^{b}\end{array}$ & & $\underline{11,594}$ & 11,594 & 11,594 \\
\hline Total home support delivered & 65,246 & 65,246 & 67,383 & 78,558 \\
\hline Public Home Support Waiting List & 5,436 & 5,436 & 5,436 & 5,436 \\
\hline Scenario Total ${ }^{\mathrm{C}}$ & $\underline{70,700}$ & $\underline{70,700}$ & $\underline{72,800}$ & $\underline{84,000}$ \\
\hline
\end{tabular}

Source: HSE Social Care Division; Analysis of TILDA Waves 2-4 Research Microdata File.

Notes: $\quad$ a Recipients includes 'private-only'. Hours includes privately purchased hours for private-only and public $\&$ private recipients. b All private home support now assumed to be covered by the statutory scheme.

c Delayed Transfers of Care (public hospitals) recipients captured in public home support scheme recipient numbers.

$\mathrm{d}-\mathrm{ADL}=$ difficulties with activities of daily living. 
TABLE 8.3 ESTIMATED AND SIMULATED DEMAND FOR HOME SUPPORT ACROSS SCENARIOS HOURS: AGES 65+

\begin{tabular}{|c|c|c|c|c|}
\hline & $\begin{array}{c}\text { Baseline } \\
\text { Estimation } \\
\text { (Scenario 1) }\end{array}$ & Scenario 2 & Scenario 3 & Scenario 4 \\
\hline Public home support scheme & $18,200,000$ & $20,895,600$ & $20,895,600$ & $20,895,600$ \\
\hline Public Intensive Home Care Packages & 360,000 & 360,000 & 360,000 & 360,000 \\
\hline Reductions in Admissions to LTRC & & & $\underline{4,222,700}$ & $5,070,400$ \\
\hline $\begin{array}{l}50 \% \text { increase in Pop with d-ADLs } \\
\text { demanding care }\end{array}$ & & & & $\underline{5,259,400}$ \\
\hline Total public home support delivered & $18,560,000$ & & & \\
\hline Private Home Support ${ }^{a}$ & $6,147,400$ & & & \\
\hline $\begin{array}{l}\text { Home support moved from private to } \\
\text { public }^{b}\end{array}$ & & $\underline{6,762,100}$ & $6,762,100$ & $8,630,200$ \\
\hline Total public home support delivered & $24,707,400$ & $28,017,700$ & $32,240,400$ & $40,215,500$ \\
\hline Public Home Support Waiting List & $1,512,900$ & $1,664,100$ & $1,664,100$ & $1,664,100$ \\
\hline Delayed Transfers of Care (public hospitals) & 39,300 & 39,300 & 39,300 & 39,300 \\
\hline Scenario Total & $\underline{26,259,500}$ & $\underline{29,721,100}$ & $\underline{33,943,800}$ & $\underline{41,918,900}$ \\
\hline $\begin{array}{l}\text { HSE Social Care Division; Analysis of TILDA W } \\
\text { a Recipients includes 'private-only'. Hours inc } \\
\text { b All private home support now assumed to } \\
\text { d-ADL = difficulties with activities of daily livi }\end{array}$ & $\begin{array}{l}\text { S } 2-4 \text { Research } N \\
\text { es privately purc } \\
\text { overed by the st }\end{array}$ & $\begin{array}{l}\text { data File. } \\
\text { ed hours for pr } \\
\text { ory scheme. }\end{array}$ & only and public & vate recipients. \\
\hline
\end{tabular}

\subsection{DEMAND FOR HEALTHCARE AND SOCIAL CARE SUPPORTS}

While establishing a statutory scheme and changing the model of care to keep people at home could lead to a large potential increase in demand for home support, there will also likely be increased demand for other healthcare and social care services, and especially for unpaid care. The effectiveness of the new scheme will be determined in large part by the ability of the wider healthcare and social care environment to meet the often complex and diverse needs of those receiving home support.

Chapter 6 examined the characteristics of current home support recipients, and how they differ from the older population not in receipt of professional home support. In general, home support recipients were older and had higher healthcare and social care needs (and healthcare utilisation). This means that the impact of introducing a new statutory scheme with expanded demand for the service may also include increased demand for healthcare and social care, especially for those who have substituted away from LTRC.

Table 8.4 provides descriptive statistics on average use of healthcare and social care among home support recipients and non-recipients in the older population. Across all services examined, individuals in receipt of home support have higher utilisation. The largest difference is seen for allied health professional services including public health nurses, occupational therapists, day centre care, and convalescent care. 
TABLE 8.4 HEALTHCARE AND SOCIAL CARE SERVICE UTILISATION IN THE PREVIOUS 12 MONTHS: AGES 65+

\begin{tabular}{|l|c|c|}
\hline & Home Support Recipient \% & No Home Support \% \\
\hline 5+ GP Visits & 83.8 & 74.4 \\
\hline Inpatient Stay & 21.6 & 13.0 \\
\hline Public Health Nurse Visit & 35.3 & 4.9 \\
\hline Occupational Therapist Visit & 8.6 & $<1$ \\
\hline Physiotherapist Visit & 14.8 & 5.2 \\
\hline Day Centre & 9.2 & 1.8 \\
\hline Respite Care & 3.3 & $<1$ \\
\hline Convalescent Care & 10.1 & 1.6 \\
\hline
\end{tabular}

Source: $\quad$ Analysis of TILDA Waves 2-4 Research Microdata File.

Notes: $\quad$ Home Support includes: Home Help, Home Care Packages, and Personal Care Attendant. Survey weights applied.

It also is possible that additional home support will reduce demand for healthcare and social care services for some individuals, since some basic aspects of care can be provided in their own home. However, for many people, the expansion of service provision associated with the introduction of a statutory scheme will involve additional demand for healthcare and social care services in the community. For example, where home support is expanded to reduce admission to LTRC, as stated in our discussion of Scenario 3, and as highlighted by Carter et al. (2019), additional healthcare and social care support would also be required, and tailored, to the needs of recipients. We also show in Table 8.4 that home support recipients have much higher use of public health nurses, occupational therapists and day centre care. There is scope to do further research examining how the planned statutory home support scheme might affect demand for other healthcare and social care services.

\subsection{WHO WILL PROVIDE THE CARE?}

The success of a new statutory scheme will be determined by the ability of the scheme to meet the demands of the home support recipients in an efficient and equitable manner. Demand is likely to grow considerably due to the introduction of the statutory scheme and the effects of demographic change. If supply of services does not keep pace, there are likely to be further extensions in waiting lists for care, diversion of demand to private provision and some non-provision or substitution by alternatives such as LTRC and acute hospital care. The ability to meet demand in a timely way could be the greatest challenge to implementation.

Home support in Ireland is provided by a mixture of the HSE, voluntary organisations, and for-profit organisations. In Chapter 7, we noted that the bulk of home support in Ireland is provided by for-profit organisations. Table 8.5 presents the estimated number of hours provided by HSE staff, the voluntary sector, and for-profit organisations in 2019. Overall, the report estimated that approximately 33.4 per cent of total (public and private) home support in 2019 was provided by HSE staff ( 8.24 million hours), 8.4 per cent was provided by the voluntary sector 
(2.06 million hours), and 58.3 per cent provided by for-profit organisations (14.4 million hours).

TABLE 8.5 ESTIMATED HOME SUPPORT HOURS (MILLIONS) FOR OLDER PERSONS PROVISION BY HSE, VOLUNTARY, AND FOR-PROFIT STAFF IN 2019

\begin{tabular}{l|c|c|c|c}
\hline & \multicolumn{1}{c}{ HSE } & Voluntary & For-Profit & All \\
\hline Public Home Support & 8.24 million & 2.06 million & 8.25 million & \\
\hline $\begin{array}{l}\text { Private Home Support } \\
\text { Total Home Support }\end{array}$ & - & - & 6.15 million & \\
\hline $\begin{array}{l}\text { Source: } \\
\text { Notes: }\end{array}$ & $\begin{array}{l}\text { HSE Social Care Division; Analysis of TILDA Waves 2-4 Research Microdata File. } \\
\text { Non-HSE includes home support provided by voluntary organisations and for-profit organisations. Voluntary:For-Profit split } \\
\text { assumed as 4:1 (Mercille and O'Neill, 2020) }\end{array}$
\end{tabular}

It is not clear at this stage how the introduction of the new statutory scheme will affect the public-private mix of services. If there is an increased dependence on for-profit organisations to support the implementation of the new scheme, this is likely to require significant work on planning by the HSE, voluntary organisations and for-profit organisations to hire new staff. Furthermore, to better help tailor services to home support recipients, specific training may be needed to ensure the skill mix of carers matches the needs of the recipient population.

In Chapter 7, the report provides a short overview of what is known about carers in Ireland. The majority of HSE employed home carers are HCSAs (formally home helps) with 96 per cent being female. There is relatively little information on how many carers are employed in voluntary organisations and for-profit organisations, the skills of these carers, and the scope to increase carer numbers. Information on carers employed in voluntary organisations is even more limited. Collection of comprehensive and up-to-date data on carers in Ireland, for example through a carer register or regular large-scale surveys, would be of assistance to policymakers, employers, carers, and home support recipients.

\subsection{RELATED STUDIES AND AVENUES FOR FUTURE RESEARCH}

The focus of this report was on potential demand implications of introducing a statutory home support scheme in Ireland. While our demand scenarios are based upon a hypothetical scheme, the final parameters of the scheme may have material effects on the level and pattern of demand that will be observed in practice. It may be useful to revisit these scenarios and provide updated simulations once the final parameters of the scheme are known.

Further research is planned at the ESRI on the potential cost implications of, and financing options for, a statutory home support scheme. The Tax, Welfare and Pensions team at the ESRI will carry out a micro-simulation analysis using the ESRI SWITCH model to examine the implications of potential funding mechanisms (e.g. Exchequer funding, co-payments, asset-testing) for the allocation of costs, 
distributional effects and demand for services. This report is planned for later in 2021. A third planned report will project the costs of home support in Ireland in the longer term, as part of a wider analysis of primary, community, and long-term care in Ireland. This report should also be completed in 2021.

Another area where it would be useful to do further research concerns the extent to which home support acts as a substitute or complement for other healthcare and social care services. A statutory home support scheme could have significant effects on the model of care for older people in particular. A home support scheme that permits many more people to remain at home for longer and receive the required care and support at home or in their local community could also help reduce the demand on acute hospitals and LTRC facilities. Demand Scenario 3 in this report modelled the implications of substituting LTRC with home support for some individuals. To the extent that this sort of substitution is practicable, it would reduce LTRC utilisation. However, appropriate home support services and broader healthcare and social care supports need to be in place to allow this substitution to occur (Carter et al., 2019). Similarly, previous ESRI research has found that better access to home support reduces long lengths of stay in hospital (Walsh et al., 2020a). Further examination might be useful of the scale and pattern of substitution effects and the system-wide implications of these effects as home support services are strengthened in Ireland.

As we highlight in this report, demand for home support is likely to increase with the introduction of a statutory home support scheme. Therefore, corresponding increases in home support workforce will be required to meet this demand. Recently the ESRI, HSE and Department of Health began work to prepare national and regional projections of healthcare workforce requirements. This research should help provide a forward-looking perspective on the analysis of workforce requirements, allow regional differences to be examined and facilitate analysis of how workforce needs will change as the reform agenda progresses.

Although the present report focused on demand for home support among the older population, we understand that the new scheme may extend to adults of all ages (see Box 1.1) including the population living with a disability. It is imperative future research examines this population, but currently such research is difficult due to data limitations (Brick et al., 2020). The recent introduction of the National Ability Supports System (NASS), ${ }^{28}$ collected by the HRB, should improve the quality of information gathered about use of disability services in Ireland. These data could be used to inform analysis of demand for home support and other important support services among the population living with a disability, such as personal assistance services. 


\section{REFERENCES}

Aspell, N., M. O'Sullivan, E. O'Shea, K. Irving, C. Duffy, R. Gorman and A. Warters (2019). 'Predicting admission to long-term care and mortality among community-based, dependent older people in Ireland', Int J Geriatr Psychiatry, 34(7): 999-1007. 10.1002/gps.5101.

Baicker, K., W.J. Congdon and S. Mullainathan (2012). 'Health insurance coverage and take-up: lessons from behavioral economics', The Milbank Quarterly, 90(1): 107 134. 10.1111/j.1468-0009.2011.00656.x.

Baicker, K., S.L. Taubman, H.L. Allen, M. Bernstein, J.H. Gruber, J.P. Newhouse, E.C. Schneider, B.J. Wright, A.M. Zaslavsky and A.N. Finkelstein (2013). 'The Oregon Experiment - Effects of Medicaid on Clinical Outcomes', New England Journal of Medicine, 368(18): 1713-1722. 10.1056/NEJMsa1212321.

Bakx, P., B. Wouterse, E. van Doorslaer and A. Wong (2020). 'Better off at home? Effects of nursing home eligibility on costs, hospitalizations and survival', Journal of Health Economics, 73: 102354. https://doi.org/10.1016/j.jhealeco.2020.102354.

Brick, A. and C. Keegan (2020). 'Paying more to wait less: Estimating the cost of reducing Ireland's public hospital waiting lists', Economic and Social Research Institute Working Paper 688, https://www.esri.ie/publications/paying-more-to-wait-lessestimating-the-cost-of-reducing-irelands-public-hospital.

Brick, A., C. Keegan and M.A. Wren (2020). Utilisation of Specialist Disability Services in Ireland - Baseline Analysis for the Hippocrates Model. Survey and Statistical Report Series Number 89. Economic and Social Research Institute, Dublin, https://doi.org/10.26504/sustat89.

Brick, A., A. Nolan, J. O'Reilly and S. Smith (2010). Resource allocation, financing and sustainability in health care. Evidence for the Expert Group on Resource Allocation and Financing in the Health Sector, Vol. I, Dublin: Department of Health and Economic and Social Research Institute, http://www.esri.ie/publications/resource-allocation-financing-andsustainabilityin-health-care-evidence-for-the-expert-group-on-resourceallocation-andfinancing-in-the-health-sector-vols-1-and-2/.

Care Alliance Ireland (2018). 'Briefing Paper 2: Public Provision of Home Care in Ireland Update'. Care Alliance Ireland, http://www.carealliance.ie/userfiles/file/Briefing\%20Paper\%202\%20Web.pdf.

Carers Week (2020). 'The rise in the number of unpaid carers during the coronavirus (COVID-19) outbreak'. https://www.carersweek.org/images/CW\%202020\%20Research\%20Report\%20 WEB.pdf.

Carter, L., S. O'Neill, F. Keogh, M. Pierce and E. O'Shea (2019). 'Intensive home care supports, informal care and private provision for people with dementia in Ireland', Dementia (London), 1471301219863580. 10.1177/1471301219863580.

Carter, L., S. O'Neill, P.C. Austin, F. Keogh, M. Pierce and E. O'Shea (2020). 'Admission to long-stay residential care and mortality among people with and without dementia living at home but on the boundary of residential care: a competing risks survival analysis', Aging \& Mental Health, 1-8. 10.1080/13607863.2020.1857698. 
Coe, N.B. and C.H. Van Houtven (2009). 'Caring for mom and neglecting yourself? The health effects of caring for an elderly parent', Health Economics, 18(9): 991-1010. 10.1002/hec.1512.

Collins, D. (2019). 'Social Impact Assessment Series Nursing Home Support Scheme (NHSS)'. IGEES, https://igees.gov.ie/wp-content/uploads/2019/10/NursingHome-Support-Scheme-NHSS.pdf.

Comas-Herrera, A., J. Zalakaín, E. Lemmon, D. Henderson, C. Litwin, A.T. Hsu, A.E. Schmidt, G. Arling and J.-L. Fernández (2020a). 'Mortality associated with COVID19 in care homes: international evidence'. LTCcovid.org, CPEC-LSE, https://ltccovid.org/wp-content/uploads/2021/02/Mortality-associated-withCOVID-among-people-living-in-care-homes-14-October-2020.pdf.

Comas-Herrera, A., J. Zalakaín, C. Litwin, A.T. Hsu, E. Lemmon, D. Henderson and J.-L. Fernández (2020b). 'Mortality associated with COVID-19 outbreaks in care homes: early international evidence'. LTCcovid, CPEC-LSE, https://ltccovid.org/wp-content/uploads/2020/06/Mortality-associatedwithCOVID-among-people-who-use-long-term-care-26-June-1.pdf.

Comas-Herrera, A., J. Zalakaín, E. Lemmon, D. Henderson, C. Litwin, A.T. Hsu, A.E. Schmidt, A. G., F.M. Kruse and J.-L. Fernández (2021). 'Mortality associated with COVID-19 in care homes: international evidence'. I. L.-T. C. P. N. Article in LTCcovid.org, CPEC-LSE, https://ltccovid.org/wpcontent/uploads/2021/02/LTC_COVID_19_international_report_January-1February-.pdf.

Conyard, K.F., A. Metcalfe, S. Corish, J. Flannery, P. Hannon, B. Rusk, S. Yeates and M.B. Codd (2020). Healthcare assistants and Qualified Carers, A Trained, but untapped underutilised resource: A population-based study in Ireland. HCA and Carers Ireland \& Centre for Support and Training in Analysis and Research, University College Dublin., https://www.hca.ie/full-report.

Costa-Font, J., D. Elvira and O. Mascarilla-Miró (2009). "'Ageing in Place?" Exploring Elderly People's Housing Preferences in Spain', Urban Studies, 46(2): 295-316. 10.1177/0042098008099356.

Costa-Font, J., M. Karlsson and H. Øien (2016). 'Careful in the Crisis? Determinants of Older People's Informal Care Receipt in Crisis-Struck European Countries', Health Econ 25 Suppl 2: 25-42. 10.1002/hec.3385.

CSO (2018). 'Census of Population 2016 - Profile 9 Health, Disability and Carers'. Central Statistics Office, Dublin, Ireland, https://www.cso.ie/en/releasesandpublications/ep/pcp9hdc/p8hdc/p9cr/\#: :text=Increase\%20in\%20carers\&text=The\%20census\%2 Oshowed\%20a\%20total, with\%2077\%2C112\%20(39.5\%25)\%20men.

Cullis, J.G., P.R. Jones and C. Propper (2000). 'Chapter 23 Waiting lists and medical treatment: Analysis and policies'. Handbook of Health Economics. Elsevier.

de Meijer, C., P. Bakx, E. van Doorslaer and M. Koopmanschap (2015). 'Explaining Declining Rates of Institutional LTC Use in the Netherlands: A Decomposition Approach', Health Economics, 24(S1): 18-31. https://doi.org/10.1002/hec.3114.

Delaney, M. (2020). “It's demoralising and makes me want to leave": How poor pay is impacting home carers in this "lucrative" sector", The Journal.ie. 
Department of Health (2012). 'Value for Money and Policy Review of Disability Services in Ireland', https://assets.gov.ie/16118/73763752d55d4618bc9f8e18f3091290.pdf.

Department of Health (2018a). 'Independent Expert Review of Delayed Discharge's, https://health.gov.ie/wp-content/uploads/2018/11/Delayed-DischargesReport-November-2018.pdf.

Department of Health (2018b). 'Towards Personalised Budgets for People with a Disability in Ireland: Report of the Task Force on Personalised Budgets', https://www.gov.ie/en/publication/4ea89a-task-force-on-personalisedbudgets/.

Department of the Taoiseach (2020). 'Programme for Government - Our Shared Future', https://static.rasset.ie/documents/news/2020/06/draft-programme-forgovt.pdf.

Doyle, A. and A.M. Carew (2018). 'Annual Report of the National Physical and Sensory Disability Database Committee 2017: Main Findings', HRB Statistics Series 36, https://www.hrb.ie/fileadmin/2._Plugin_related_files/Publications/2018_pubs/ Disability/NPSDD/NPSDD_Annual_Report_2017.pdf.

Ensor, T. and S. Cooper (2004). 'Overcoming barriers to health service access: influencing the demand side', Health Policy and Planning 19(2): 69-79. 10.1093/heapol/czh009.

Evandrou, M., J. Falkingham, M. Qin and A. Vlachantoni (2020). 'Older and 'staying at home' during lockdown: analysis of informal care receipt during the COVID-19 pandemic amongst people aged 70 and over in the UK', SocArXiv. 10.31235/osf.io/962dy.

Fischer, B. and K.-U. Müller (2020). 'Time to care? The effects of retirement on informal care provision', Journal of Health Economics, 73: 102350. 10.1016/j.jhealeco.2020.102350.

Frazer, K., L. Mitchell, D. Stokes, E. Crowley and C. Kelleher (2020). 'COVID-19 Nursing Homes Expert Panel Examination of Measures to 2021'. Report to the Minister for Health, https://assets.gov.ie/84889/b636c7a7-a553-47c0-88a5235750b7625e.pdf.

Glendinning, C. (2012). 'Home care in England: markets in the context of under-funding', Health \& Social Care in the Community, 20(3): 292-299. https://doi.org/10.1111/j.1365-2524.2012.01059.x.

Glynn, J.R., K. Fielding, T. Shakespeare and O. Campbell (2020). 'Covid-19: excess all cause mortality in domiciliary care', BMJ, 370: m2751. 10.1136/bmj.m2751.

Government of Ireland (2018). 'Sláintecare Implementation Strategy', https://assets.gov.ie/9914/3b6c2faf7ba34bb1a0e854cfa3f9b5ea.pdf.

Gov.ie (2019). 'Voluntary Organisations Dialogue Forum Minutes 2 December 2019'. Retrieved $21 / 12 / 2020$, https://assets.gov.ie/47325/a71c6144f999462fb0d6b6ed328ae850.pdf.

Grossman, M. (1972). 'On the Concept of Health Capital and the Demand for Health', Journal of Political Economy, 80(2): 223-255. 10.1086/259880. 
Guo, J., R.T. Konetzka and W.G. Manning (2015). 'The Causal Effects of Home Care Use on Institutional Long-Term Care Utilization and Expenditures', Health Economics, 24(S1): 4-17. 10.1002/hec.3155.

Hanly, P. and C. Sheerin (2017). 'Valuing Informal Care in Ireland: Beyond the Traditional Production Boundary', The Economic and Social Review, 48(3, Autumn): 28, https://www.esr.ie/article/view/773.

Harlock, J., J. Caiels, J. Marczak, M. Peters, R. Fitzpatrick, G. Wistow, J. Forder and K. Jones (2020). 'Challenges in integrating health and social care: the Better Care Fund in England', Journal of Health Services Research \& Policy, 25(2): 86-93. $10.1177 / 1355819619869745$.

$\mathrm{HCCl}$ (2019a). 'Providing more citizens the freedom to live at home: A road map to the statutory scheme for home care in Ireland', https://hcci.ie/wpcontent/uploads/2019/10/2019-HCCI-Report-FINAL.pdf.

$\mathrm{HCCl}$ (2019b). 'General Scheme of the Employment Permits (Consolidation and Amendment) Bill $2019 \quad$ Submission'. https://data.oireachtas.ie/ie/oireachtas/committee/dail/32/joint_committee_o n_business_enterprise_and_innovation/submissions/2019/2019-11-

27_submission-home-and-community-care-ireland_en.pdf.

Houses of the Oireachtas Committee on the Future of Healthcare (2017). 'Sláintecare Report', http://www.oireachtas.ie/parliament/media/committees/futureofhealthcare/O ireachtas-Committee-on-the-Future-of-Healthcare-Slaintecare-Report300517.pdf.

HSE (2011). 'Time to Move on from Congregated Settings A Strategy for Community Inclusion', https://www.hse.ie/eng/services/list/4/disability/congregatedsettings/time-tomove-on-from-congregated-settings-\%E2\%80\%93-a-strategy-for-communityinclusion.pdf.

HSE (2016). 'TRANSFORMING LIVES: Supporting Person-Centred Disability Services', https://www.hse.ie/eng/services/publications/transforming-lives-progressreport-2016.pdf.

HSE (2018). 'Review and Role of Health Care Assistants', https://www.hse.ie/eng/staff/resources/hrstrategiesreports/health-careassistant-review-final-report-2018.pdf.

HSE (2020). 'Winter Planning within the COVID-19 Pandemic October 2020 - April 2021'. H. S. Executive, https://www.hse.ie/eng/services/publications/winter-planningwithin-the-covid19-pandemic-october-2020-april-2021.pdf.

Ilinca, S., K. Leichsenring and R. Rodrigues (2015). 'From care in homes to care at home: European experiences with (de)institutionalisation in long-term care'. Policy Brief 12/2015. Vienna: European Centre, https://www.euro.centre.org/downloads/detail/1540.

Indeed (2020). 'Healthcare Assistant jobs'. Retrieved 06/08/2020, https://ie.indeed.com/jobs?q=HSE+Healthcare+Assistant\&l=. 
Kamiya, Y., C. Murphy, G. Savva and V. Timonen (2012). Profile of Community-Dwelling Older People with Disability and their Caregivers in Ireland. The Irish Longitudinal Study on Ageing. 10.38018/TildaRe.2012-00.

Keegan, C., A. Brick, A. Bergin, M.-A. Wren, E. Henry and R. Whyte (2020). Projections of expenditure for public hospitals in Ireland, 2018-2035, based on the Hippocrates Model, ESRI Research Series Report 117, https://www.esri.ie/system/files/publications/RS117_1.pdf.

Keogh, F., M. Pierce, K. Neylon and P. Fleming (2018a). 'Intensive home care packages for people with dementia: a realist evaluation protocol', BMC Health Serv Res, 18(1): 829. 10.1186/s12913-018-3630-8.

Keogh, F., M. Pierce, K. Neylon, P. Fleming, L. Carter, S. O'Neill and E. O'Shea (2018b). 'Supporting Older People with Complex Needs at Home: Report 1: Evaluation of the HSE Intensive Home Care Package Initiative', https://www.understandtogether.ie/Training-resources/HelpfulResources/Publications/Supporting-Older-People-with-Complex-Needs-atHome-Report-1-Evaluation-of-the-HSE-Intensive-Home-Care-Package-Initiative2018-.pdf.

Kiersey, R.A. and A. Coleman (2017). 'Approaches to the regulation and financing of home care services in four European countries'. HRB, Health Research Board, Dublin, https://www.hrb.ie/fileadmin/publications_files/Approaches_to_the_regulatio n_and_financing_of_home_care_services_in_four_European_countries.pdf.

Landsem, M.M. and J. Magnussen (2018). 'The effect of copayments on the utilization of the GP service in Norway', Social Science \& Medicine, 205: 99-106. 10.1016/j.socscimed.2018.03.034.

Lemmon, E. (2020). 'Utilisation of Personal Care Services in Scotland: The Influence of Unpaid Carers', Journal of Long-Term Care, 2020: 54-69, http://eprints.Ise.ac.uk/106226/1/23_276_1_PB.pdf.

Ma, Y. and A. Nolan (2016). 'Public Healthcare Entitlements and Healthcare Utilisation among the Older Population in Ireland', Health Economics, 10.1002/hec.3429.

Mac Domhnaill, C., S. Lyons and S. McCoy (2020). Specialist support for persons with disabilities living in the community: Review of international practice, ESRI Survey and Statistical Report Series 97. 10.26504/sustat97.

McDonald, A., L. Lolich, V. Timonen and A. Warters (2019). 'Time is more important than anything else: tensions of time in the home care of older adults in Ireland', International Journal of Care and Caring, 3(4): 501-515. $10.1332 / 239788219 \times 15622468259858$.

McGarrigle, C. and R.A. Kenny (2020). Receipt of care and caring in community-dwelling adults aged 50 years and over in Ireland. The Irish Longitudinal Study on Ageing. 10.38018/TildaRe.2020-09

McQuinn, K., C. O’Toole, M. Allen-Coghlan and C. Coffey (2020). Quarterly Economic Commentary, Autumn 2020. ESRI, Dublin, https://www.esri.ie/publications/quarterly-economic-commentary-autumn2020. 10.26504/qec2020aut

Mercille, J. and N. O'Neill (2020). 'The growth of private home care providers in Europe: The case of Ireland', Social Policy \& Administration, 10.1111/spol.12646. 
Mulkeen, M. (2016). 'Going to market! An exploration of markets in social care', Administration, 64(2): 33. 10.1515/admin-2016-0015.

Murphy, C.M., B.J. Whelan and C. Normand (2015). 'Formal home-care utilisation by older adults in Ireland: evidence from the Irish Longitudinal Study on Ageing (TILDA)', Health Soc Care Community, 23(4): 408-418. 10.1111/hsc.12157.

NCCN (2017). 'Opening Statement to Oireachtas Joint Committee on Health - 15 November 2017.' https://data.oireachtas.ie/ie/oireachtas/committee/dail/32/joint_committee_o n_health/submissions/2017/2017-11-15_opening-statement-nationalcommunity-care-network-nccn_en.pdf.

Ní Shé, É., D. O’Donnell, M. O’Shea and D. Stokes (2020). 'New Ways of Working? A Rapid Exploration of Emerging Evidence Regarding the Care of Older People during COVID19', International Journal of Environmental Research and Public Health, 17(18). 10.3390/ijerph17186442.

Nilsson, A. and A. Paul (2018). 'Patient Cost-Sharing, Socioeconomic Status, and Children's Health Care Utilization', Journal of Health Economics, 59(5): 109-124. 10.1016/j.jhealeco.2018.03.006.

Nolan, A. (2007). 'The financing and delivery of GP services in Ireland', in: B. Nolan (ed.) The provision and use of health services, health inequalities and health and social gain. Dublin, Ireland: Economic and Social Research Institute.

Nolan, A. (2008). 'Evaluating the impact of eligibility for free care on the use of general practitioner (GP) services: a difference-in-difference matching approach', Soc Sci Med, 67(7): 1164-1172. 10.1016/j.socscimed.2008.06.021.

Nolan, A. (2011). 'An extension in eligibility for free primary care and avoidable hospitalisations: a natural experiment', Soc Sci Med, 73(7): 978-985. 10.1016/j.socscimed.2011.06.057.

Nolan, A. and R. Layte (2017). 'The impact of transitions in insurance coverage on GP visiting among children in Ireland', Soc Sci Med, 180: 94-100. 10.1016/j.socscimed.2017.03.026.

O'Brien, I., K. Smuts, C.W. Fan, M. O'Sullivan and A. Warters (2019). 'High prevalence of dementia among community dwelling older adults in receipt of state funded home care packages: implications for health care planning', Ir J Psychol Med, 36(2): 139-144. 10.1017/ipm.2017.80.

O'Sullivan, D. (2019). 'Mind the care gap: Exposing the health system's vulnerability to the gap between family care provision and anticipated demand'. H. o. t. O. L. R. Service, https://data.oireachtas.ie/ie/oireachtas/libraryResearch/2019/201904-02_spotlight-mind-the-care-gap-exposing-the-health-system-s-vulnerabilityto-the-gap-between-family-care-provision-and-anticipated-demand_en.pdf.

O'Halloran, A., C. McGarrigle, S. Scarlett, L. Roe, R. Romero-Ortuno and R.A. Kenny (2020). 'TILDA Report on Population Estimates of Physical Frailty in Ireland to Inform Demographics for Over 50s in Ireland during the COVID-19 Pandemic'. T. I. L. S. o. Ageing, https://tilda.tcd.ie/publications/reports/pdf/Report_Covid19Frailty.pdf. 
Olsen, C.B. and H.O. Melberg (2018). 'Did adolescents in Norway respond to the elimination of copayments for general practitioner services?', Health Econ, 27(7): 1120-1130. 10.1002/hec.3660.

Phelan, A.A., A. Duggan, D. O'Donnell and G. Fealy (2017). 'An Evaluation of the Consumer Directed Home Care Pilot Project in Community Healthcare Organisation 3', https://www.hse.ie/eng/services/list/4/olderpeople/consumer-directed-homesupport-evaluation-report.pdf.

Phelan, A.A., A. Duggan, D. O'Donnell and G. Fealy (2019). 'Evaluating a consumerdirected health care pilot for older people in the community', Innovation in Aging, 3(Suppl 1): S498-S498. 10.1093/geroni/igz038.1844.

Pierce, M., F. Keogh and E. O'Shea (2020). 'The impact of COVID-19 on people who use and provide long-term care in Ireland and mitigating measures'. I. L. T. C. P. Network, https://ltccovid.org/wp-content/uploads/2020/05/Ireland-COVID-LTCreport-updated-13-May-2020.pdf.

Privalko, I., B. Maître, D. Watson and R. Grotti (2019). Access to childcare and home care services across Europe: an analysis of the Survey on Income and Living Conditions (SILC), $2016 . \quad$ Social Inclusion Report. ESRI, https://www.esri.ie/system/files/publications/2019-08-29-

Access\%20To\%20Care\%20Services\%20Final\%20Version\%202.0_1.pdf.

Review Group on Health and Personal Social Services for People with Physical and Sensory Disabilities (1996). Towards an independent future: report of the review group on health and personal social services for people with physical and sensory disabilities, The Stationery Office, Dublin, https://www.lenus.ie/bitstream/handle/10147/46677/1720.pdf?sequence=1\&i sAllowed=y.

Saltman, R.B., V. Bankauskaite and K. Vrangbaek (2007). Decentralization in health care. Strategies and outcomes. Berkshire, England, Open University Press.

Skills For Care (2020). 'The size and structure of the adult social care sector and workforce in England'. https://www.skillsforcare.org.uk/adult-social-care-workforcedata/Workforce-intelligence/documents/Size-of-the-adult-social-caresector/Size-and-Structure-2020.pdf.

Smith, S., S. Barron, M.-A. Wren, B. Walsh, E. Morgenroth, J. Eighan and S. Lyons (2019). Geographic Profile of Healthcare Needs and Non-Acute Healthcare Supply in Ireland, ESRI Research Series Report 90, https://www.esri.ie/publications/geographic-profile-of-healthcare-needs-andnon-acute-healthcare-supply-in-ireland.

Szebehely, M. and G. Meagher (2017). 'Nordic eldercare - Weak universalism becoming weaker?', Journal of European Social Policy, 28(3): 294-308. 10.1177/0958928717735062.

Tallock, C., A. Charlesworth, E. Kelly, R. McConkey and S. Rocks (2020). REAL Centre The bigger picture: learning from two decades of changing NHS care in England. T. H. Foundation, https://www.health.org.uk/publications/reports/the-biggerpicture. 
The Commission on the Status of People with Disabilities (1996). A Strategy for Equality - Report of the Commission on the Status of People with Disabilities. N. D. Authority, http://nda.ie/nda-files/A-Strategy-for-Equality.pdf.

Timonen, V. and M. Doyle (2008). 'From the workhouse to the home: evolution of care policy for older people in Ireland', International Journal of Sociology and Social Policy, 28(3/4): 76-89. 10.1108/01443330810862151.

Van Houtven, C.H., R.T. Konetzka, E. Taggert and N.B. Coe (2020). 'Informal And Formal Home Care For Older Adults With Disabilities Increased, 2004-16', Health Affairs, 39(8): 1297-1301. 10.1377/hlthaff.2019.01800.

Walsh, B., M.-A. Wren, S. Smith, S. Lyons, J. Eighan and E. Morgenroth (2019). An Analysis of the Effects on Irish Hospital Care of the Supply of Care Inside and Outside the Hospital. ESRI Research Series Report https://www.esri.ie/system/files/publications/RS91_0.pdf.

Walsh, B., S. Lyons, S. Smith, M.-A. Wren and J. Eighan (2020a). 'Does formal home care reduce inpatient length of stay?', Health Econ 29(12):1620-1636. 10.1002/hec.4158.

Walsh, B., P. Redmond and B. Roantree (2020b). Differences in risk of severe outcomes from COVID-19 across occupations in Ireland, ESRI Survey and Statistical Report Series 93. 10.26504/sustat93.

Walsh, E. and A. Murphy (2018). 'Investigating the causal relationship between employment and informal caregiving of the elderly', BMC research notes 11(1): 570-570. 10.1186/s13104-018-3684-z.

Walsh, S., E. O'Shea, T. Pierse, B. Kennelly, F. Keogh and E. Doherty (2020c). 'Public preferences for home care services for people with dementia: A discrete choice experiment on personhood', Soc Sci Med, 245: 112675. 10.1016/j.socscimed.2019.112675.

Walshe, K., C. Lorne, A. Coleman, R. McDonald and A. Turner (2018). 'Devolving health and social care'. Learning from Greater Manchester, Manchester: The University of Manchester, https://www.alliancembs.manchester.ac.uk/media/ambs/contentassets/documents/news/devolving-health-and-social-care-learning-fromgreater-manchester.pdf.

Watt, T., M. Varrow, A. Roberts and A. Charlesworth (2018). 'Social care funding options How much and where from?'. The Health Foundation, London, https://www.health.org.uk/sites/default/files/Social-care-funding-options-May2018.pdf.

Weaver, F., S.C. Stearns, E.C. Norton and W. Spector (2009). 'Proximity to death and participation in the long-term care market', Health economics, 18(8): 867-883. 10.1002/hec.1409.

Wren, M.A., C. Keegan, B. Walsh, A. Bergin, J. Eighan, A. Brick, S. Connolly, D. Watson and J. Banks (2017). Projections of Demand for Healthcare in Ireland, 2015-2030. First Report from the Hippocrates Model. ESRI Research Series 67, https://www.esri.ie/system/files/publications/RS67.pdf. 


\section{TABLE A.1 PRIORITISATION CRITERIA FOR HOME SUPPORT SERVICES: JANUARY 2021}

\begin{tabular}{|c|c|c|c|}
\hline \multicolumn{4}{|l|}{$\begin{array}{l}\text { Prioritisation Criteria for Home Support Services } \\
\text { v. } 2 \text { Updated } 8 \text { January } 2021\end{array}$} \\
\hline Priority 1 & Priority 2 & Priority 3 & Priority 4 \\
\hline $\begin{array}{l}\text { Clients receiving 7-day service with low } \\
\text { Barthel score, Hoist required and / or } 2 \text { carers } \\
\text { several calls a day, palliative care clients. } \\
\text { Clients with suspected or confirmed } \\
\text { safeguarding issues } \\
\text { Clients with cognitive impairment impacting } \\
\text { on ADLs and presents risks within the } \\
\text { environment }\end{array}$ & $\begin{array}{l}\text { Not an existing 7- } \\
\text { day service, } 5 \text { days. } \\
\text { Receive assistance } \\
\text { with toileting and } \\
\text { personal care. }\end{array}$ & $\begin{array}{l}\text { Clients who } \\
\text { don't have a } \\
\text { service daily }\end{array}$ & $\begin{array}{l}\text { Clients who have } \\
\text { a } 1-2 \text { calls weekly } \\
\text { service and have } \\
\text { family and } \\
\text { supports. }\end{array}$ \\
\hline $\begin{array}{l}\text { Family situation may determine support e.g. } \\
\text { may have elderly carer with no other family }\end{array}$ & $\begin{array}{l}\text { Minimal supports, } \\
\text { living alone. }\end{array}$ & $\begin{array}{l}\text { Personal care } \\
\text { clients who } \\
\text { have support } \\
\text { from family / } \\
\text { friends }\end{array}$ & $\begin{array}{l}\text { Clients who have } \\
\text { family and } \\
\text { friends }\end{array}$ \\
\hline
\end{tabular}

In some cases, client is isolated, living alone

If day centre and with no family. other groups are closed thus isolating client.

Client may be living in isolated area.

Source: https://www.gov.ie/pdf/?file=https://assets.gov.ie/124134/96d68eaf-cd8d-4232-9676414468f46c27.pdf\#page=1. 
TABLE A.2 HOME SUPPORT FOR OLDER PEOPLE (AGES 65+) DEMAND PROJECTIONS, 2015-2030

\begin{tabular}{|c|c|c|c|c|c|c|c|}
\hline & \multirow{4}{*}{ Scenario } & \multirow{3}{*}{$\begin{array}{l}\text { Baseline Activity } \\
\text { (2015) }\end{array}$} & \multicolumn{5}{|c|}{ Percentage change 2015-2030 } \\
\hline & & & \multirow{2}{*}{$\begin{array}{c}\text { Comparator } \\
\text { Central } \\
\text { Population } \\
\text { Only }\end{array}$} & \multicolumn{4}{|c|}{ Preferred Projections } \\
\hline & & & & DE & CM & $\begin{array}{l}\text { CM + High } \\
\text { Population }\end{array}$ & $\begin{array}{c}\text { CM + } \\
\text { Unmet } \\
\text { Demand }\end{array}$ \\
\hline & & $\begin{array}{c}\text { Number of } \\
\text { Recipients/Hours } \\
\text { ('000s for Hours) }\end{array}$ & $\%$ Change & $\%$ Change & \% Change & $\%$ Change & $\%$ Change \\
\hline $\begin{array}{l}\text { Public home help } \\
\text { recipients }\end{array}$ & Total & 47,500 & 84.5 & 57.4 & 43.8 & 44.3 & 50.0 \\
\hline $\begin{array}{l}\text { Public and private } \\
\text { home help } \\
\text { recipients/ uses }\end{array}$ & Total & 65,659 & 83.0 & 56.9 & 43.9 & 44.4 & 48.4 \\
\hline $\begin{array}{l}\text { Public home help } \\
\text { hours }\end{array}$ & Total & 10,456 & 86.7 & 54.2 & 37.9 & 38.0 & - \\
\hline $\begin{array}{l}\text { Public and private } \\
\text { home help hours }\end{array}$ & Total & 14,311 & 85.6 & 53.7 & 37.8 & 37.9 & - \\
\hline $\begin{array}{l}\text { Home care } \\
\text { package recipients }\end{array}$ & Total & 15,300 & 84.5 & 57.4 & 43.8 & 44.3 & 65.9 \\
\hline $\begin{array}{l}\text { Wren et al. } \\
\text { population }\end{array}$ & $\begin{array}{l}\text { ). The } \\
\text { net Nee }\end{array}$ & eing assumpt & which appear & ter sup & by th & ce is & \\
\hline tes: & 5 & & & & & & \\
\hline
\end{tabular}

TABLE A.3 ESTIMATION OF HOME SUPPORT HOURS REQUIRED BY DELAYED TRANSFERS OF CARE

\begin{tabular}{|l|c|c|c|c|c|}
\hline & $\begin{array}{c}\text { Mean } \\
\text { Delayed Los }\end{array}$ & $\begin{array}{c}\text { \% Delayed } \\
\text { Transfers of Care }\end{array}$ & $\begin{array}{c}\text { Estimated Delayed } \\
\text { Transfers of Care }\end{array}$ & $\begin{array}{c}\text { Mean Delayed } \\
\text { Bed Days }^{\text {a }}\end{array}$ & $\begin{array}{c}\text { Estimated Hours } \\
\text { required }^{\mathbf{b}}\end{array}$ \\
\hline $\mathbf{1 - 1 0}$ days & 5 & 56 & 724 & 3,618 & 7,690 \\
\hline $\mathbf{1 1 - 2 0}$ days & 15 & 20 & 258 & 3,876 & 8,239 \\
\hline $\mathbf{2 1 - 3 0}$ days & 25 & 11 & 142 & 3,553 & 7,552 \\
\hline $\mathbf{3 1 - 4 0}$ days & 35 & 4 & 52 & 1,809 & 3,845 \\
\hline $\mathbf{4 1 - 5 0}$ days & 45 & 3 & 39 & 1,744 & 3,708 \\
\hline $\mathbf{5 0 +}$ days & 50 & 6 & 78 & 3,876 & 8,239 \\
\hline
\end{tabular}

Source: (Department of Health, 2018a), b HSE

Notes: $\quad$ a (LOS * Number of Delayed Transfers of Care). 
TABLE A.4 RECEIPT OF HOME SUPPORT BY SOCIAL SUPPORTS BY AGE: AGES 65+

\begin{tabular}{|c|c|c|c|c|c|c|c|}
\hline & & $\begin{array}{c}65-69 \\
\%\end{array}$ & $\begin{array}{c}70-74 \\
\% \\
\end{array}$ & $\begin{array}{c}75-79 \\
\%\end{array}$ & $\begin{array}{c}80-84 \\
\% \\
\end{array}$ & $\begin{array}{c}85-89 \\
\%\end{array}$ & $\begin{array}{c}90+ \\
\%\end{array}$ \\
\hline \multirow{2}{*}{ Marital Status } & $\begin{array}{l}\text { Not } \\
\text { Married }\end{array}$ & 3.96 & 6.05 & 13.14 & 21.70 & 36.39 & 51.10 \\
\hline & Married & 1.79 & 3.43 & 2.85 & 6.51 & 20.80 & 36.08 \\
\hline \multirow{2}{*}{$\begin{array}{l}\text { Social Connectedness } \\
\text { Score } \\
29\end{array}$} & Score 0-1 & 5.00 & 3.99 & 14.05 & 32.61 & 43.48 & 55.73 \\
\hline & Score 2-4 & 2.46 & 4.32 & 7.28 & 15.36 & 31.81 & 47.52 \\
\hline
\end{tabular}

Source: Analysis of TILDA Waves 2-4 Research Microdata File.

Notes: Home Support includes: Home Help, Home Care Packages, and Personal Care Attendant. Survey weights applied.

TABLE A.5 RECEIPT OF HOME SUPPORT BY SOCIOECONOMIC STATUS (EDUCATION AND EQUIVALISED HOUSEHOLD INCOME) BY AGE: AGES 65+

\begin{tabular}{|c|c|c|c|c|c|c|c|}
\hline & & $\begin{array}{c}65-69 \\
\% \\
\end{array}$ & $\begin{array}{c}70-74 \\
\%\end{array}$ & $\begin{array}{c}75-79 \\
\%\end{array}$ & $\begin{array}{c}80-84 \\
\%\end{array}$ & $\begin{array}{c}85-89 \\
\%\end{array}$ & $\begin{array}{c}90+ \\
\%\end{array}$ \\
\hline \multirow{3}{*}{$\begin{array}{l}\text { Educational } \\
\text { Attainment }\end{array}$} & Primary Educ & 3.52 & 3.86 & 6.35 & 17.01 & 30.85 & 43.35 \\
\hline & Secondary Educ & 1.96 & 4.82 & 7.77 & 14.14 & 37.02 & 55.91 \\
\hline & Post Secondary Educ & 1.88 & 4.20 & 8.61 & 13.86 & 22.66 & 36.12 \\
\hline \multirow{5}{*}{$\begin{array}{l}\text { Household } \\
\text { Income }\end{array}$} & Income 1 (poorest) & 2.61 & 5.05 & 11.85 & 24.07 & 36.24 & 53.65 \\
\hline & Income 2 & 3.06 & 5.25 & 10.24 & 21.42 & 30.85 & 60.27 \\
\hline & Income 3 & 2.41 & 3.99 & 3.29 & 12.86 & 31.81 & 38.26 \\
\hline & Income 4 & 2.34 & 3.81 & 3.67 & 14.27 & 7.20 & 55.57 \\
\hline & Income 5 (richest) & 1.86 & 3.99 & 7.32 & 6.72 & 9.13 & - \\
\hline
\end{tabular}

Source: $\quad$ Analysis of TILDA Waves 2-4 Research Microdata File.

Notes: Home Support includes: Home Help, Home Care Packages, and Personal Care Attendant. Survey weights applied.

29 Count of respondent's social connectedness score. A value of 1 is added to respondent's score for each instance they meet the following criteria: Member of church; Married / Living with partner as if married; Member of organisation excluding the church; Has at least one close relative or friend. 
FIGURE A.1 DELAYED TRANSFERS OF CARE BY REASON IN PUBLIC HOSPITALS, JULY 2016 - JUNE 2018

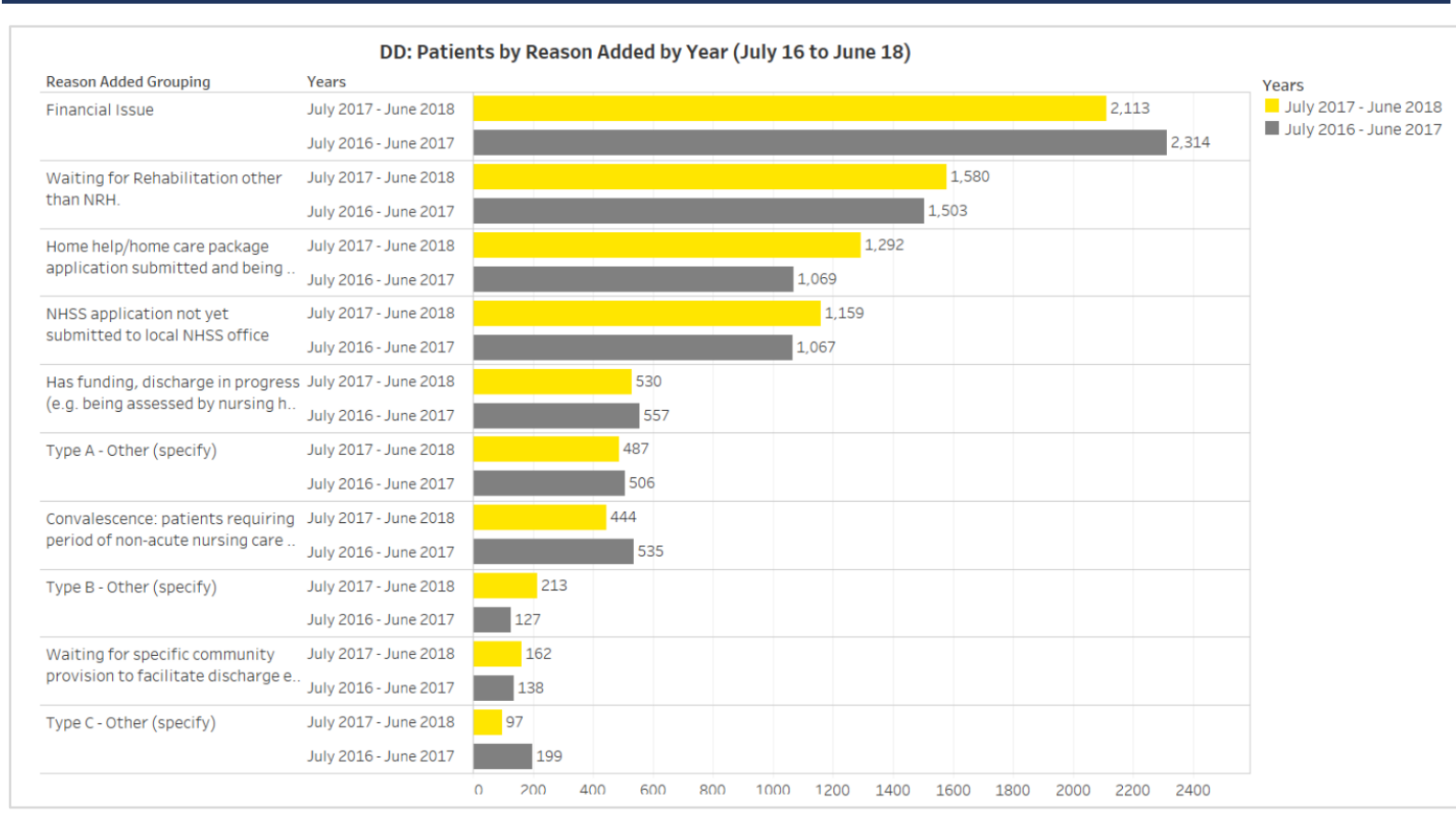

FIGURE A.2 DELAYED TRANSFERS OF CARE BY LENGTH OF DELAY AND REASON IN PUBLIC HOSPITALS, JULY 2016 - JUNE 2018

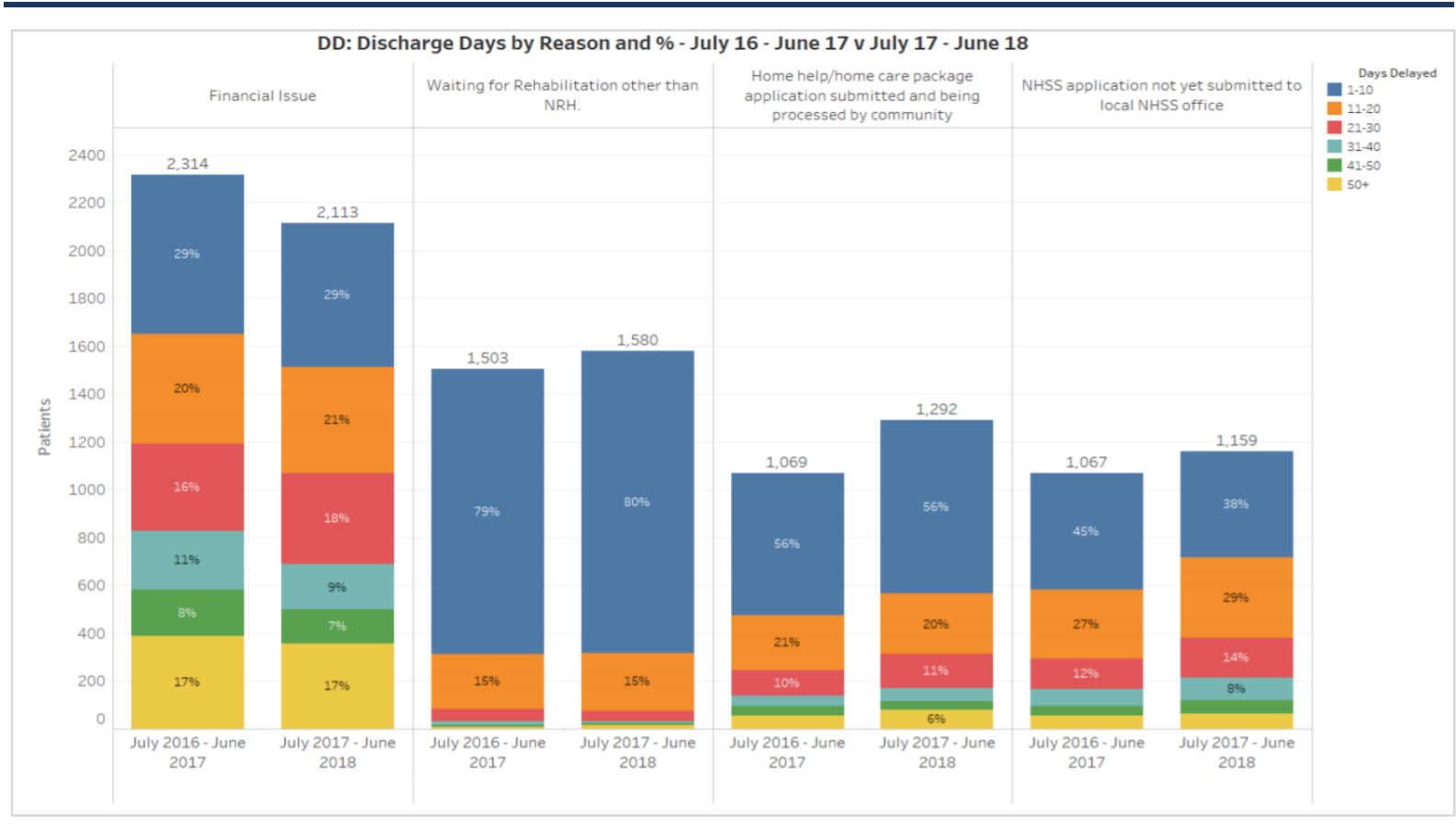

We use information from Figure A.1 and Figure A.2 to estimate unmet demand from delayed transfers of care. As days are included in categories, we took at category midpoint (e.g. five days for the 0-10 days category) and multiplied that by the percentage of delayed transfers of care in the category. Using this approach, 
we estimate that these 1,292 delayed transfers of care used 18,476 bed days during their wait for discharge/transfer.

To apportion hours we use the average number of hours used by those with a d-ADL from TILDA data, i.e. 2.13 hours per day, to estimate the number of home support hours required to discharge inpatients home. As a further check, we examined the average hours provided to those in recent 'egress' schemes. In the Winter Plan 2020/21, effort was placed on 'egress' schemes to reduce the number of delayed transfers of care in hospitals awaiting home support. The Egress Q4-19 scheme was operational from 24 September until 31 December 2019. The HSE report shows that in this period, 622 clients were allocated 5,630 weekly home support hours. This equates to 9.05 hours per client per week, or 1.8 hours per 5day week. This compares favourably (although slightly below) the 2.14 hours we use in the demand scenarios.

FIGURE A.3 RECEIPT OF HOME SUPPORT BY EDUCATIONAL ATTAINMENT AND SEX: AGES 65+

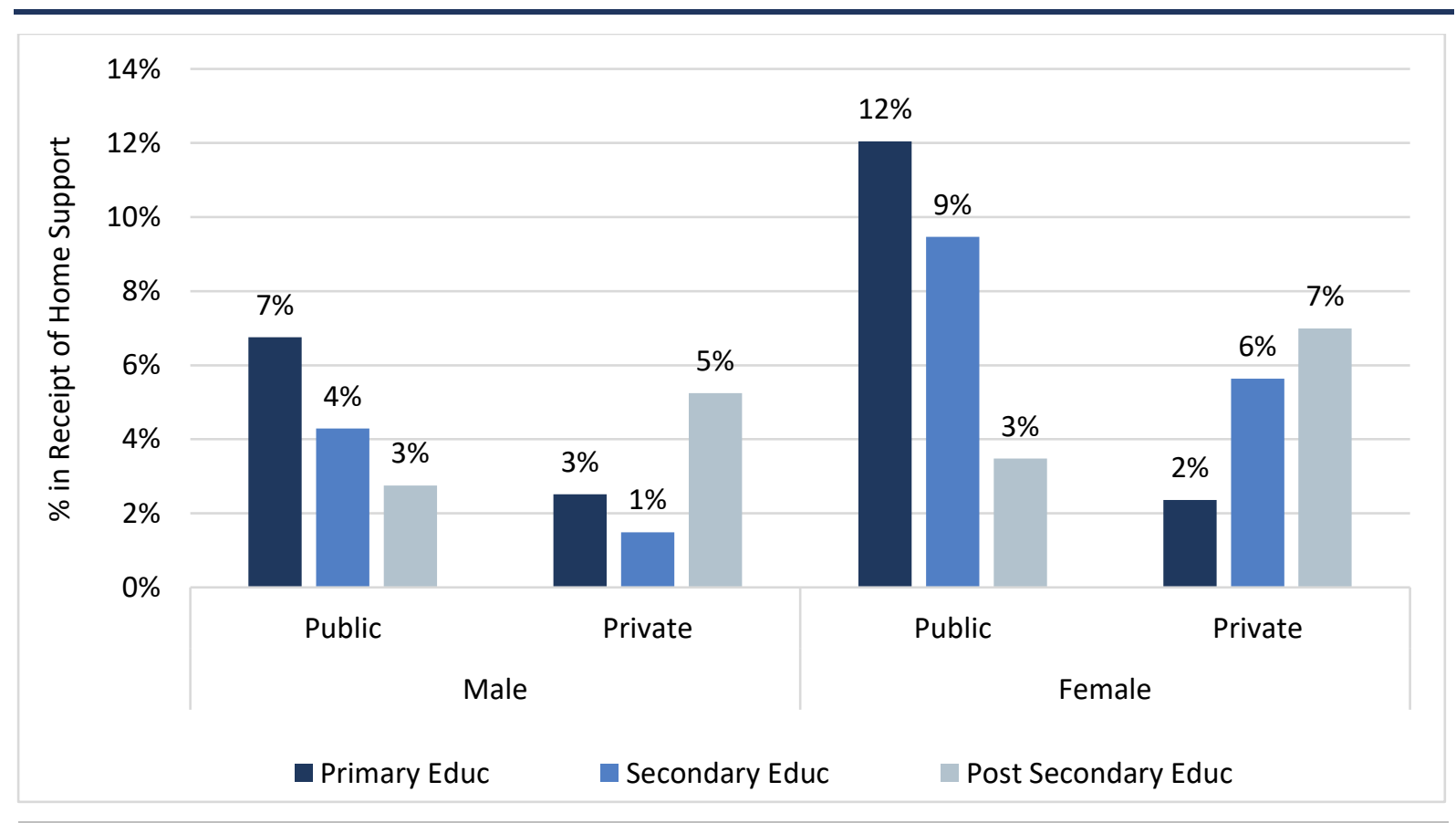

Source: $\quad$ Analysis of TILDA Waves 2-4 Research Microdata File.

Notes: $\quad$ Home Support includes: Home Help, Home Care Packages, and Personal Care Attendant. Survey weights applied. 
FIGURE A.4 RECEIPT OF PUBLIC AND PRIVATE HOME SUPPORT BY EQUIVALISED HOUSEHOLD INCOME QUANTILE AND SEX: AGES 65+

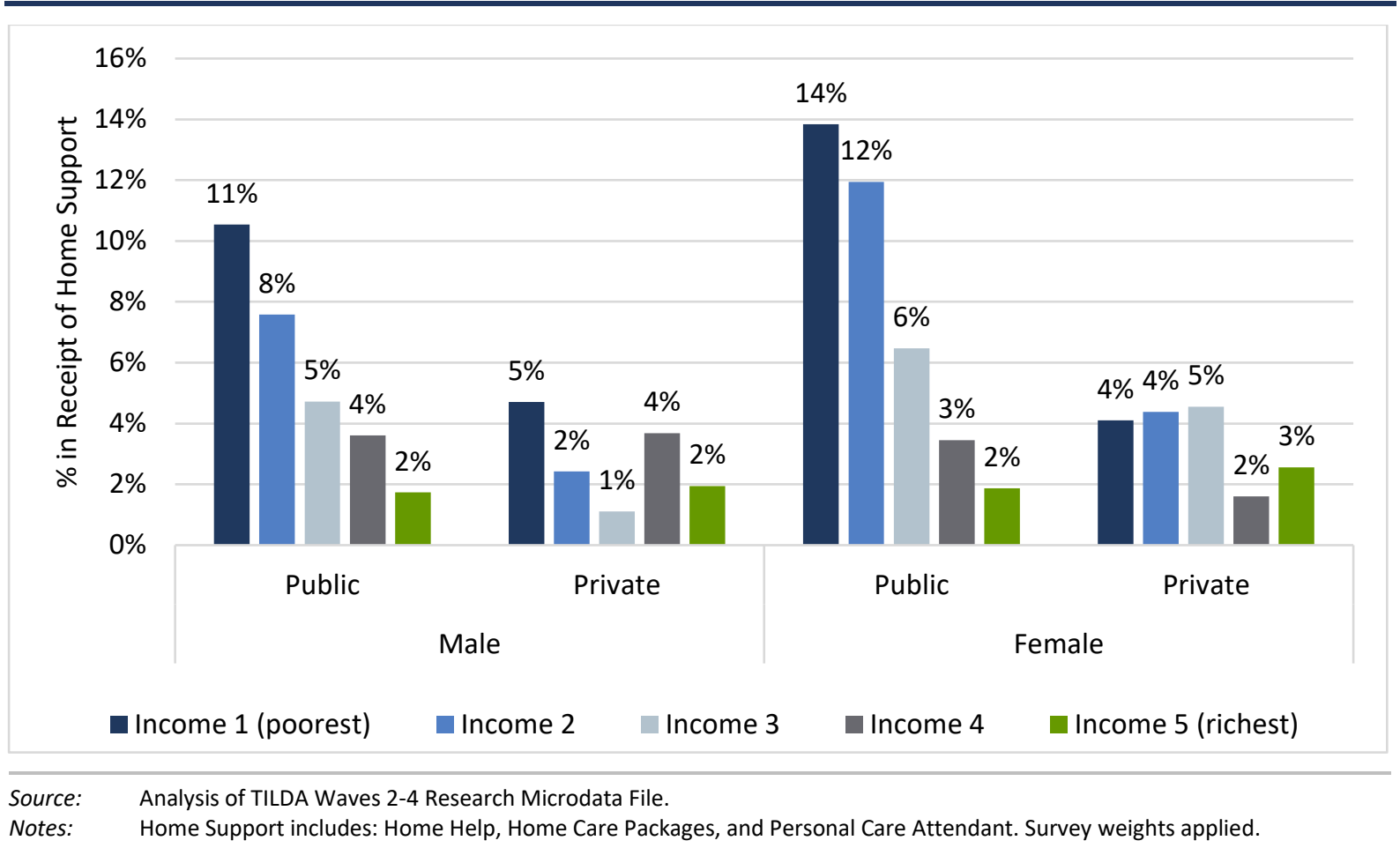

FIGURE A.5 RECEIPT OF PUBLIC AND PRIVATE HOME SUPPORT BY D-ADL AND SEX: AGES 65+

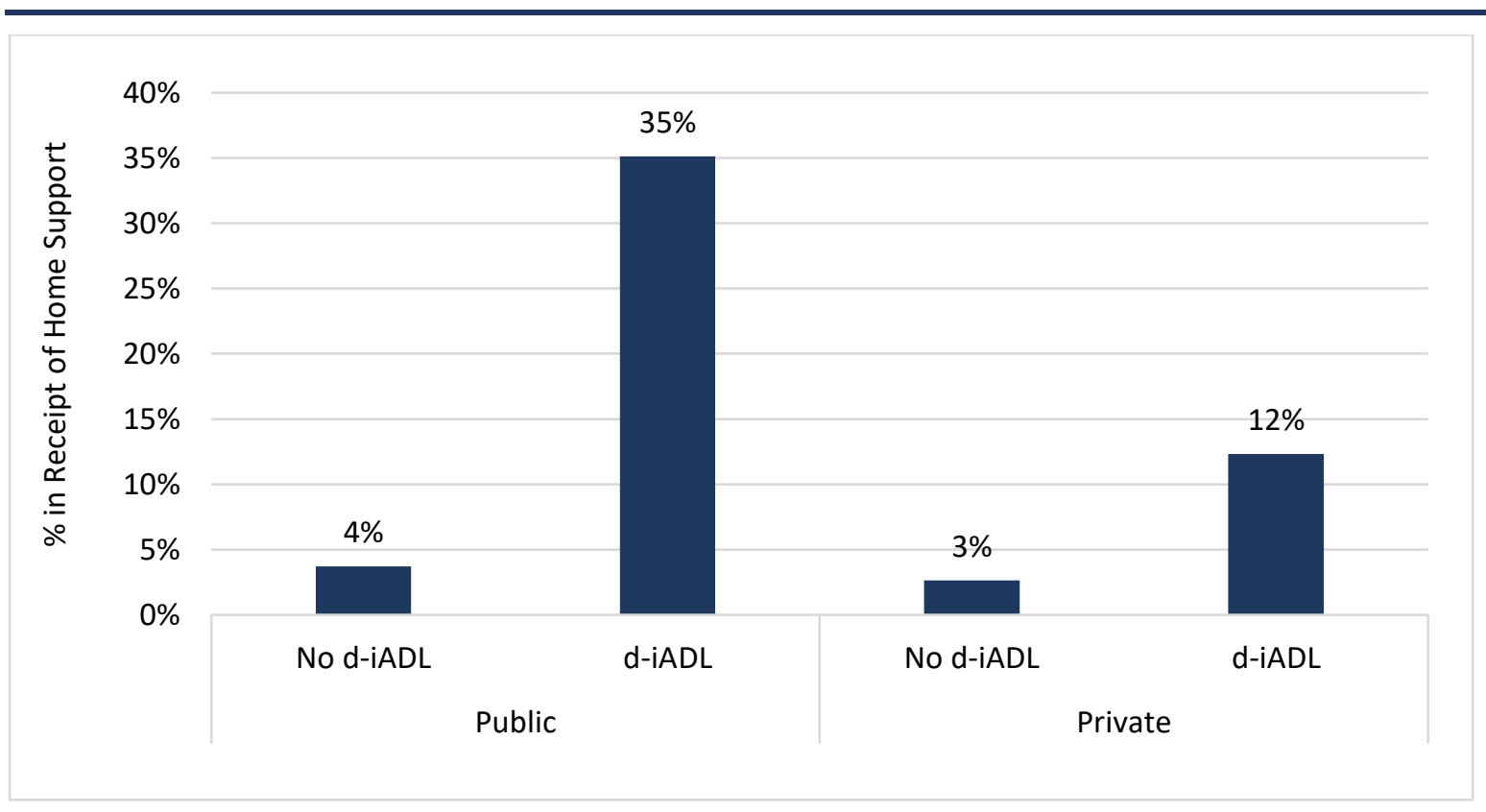

Source: $\quad$ Analysis of TILDA Waves 2-4 Research Microdata File.

Notes: Home Support includes: Home Help, Home Care Packages, and Personal Care Attendant. Survey weights applied. 
FIGURE A.6 RECEIPT OF PUBLIC AND PRIVATE HOME SUPPORT BY D-IADL AND SEX: AGES 65+

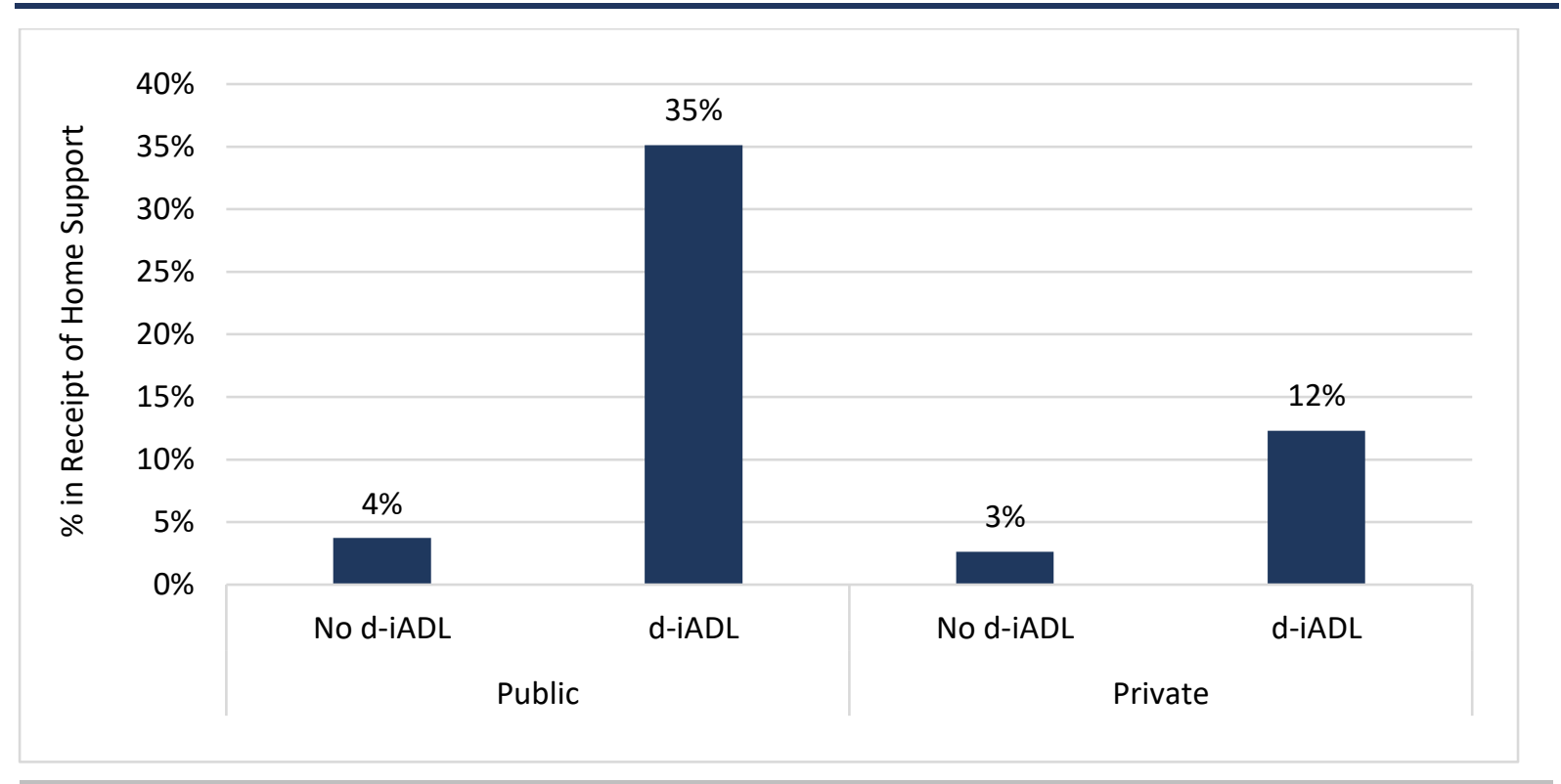

Source: $\quad$ Analysis of TILDA Waves 2-4 Research Microdata File.

Notes: Home Support includes: Home Help, Home Care Packages, and Personal Care Attendant. Survey weights applied. 
Whitaker Square,

Sir John Rogerson's Quay,

Dublin 2

Telephone +35318632000

Email admin@esri.ie

Web www.esri.ie

Twitter @ESRIDublin 